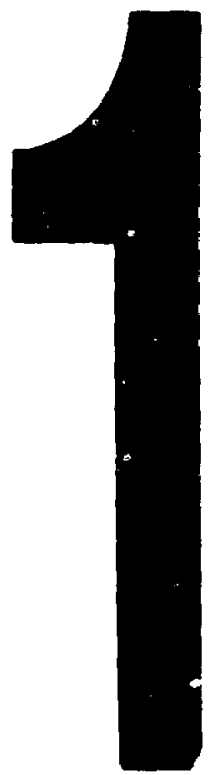

PM-1 3\%"2"x4" PHOTOGI 'PHIC MICRGCOPY TARGET NBS 1010a ANSI/ISO \#2 EQUIVALENT

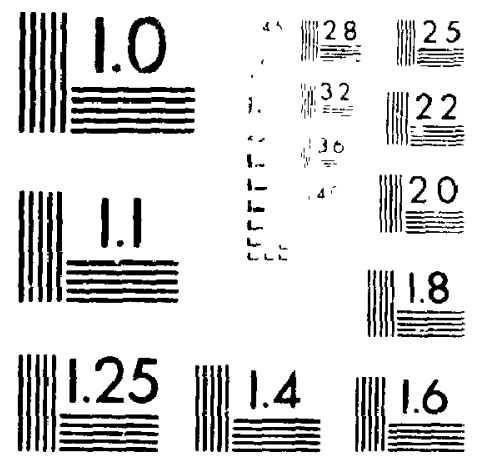


A FINANCIAL MODEL FOR THE VALUATION

GF

ADVANCED MANUFACTURING TECHNOLOGY

by

Richard Cantin. B Comm

A thesis submitted to

the Faculty of Graduate Studies and Research

in partial fulfillment of

the requirements for the degree of

Master of Management Studies

School of Business

Carleton University

Ottawa, Ontario

March 25, 1996

(C) Copyright

1996. Richard Cantin 
National Library

of Canada

Acquisitions and

Bibliographic Services Branch

395 Wellington Street

Ottawa, Ontario

K1A ONG
Bibliothèque nationale

du Canada

Direction des acquisitions et des services bibliographiques

395, rue Wellington

Ottawa (Ontarı)

Your file Votre reterence

Our the Nolre relerence

The author has granted an irrevocable non-exclusive licence allowing the National Library of Canada to reproduce, loan, distribute or sell copies of his/her thesis by any means and in any form or format, making this thesis available to interested persons.
L'auteur a accordé une licence irrévocable et non exclusive permettant à la Bibliothèque nationale du Canada de reproduire, prêter, distribuer ou vendre des copies de sa thèse de quelque manière et sous quelque forme que ce soit pour mettre des exemplaires de cette thèse à la disposition des personnes intéressées.

L'auteur conserve la propriété du droit d'auteur qui protège sa thèse. Ni la thèse ni des extraits substantiels de celle-ci ne doivent être imprimés ou autrement reproduits sans son autorisation.

ISBN $\quad 0-612-13857-7$ 
Name NICHARD LANTEN

Discortotion Abstracts Intemotional is arranged by brood, general subject categories. Please select the one subject which most nectly describes the content of your dissertotion. Enter the corresponding four-digit code in the spoces provided.

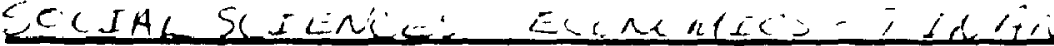

\section{Subject Colagories}

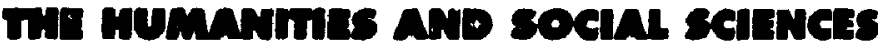

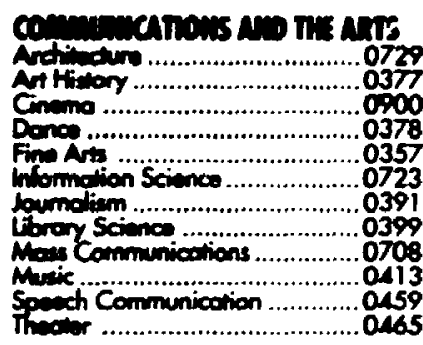

\section{Eucamen}

Gerterd ..................................0515

Administrotion ............0514

Adeth and Continuing ...............0516

Agriculturol ......................... 0517

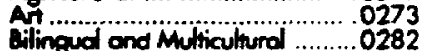

Qusiness ...................... . .0688

Community Colloge …..... ....0275

Curriculum and Instuction .. . ....0727

Eor, Gildhood ..................... 0.518

Eementory ............................. 052

finonce ........................ .027

Guidonce and Counseling ， 0519

Hedth ...................... $\quad 0680$

History of ..................., , 0520

Home Economics

Ind trol 0521

Languogs and likeroture : . . 0279

Anolifematics ................. 028

Mursic ..................... . . 0522

Phrsical. ............. 0523

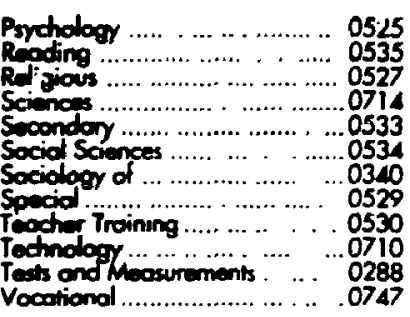

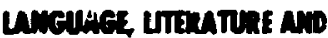
Inietistics

Language

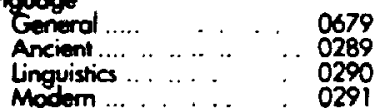

Literoture

General

Comporative

Medieval

Madern

Americon

Canodion (English)

Canadian (French)

English

Germonic

Lotin Americon

Middle Eostern

Romance

Slovic and East European
Prinosomy, ReLGion ayn

Tirelogr

Philosophy

Religion

Gonord

Biblical Sindies

History of

Pistory of ...

Theology

sacal sasucts

Americon Shudies

Anthropology

Archoestogy

Cuthrol

Business Administoton

Generol.

Accounting

Bonking

Monogemen

Morkenng

Economics

Generol

Agricultural

Commerce-Business

Finonce

History

Labor

Theory

Folktore

Geogrophy

Gerontology

History

General
042

0318

032

0319

0320

0322

0323

0324

0324
0326

0327

0310

0272

0770

045

0338

0385

0501

0503

0505

0508

0509

0510

0511

036

0351

0578

THE SCIENCES AND ENGINEARING

\section{moloercl somas}

Agriculture

General .. ........ 0473

Agronolmy

Nutrition...

Animal Pothologry.

Food Science and

Fochnology wild wite

Plont Culture.

Plont Pothology.

Plant Ptysidogy ....

Wange Manogemen

Brology

Gerverol ..........

.0285

0475

0476

0359

0478

0478

0480

0817

0746

Anotorry .......... 028

Biostotistics ..... . . ....0308

Bolbiny ............... . . 0309

Celly …..................

Ecology .............. 0329

Enlomology....... . 0353

Genetics........ .. .. 0369

Microbiology".......... "0..

Moloculor . ............... . 0307

Neuroscrence... ... . . 0317

Oceonogrophy ... 0416

Phyiology ....... . . . 0433

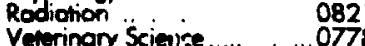

Zoology ..... .......... ....... 0472

Brophysics

Generol ................ 0786

ERTH satwas

Biogeothemistry ..... ....... 0425

Geochemistry ............ ..... 0996
Guodesy

Geology.

Geophrsics

Mineraloor

Poleobotiny

Poleoecology

Paleoniology
Paleozoology

Palynology

Physicol Geogrophy

Physical Oceonograpty

HEITH AM ENMROWIETAL

\section{satmas}

Emironmentol Sciences

Health Scrences

Generol

Audiology

Chemotheropy

Dentisity.

Hospital Nonogemen

Humon Derelopment

Imodicine ond Surgery

Mentol Health

Nursing

Obstetrics and Gynecology

Occupational Health and

Theropy

Ophithalmology

Pathology,

Phormacy

Physicol theropy

Public Heolith.

Rodiotogy
Recreotion
0768

0370

0372

38

0411

0345

0426

0418

0427

368

0415

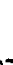

0500

0300

0992

0992
0567
0350
0769

0769

0758

0564

0564
0347
0569

0570

0380

0354
0381

0381
0571

05719

0572

0382

0573

0575

\footnotetext{
Speech Pothology

Toxicology

Home Economics
}

\section{PHYSICAL SaENCES}

Pure Sciences

Chemisiny

Agricultura

Analytical

Bucchemistry

Inorgonic

Orgonic

Pharmoceutical

Physical

Polymer

Rodiotion

Physic:

Ger.zral

Acoustics

Astronomy and

Astroohysics

Almospheric Science

Alomic

Electronics and Electriciny

Elementary Particles and

High Energy

Fluid and Plosmo

Malecular

Nucleor

Optics

Rodiotion

Statisties

Applied Sciences

Applied Mechonics

Computer Science

0460
0383

0386

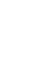

0485

0749

0486

0487
0.488

0738

6490

0491

0494

0495

0754
0405

0605

0986

0606

0608 
The undersigned recommend to the Faculty of Graduate Studies and Research acceptance of the thesis

\section{" FINANCIAL MODEL FOR THE VALLATION OF ADVANCED MANLFACTLRNG TECHNOLOGIES"}

submitted by Richard Cantin. B Comm.

in partial fulfillment of the requirements for the degree of Master of Management Studies

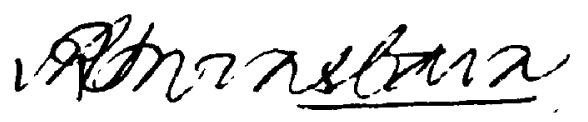

Thesis Supervisor

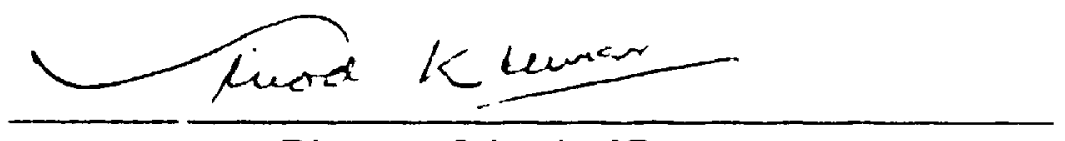

Director. School of Business

Carleton Lniversity

Vlav 13. 1996 


\begin{abstract}
Manufacturing technologies that provide flexibility to the firm are value enhancing in an uncertain environment. Traditional capital budgeting techn:ques are criticized for their inability to value such technologies Other methods were proposed but they remain insuccessful
\end{abstract}

This research proposes a more intuitive and practicable alternative. We used the financial options framework to model manufacturing flexibility Volume, expansion and product ( $\&$ production) flexibilities are incorporated in our model for proper valuation of these instruments responsiveness to uncertainty The model is a blueprint for valuing Hexible manufacturing systems (FMS)

We studied the behavior of a generic FMS under changes of the variance of returns if the project and changes in the risk free rate The results show that manufacturing Alevibility is in fact value enhancing when demand is uncertain Also. we show that both discounting cash flows and valuing uncertainty opportunities are inıportant to investment project salue 


\section{ACKNOWLEDGMENTS:}

First and for most, I would like to thank the Research Program in Manufacturing Technological Change in Manufacturing for its financial support, without which this thesis "rould not have been possible. Professor Gerwin provided me with an incredible opportunity and I am very grateful for it Also, a congratulation on the whole research program staff especially Professor Hauptman for organizing, such interesting seminars: they were a source of inspiration and kept me going all this time. Also many thanks to Professor Lawson for agreeing to participate in this thesis, it's greatly appreciated

My greatest thanks and admiration for Professor Srivastava for being so understanding and patient; the best supervisor anyone could ask for He is the one who always believed in me and my work even at my darkest and most desperate hours.

I would like to dedicate this thesis to my understancing wife, Julie, who put up with this research for so long without showing any sign of fatigue. A kind word for my mother for being such a good editor; she is probably the one who read this thesis the most imes. To my brother in law, Jean-Sebastien, you took me away from my thesis and put things into perspective when I needed it; thank you 
Finally. I would fike to show my appreciation to the School of Business and Carleton University for three great years 
and policies (Meredith \& Suresh 1986). The main reason for failure in adoption of AMT's is the inadequacy in idencifying the value of such technologies to organizations.

Justification of such projects is of great strotegic value, and thus, falls in the hands of upper nanagement. However, the decision makers are not always equipped with the appropriate tools and knowledge. Often, this incapability and the need to rely on quantitative, measurable facts, push the managers to delegate the analysis to the finance department. Most authors agree that traditional financial methodologies for capital budgeting are inadequate at best, for such a task (Gerwin and Kolodny 1992, Meredith \& Suresh 1986, Aggarwal 1991, Baldwin 1991)

The purpose of this research is two-fold. Firstly, to identify the integrative elet.ents necessary in valuing FMS, both production and finance literature $a_{i}$ e studied. Secondly, to help managers deal with the problems associated with the tinancial iustification and the adoption of advanced manufacturing technologies, a model is developed

The model developed here is a financial model that will attempt to evaluate the proper value of AMT's. The shortcomings of the previous financial techniques are due to practical reasons and not theoretical ones. For example, the net present value (NPV) methodology does provide the theoretically correct value of future cash flows associated with a project. However, if the benefits from the technology are unpredictable, 


\section{G. CONCLISION}

"I IMIIIC IIIOSSCH IIIS RISI IRCH

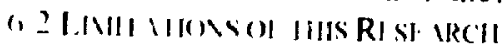

6: PFI II RI RI का IRCH

6.5

66

7. REFERENCES

67 


\section{LIST OF TABLES}

T vil r I - Robi 'stness Criteria for Assessino Capital Budoeting Techniques

T.uBi f. 2 - Practica. Use Of OptIons Theory At Merck (Nichols. 1994)

T IIH IE 3 - MODELING OF FLEXIBILITY INTO PARAMETERS Of OPTIONS VALLIATION

T.IAI F 4 - ADJ ISTMENT FOR MiLTIPI. REAL OPTION (TRIOEOROIS. 1991)

T UH F $S$ - OPTION INTERACTION

T IBI E 6 - NPV WITHOT TT FLENBILIT:

T IBI.E 7 - V.LL 'E OF EXPANSION FLEXIBILTT:

T IRI.E 8 - VAILIE OF VOLIME \& EXPANSION FLEXIBILITY COMBINED

T IBI IE 9 - VALI'E OF PRODIICT FLEXIBILITY

T IHIF. 10 - V.ILLIE OF PRODICT AND VOI L IME FLEXIBILITY COMBINED

TIRI.F 11 - VALUF OF PRODUCT AND EXPANSION FLEXIBILITY

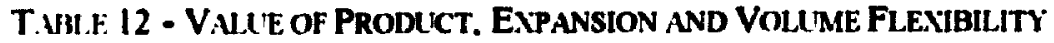

T IBI.F 13 - V.IIIF OF VOLLIME FLEXIBILITY 


\section{LIST OF FIGURES}

FII ; RF I - Cl.ISSIFIC:ITION OF APPROACHES

FICII RF 2 - BINOMIII. TRFE FOR EXPANSION FI.EXIBIIITI

FICII RF ? - BINOMII.U. TREE FISR VOI.UME. FI.EXIBILITY

FIC II RI: 4 - GR.IPII OF NPV

FICI RF 5 - GR IPH OF OPTIONS V.ULTES 


\section{LIST OF APPENDICES}

APPENDIX I - REIIEW OF OPTION PRICINO

APPFNDIN 2 - ROBU ISTNESS TESTS

APPFIDIN 3 - ROBUISTNESS TEST

APPENDIX + - VALUE OF THE NPV WITH AND WITHOIT FLEXIBILITY

APPINDIX 5 - VALLE OF FLEXIBILITY

APPENDIX 6 - ADDITION.NL. REsLtTS

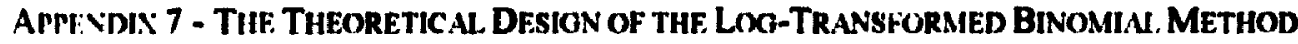

TRICAFOROIS( 1991$)$.

APPFNDIX - TIE ALOORITHM

APPENDIX 9 - THE PROORAM

APPFNDIX 10 - JL STIFICATION APPROACHES (SURESH \& MEREDITH. 1986)

APPFSIDT 11 - How TO UsE THE MODEL 


\section{INTRODUCTION}

With any firm, from minor day-to-day activities to major strategic capital investments, profitability is a major factor in the justification process. This premire of profitability for all 'profit seeking organizations' has caused problems in certain arc. of valuation. Projects that offer intangible benefits are difficult to evaluate using traditional approaches such as the discounted cash flows (DCF) method. For this primary reason. such traditional analysis is not complete or adequate.

Engineers and production professionals have been interested in manufacturing technologies such as CAD/CAM (computer-aided design/manufacturing), FMS (flexible manufacturing systems), GT/CM (group technology and cellular manufacturing), and robots, to enhance the productivity and competitiveness of the manufacturing firm. These technologies are often called Advanced Manufacturing Technologies (AMT's). It is now recognized that while many firms adopt such technologies, others do not; this has created major competitive differences nationally and even internationally. Both types of firms have had their share of successes and failures. While new technologies have often been beneficial to firms, some have blindly invested in AMT's and FMS without studying the impact on their manufacturing unit. ${ }^{\prime}$ The major roadblock to adoption of such technologies in North America is not engineering shortcomings, but managerial attitudes

The ternis AMT's and FMS are used interchangeably throughout this text. 
and policies (Meredith \& Suresh 1986). The main reason for failure in adoption of AMT's is the inadequacy in idencifying the value of such technologies to organizations.

Justification of such projects is of great strategic value, and thus, falls in the hands of upper management. However, the decision makers are not always equipped with the appropriate tools and knowledge. Often, this incapability and the need to rely on quantitative, measurable facts, push the managers to delegate the analysis to the finance department. Most authors agree that traditional financial methodologies for capital budgeting are inadequate at best, for such a task (Gerwin and Kolodny 1992, Meredith \& Suresh 1986, Aggarwal 1991, Baldwin 1991).

The purpose of this research is two-fold. Firstly, to identify the integrative eler.1ents necessary in valuing FMS, both production and finance literature aie studied. Secondly, to help managers deal with the problems associated with the tinancial justification and the adoption of advanced manufacturing technologies, a model is developed.

The model developed here is a financial model that will attempt to evaluate the proper value of AMT's. The shortcomings of the previous financial techniques are due to practical reasons and not theoretical ones. For example, the net present value (NPV) methodology does provide the theoretically correct value of future cash flows associated with a project. However, if the benefits from the technology are unpredictable, 
approximations must be used as parameters for the model; this renders decisions based on the model suspect. Moreover, intangible benefits are often omitted, thus returning a bias value for the project at hand. AMT's are new technologies and as such, their potential is often barely understood. For example, a major benefit of a flexible manufacturing system might be in its capability to produce yet unidentified products with some unknown parts in the future. How does one assign value to such a benefit (Gerwin and Kolodny, 1992)? This lack of valuation of intangible benefits produces a bias towards investments involving less uncertainty and shorter terms, thereby eliminating projects such as AMT's and R\&D (Mitchell \& Hamilton 1988, Luehrman 1994). In the literature review, we will see what researchers are doing to address this problem either by adjusting the NPV model or attacking the problem with other tools.

It is also argued that manufacturing equipment and technology evaluation suffer from historical patterns of thinking. The machinery, in the past, was most often evaluated according to the labor savings it provided. Now the thinking is moving away from cost savings to lead time reduction, quality, flexibility, safety, etc. Production facilities are becoming more and more a strategic weapon to be used in an intensely competitive and uncertain marketplace. The cost savings' justification approach is not adequate to evaluate strategic competitive decisions (Meredith \& Hill, 1987). Such technologies not only offer the flexibility to respond to uncertain and changing environments, but also provide the ability to transform and change the environment itself. This crnitrol oi the environment by 
the firm is a great competitive advantage because it reduces uncertainty for the firm while increasing it for its competition.

The research in evaluation of AMT's is mixed. Some authors suggest adding strategic qualitative analysis to the traditional financial justificaliun process. Another approach, more radical, is to eliminate completely the financial analysis because it is incapable of coping with the complexities of AMT's justification. A more substantial research thrust evolves around fine tuning the present techniques as well as using methodologies such as dynamic programming, analytical hierarchy process, goal programming. multi-criteria analysis and option theory. At the outset, two things must be considered that will downplay some of the proposed methods. First, a project is adopted only if it fits within the strategic plan of the firm. Thus, strategic analysis has to be done formally or informally. Second, a project should be adopted only if it adds value to the firm (at least for profit seeking enterprises). The most promising avenues of research involve financial models that incorporate those extraneous quantifiable variables (usually of strategic nature) which cannot be measured in monetary terms.

This work will attempt to fill the gap between theory and practice in the area of sapital budgeting for AMT's. The contribution of this research is the modeling of three 1:ajor manufacturing flexibilities; volume, expansion and product flexibility, using the real option framework for the purpose of valuation. The benefits of this research are clear cut for the managers. Managers need this kind of tool to allow them to compete in the 
present business environment. Also, if the tool is easy to use, it will be used regularly, thus improving the evaluation of projects, not only at the time of justification but also throughout the life of the investment. For researchers in the manufacturing field, this research will provide a better understanding of AMT's and their value. For researchers in linance. it will provide a framework for evaluating projects when intangible benefits are a significant proportion of overall benefits. In the very least, it will provide an additional tool for researchers to acquire this knowledge. In addition, this work is one more step in finance research towards the study of relationship between uncertainty, risk, time and value of investments. 


\section{LITERATURE REVIEW}

To address the problem of evaluating advanced manufacturing technologies, the terminology used by Gerwin and Kolodny (1992) seems appropriate; that is, the problem is approached according to different characteristics of the technologies that fall in four groups of intangibles. Gerwin and Kolodny (1992) classification is as follows:

- Zero-order intangibles: these are basically the tangibles that consist of the costs and savings that are usually readily identifiable with each technology.

- First-order intangibles: these are the variables that are quantifiable in physical terms, but which cannot be translated into economir terms (e.g., reduction in lead time by 2 hours).

- Second-order intangibles: these are characteristics that are identifiable but not quantifiable in any terms (e.g., learning, experience, quality).

- Third-order intangibles: these are unanticipated costs and benefits (they are not entirely unanticipated; they are expected but their source, form and timing are usually unknown and uncertain). This category includes new possible products or processes emanatıng from the new technology being evaluated and sometimes even transfer of technology to other business activities. 
Traditionally, the discounted cash flow methods focused on tangibles. They are appropriate for such an analysis, and when dealing with simple investment replacement decisions, are often sufficient. When we deal with new technologies, however, the main benefits fall in the categories of first- to third-order intangibles. Also, as we go from stand-alone to integrated manufacturing technologies, we have less zero-order intangibles and more of the third-order intangibles or strategic variables ${ }^{2}$. Meredith and Stiresh (1986) suggest three classes of justification approaches: economic, analytic and strategic. Another approach discussed in the literature is based on the options theory.

The purpose of this research, as stated earlier, is to find a methodology that can appropriately evaluate advanced manufacturing technologies. However, since the optimal inv estment in such technology is very unclear, many companies suffer from over or under im esting in such projects. The benefits are strategic and difficult to quantify because they involve characteristics such as higher quality, faster response to wider ranges of customer needs and options for future growth (Aggarwal, Edward, Mellor. 1991).

The literature in this area makes references to many different methodologies for raluing investment projects in manufacturing For this reason, a set of rules must be used to systematically assess the robustness of these various methodologies. A set of criteria

\footnotetext{
Another classification. proposed by Meredith \& Suresh (1986). uses three categories in which manufacturing technologies fall: stand-alone (Robots \& numerically controlled machin's). linked (GT. FMS. MRP II. AS/RS and CAD/CAPP). integrated (Computer integrated manufacturing). We "ill see that these catcgories are also useful because they reflect the intangibles list.
} 
traditionally used in evaluating capital budgeting methodologies is used here (Copeland and Weston, 1988, p 26). The criteria have been modified slightly to better suit this research. Moreover, intuitive criteria have been added to the list to make it more complete and appropriate for investment projects in AMT's (for evaluating qualitative as in ell as quantitative methodologies). The following table indicates the original criteria and the modified, more generic, criteria for this work:

\section{Table 1 - Robustness Criteria for Assessing Capital Budgeting Techniques}

\begin{tabular}{|c|c|c|}
\hline & $\begin{array}{c}\text { Original Criteria for Assessing Capital Budgcting } \\
\text { Techniques }\end{array}$ & Modified Criteria \\
\hline 1 & All cash hows must be considered & All sources of value must be considered \\
\hline 2 & $\begin{array}{l}\text { Casli flows should be discounted at the opportunity } \\
\text { cost of funds }\end{array}$ & $\begin{array}{l}\text { Time should affect the value of the project } \\
\text { (note: we will see that the value of projects } \\
\text { surrounded with uncertainty can benefit } \\
\text { from longer time) }\end{array}$ \\
\hline$?$ & $\begin{array}{l}\text { The technique should select from a set of mutually } \\
\text { crclusive projects the one that maximizes } \\
\text { shareholders wealth }\end{array}$ & $\begin{array}{l}\text { The technique should select from a set of } \\
\text { mutually exclusive projects the one that } \\
\text { maximizes shareholders wealth }\end{array}$ \\
\hline$t$ & $\begin{array}{l}\text { Managers should be able to consider one project } \\
\text { independently from all others }\end{array}$ & $\begin{array}{l}\text { The method should identify a project that } \\
\text { dominates all others }\end{array}$ \\
\hline 5 & $\mathrm{~N} / \mathrm{A}$ & $\begin{array}{l}\text { The incthodology should require as few } \\
\text { subjective inputs as possible }\end{array}$ \\
\hline 1 & $\mathrm{~N} / \mathrm{A}$ & $\begin{array}{l}\text { It is feasible in practical terms: meaning } \\
\text { that the information is available and the } \\
\text { time and the cost to acquire it is reasonable }\end{array}$ \\
\hline
\end{tabular}

The following study of the literature is structured according to Figure 1 . It is a modification of the classification proposed by Meredith and Suresh (1986). ${ }^{4}$

" These rules are based in the case of certainty: however they are still very useful for the evaluation of tecliriques even though some of the rules have to be relaxed for uncertainty

Sec Appendix 10 for the original classification. 
Figure 1 - Classification of Approaches

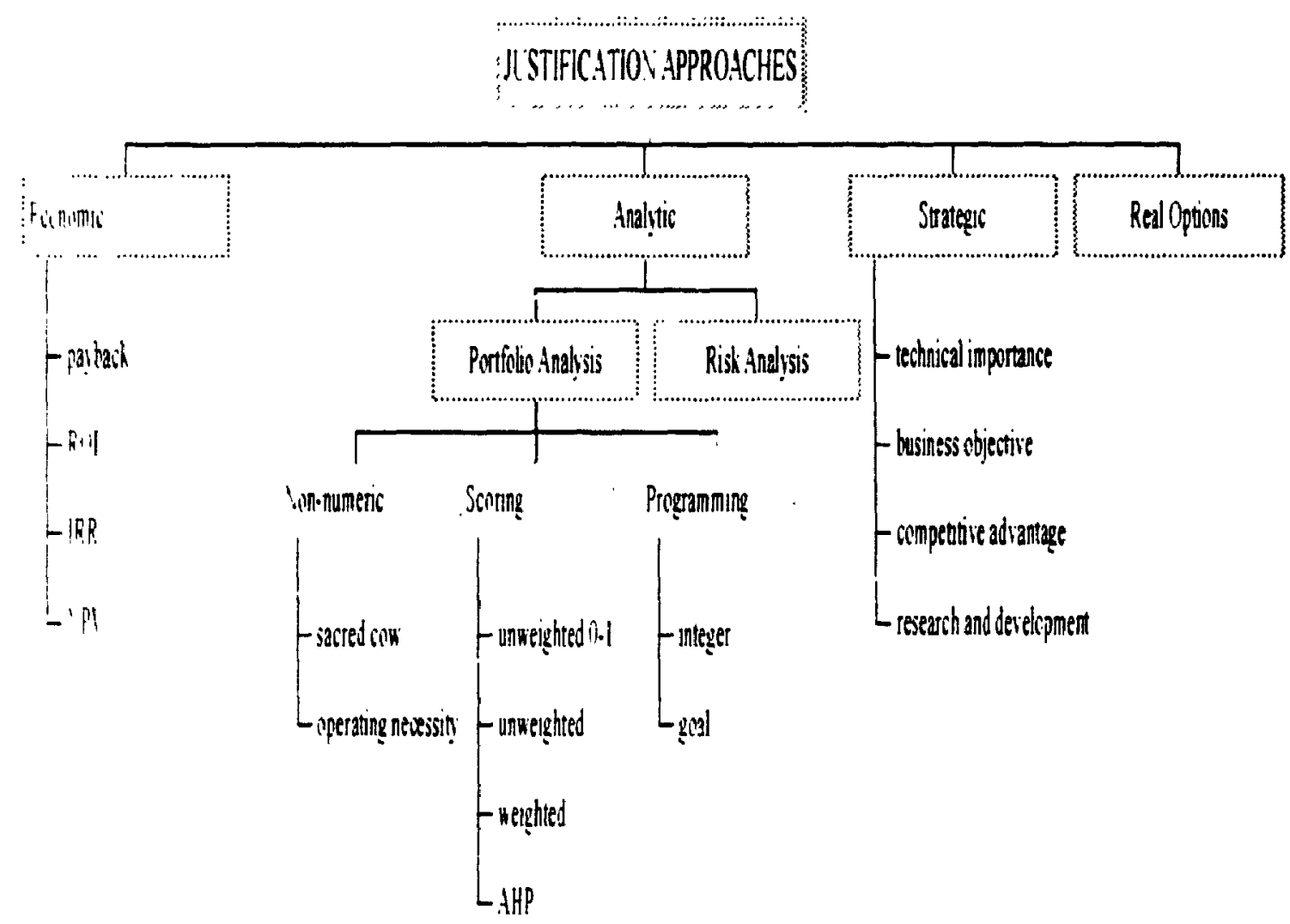

\subsection{Economic Justification Approaches}

Traditional economic justification approaches include the pay-back method, the accounting rate of return method, the internal rate of return method (IRR) and the net present value method (NPV) Both the pay-back method and the accounting rate of return fail to respect robustness criteria 1 and 2. These methodologies do not consider all cash flows and nor do they discount them appropriately. The theoretically robust models are the net present value and the internal rate of return. As shown by Copeland and 
Weston (1988), NPV and IRR methodologies respect the first two robustness criteria, but only the NPV method satisfies all four capital budgeting criteria. Some authors have argued that the NPV ard IRR methodologies are inadequate for evaluating AMT's because of two things: One, the cost of capital is too high for AMT's due to higher uncertainty, and two, these metnodologies place an overemphasis on the short term (Baldwin. 1991). Thus, because higher discount rates reduce the NPV, financial analysis hased on discounted cash flows unfairly discriminates against longer term, less certain and seemingly riskier projects.

However, Baldwin recognizes that the real problem is not the NPV rule itself, but the fact that the value of a wide range of competitive commitments is not included. Thus, it implies that the NPV and IRR methodologies do not satisfy the feasibility criterion because practitioners are unable to include all the necessary parameters such as the value arising from second- or third-order intangibles in AMT's. Other views have also been expressed. For example, Miller (1978) argues that traditional capital budgeting accepts too many projects. He states the difference between uncertainty and risk, suggesting that NPV only accounts for the risk and a premium should be added to the capitalization rate for the uncertainty." It is appropriate to use higher discount rate for higher risk and uncertainty. However, care must be taken to value properly the capability of certain

The argument is that two projects can have the same risk pertaining to the expected cash flows. howerer. one appears riskier if the manager is unable to clearly establish the probabilities. Miller (1978) defines an investment as risky when the outcome is not known but the probability distribution of outcomes is known: uncertainty is when the expected return is not known even though cstimates have been made. 
projects to adapt to changing environment. This is the case with FMS, and traditional DCF methodologies do not value such flexibility.

AMT investments are generally undertaken as replacement projects and as such unly costs and savings are studied. These are easily identifiable and quantifiable. Zeroorder intangibles present no problems to the managers and thus, stand-alone AMT can be II ell evaluated. Note, however, that if such equipment is integrated in a whole system, more strategic benefits will be embedded in the system that the traditional NPV analysis cannot capture adequately

\subsection{Analytic Justification Approaches}

Linked technologies usually involve mostly the evaluation of first- and secondorder intangibles. Meredith \& Suresh (1986) ${ }^{7}$ suggest a class of tools they call Analytic Justification Approaches. Analytic Justification Approaches attempt to capture more information than traditional economic approaches by dealing with uncertainty. Such methodologies are usually more realistic but, often rely on subjective data that undermine their credibility Moreover, the added data and analysis requirements add to the complexity of these methodologies (Meredith and Suresh, 1986). There are two types of approaches in the Analytic Justification: Portfolio Analysis and Risk Analysis.

The subdivisions are somew hat modified in order to remove repetition and overlapping between catcgories. Value analysis has been integrated into portfolio (programming). risk and strategic analyses. Sec Appendix 10 for the original categorization by Meredith and Suresh. 


\subsubsection{Portfolio Analysis}

The three general types of models used in this area are: (1) non-numeric models, (2) scoring models, and (3) programming models. Non-numeric models usually involve the analysis of the trade-ofi between costs and benefits. For example, 'the Sacred Cow' (see Figure 1) is a project that is sponsored by a powerful senior manager and it is not terminated until the manager recognizes failure. This is a useless method unless the manager has that uncanny ability of always making the right choices. A more substantial methodology is the 'Operating Necessity'. In this case, the project is deemed necessary for the operation of most other systems in the firm. What most practitioners fail to recognize about these projects is that they are always economically desirable if you take into account the costs associated with not accepting the project. ${ }^{8}$ These two methods do not satisfy any of the criteria for robustness, except for the fact that they are easy to use. Moreover. they do not seem to have any scientific and managerial value

The second subdivision consists of Scoring Models that are quite popular with managers. These models involve identifying certain critical characteristics of projects and assigning them scores. The project with the most desirable score is accepted; variety is added by changing weighting characteristics if some characteristics are deemed more important. Moreover, the scoring scheme can be a simple 0-1 scale, a gradual 1-5, or 1-7, scale. Canada and Sullivan (1989) cover a wide range of such models in their book; however they all suffer from the same weakness. The major weakness with such methods 
is that they rely on the subjectivity of the manager for the scoring and weighting, leaving room for errors and inconsistencies. However, that weakness is a strength in the sense that it gives managers control and discretion in their evaluation and justification of imsestments in their department. If properly done, it is possible to include enough variables to cover most sources of value and even time preferences. However, the use of iudgmental scores undermines the validity of comparing scores mutually; this is especially true in cases where the scores are close.

Another proposed model is the Analytic Hierarchy Process (AHP) to study complex. multi-person, multi-attribute and multi-period problems. It consists of having one overall objective as the first level with additional sub-levels of attributes. All attributes on the same level are of similar importance. This can be subdivided further in sub-attributes. The last level corresponds to the alternatives. The elements on one level are compared pair-wise with each other and the resulting scores are put into a matrix. The principal vector or the eigenvector is normalized to give priority weights; the same process is done for each sub-attribute and/or alternative in each attribute. The final result is a set of 'weighted evaluation for the alternatives where the highest score gives the preferred alternative During the whole process, a consistency ratio is calculated and if it is higher than 01 , the preference scoring must be re-done. It is a good theoretical method if the subjective evaluation of managers can be relied upon. However, as the number of levels

If the project is not economically desirable with the inclusion of those costs. then there is a possibility that the whole sy stem (manufacturing or whole firm) is not cconomically desirable! 
or the number of elements at each level increases, so does the length and complexity of the process. imrairing the practicality of the model.

Other quantitative methods have been developed for justifying technologies; these are programming methods. The main purpose is to make a decision that will maximize the value of the firm. Naturally, a series of models has stemmed from linear programming (LP) and optimization methods. Of the most popular, we have multi-objective and goal programming (GP) models used for capital budgeting.

The argument for the use of multi objective methods such as goal programming is that, although the primary goal of the financial manager may still be categorized as, maximization of shareholder wealth, this goal may not be pursued in the usual unidirectional manner postulated by theory. This seems appropriate to many practitioners hecause they often claim that other objectives such as sales, debt-ratio, etc. capture the essence of the inter-relationships of all the variables affecting the firm. Thus, a multi objective method provides a better way of ensuring attainment of wealth maximization than the NPV rule which does not capture these inter-relationships

Linear programming (LP) models are well known in mathematics and business for helping solve multiple problems. The usual form consists of an objective function that represents economic data such as profit, costs or revenues. The aim is to maximize (or minimize) that function within the limits set by the constrain.s on resources. Rychel 
(1977) uses such a linear programming model. However, in this case, since the problem requires multiple objectives, the normal objective function is modified to include all the ohfectives We have a single function where there are many objectives with relative weights in order to shift emphasis from one objective to the other. The advantage of this method is that it can be used with the standard linear programming packages. It is a simple model if the user possesses all the information needed.

Like the LP models, Goal Programming (GP) is subject to constraints, however the main difference is that GP has a multi-dimensional objective function that seeks to minimize deviations from the goals (Hawkins and Adams, 1974)

$$
M I N \quad Z=\sum_{i=1}^{n}\left(d_{i}+d_{1}\right)
$$

"here $(+)$ indicates a deviation above the specified goal and (-) below it. The goals are then incorporated as constraints (e g a NPV of $\$ 30$. sales of 20.000 units). Goal programming can be a very useful capital budgeting tool.

In general, programming methods focus on satisfying the first robustness criteria of incorporating all cash flows (or sources or value, approximated by other variables). ${ }^{9}$ Then. the data is analyzed using traditional discounting. These techniques are strong because they satisfy most of the requirements of good capital budgeting techniques. There exist two major flaws. however. One is the fact that these methods are often not practical hecause modeling has to be adapted to real life situation. This can be a major problem if 
the manager is not familiar with the conceptualization and mathematics of the model. In addition, many of these methodologies are still in the theoretical modeling stage to which the solution is still undeveloped. In some cases, solutions do not even exist. The second is more related to AMT's and the fact that we are dealing with long term, risky and uncertain investment. Because of this uncertainty, traditional analysis requires a much higher discount rate. However, certain characteristics of AMT's, such as flexibility, increase in value in proportion with the time they can be put to a profitable use (time to maturity). The reason is that the probability of usefulness of these characteristics increases with time to expiration. Hence, these methodologies do not have a systematic way of dealing with value of flexibility flowing from the uncertain nature of the environment.

Caplin and Kornbluth (1975) use a different approach to the problem of valuing present investments and planning. They propose to change emphasis from planning the total strategy to selecting the initial decision that will provide the greatest range of possible actions in the future. The premise here is that the future is so uncertain that the best course of action or investment today is the one that provides the most flexibility and options in the future regardless of the environment.

Caplin and Kornbluth (1975) use dynamic programming with multiple objectives. At each outcome, the possible paths to get to this point are analyzed and only the efficient ones are retained; this is done for all time periods. Of all the efficient solutions, some will

Note that no inajor stud! of those so-called proxy parameters has been done. 
dominate others. If this group of solutions is small enough and the number of objectives also small, then the planner can present this to the decision maker and a decision can be made tor pure:y subjective reasons without the fear of great error. However, in most cases the number of solutions will be large and further screening is needed. To perform this operation, Caplin and Kornbluth (1975) suggest a robustness measure. This measure is the number of efficient solutions that can be reached if a decision is implemented divided by the total number of efficient solutions Care must be taken to eliminate solutions with negligible differences Again, even if it provides for a specific methodology, the decision "ill be very subjective. The model is nevertheless useful because it takes into account uncertainty and the value of flexibility and future options This line of work, using dynamic programming for capital budgeting. has evolved since the 1970's. A recent paper hy Jog. Michalowski and Trzaskalik (1994) proposes a computationally simple method that addresses the multi-criteria and multi-stage decision environment. It is very useful for capital budgeting of many projects undertaken by the firm, but not as useful in the case of a replacement project with multiple possibilities such as the decision to invest in AMT's or MNS Moreover, these techniques still rely on a multi-objective criterion that has not been identified or ordered by priority for the welfare of the firm and its shareholders.

\subsubsection{Risk Analysis}

Risk analysis is another approach that is used to perform technology justification. The usual approach to risk analysis is to simulate projects with the variables of interest. Stuchastic dominance determines the preferred alternative. This variety of modeis is more 
flexible than other quantitative methods because it incorporates risk and uncertairty. The success of such models still greatly depends on the ability of the manager to quantify the variables. One of the major benefits of the techniques utilizing simulation is that it helps to understand the environment and often yields values for certain parameters that could be used in other techniques such as NPV analysis. However, it can become very complex and cumbersome for the manager to use.

\subsection{Strategic Justification Approaches}

The third category of justification approaches, presented by Meredith and Suresh (1986). is strategic analysis. Authors seem to agree (and firms too) that AMT's and FMS have great strategic values (Baldwin, 1991, Aggarwal, Edward \& Mellon, 1991; Azzone \& Rertele. 1989) even though such projects are surrounded with uncertainty. However, since the optimal investment in such technology is very unclear, many companies suffer from over or under investing in such projects. The benefits are strategic and difficult to quantify due to characteristics such as higher quality, faster response to wider range of customer needs and options for future growth. There are almost as many perspectives and solutions to these problems as there are authors.

For example. Baldvin (1991) says that financial analysis usually favors the postponement of product or process investments because traditional discounted cash flow analysis does not recognize a wide range of competitive commitments. Competition anticipates this and it provides them with the incentive to invest in new process or 
products. It is a problem of cannibalization ${ }^{10}$, and capital budgeting prevents cannibalization." The effect of this policy is as follows: 1. Companies that apply strict financial hurdles will face more competition than those that readily commit to innovation;

2 If ultimate success depends on deterring competition, cannibalization may be the key to long nun survival. Baldwin's analysis is flawed because the real problem is not capital budgeting itself, but the fact that it is performed naively. If new product and technology introductions are the driving force of the industry, then capital budgeting should include the impact of loss of competitiveness and market share on the cash flows. Done this way, cannibalization of its own products will come naturally out of the financial analysis as a desirable means since it will lead to the maximization of the value of the firm. However, as shown earlier, it is difficult to quantify all intangible costs and benefits. As a result, the analysis by Baldwin has only qualitative value

As per Baldwin (1991), the major benefits of the policy of cannibalization are: One, it gives the company some control on the date of obsolescence of its products; ${ }^{12}$ and Iwo. it retains its technological leadership and superior market position for the next round of competition. Baldwin (1991) provides some suggestions in redesigning the capital hudgeting system. His principal suggestion is to identify certain capabilities as legitimate

(ammibalization is defined as a firm's substitution or enhancement of its product or technology. Thus statement is based on the premise that new product or technolog? will not be introduced if it replaces all older one that is still profitable (i.c. NPV greater than (0). This analysis does not take into account the actions of competitors and its effect on the firm's NPV.

This provides the company with control over the product life cycle. In many cases. product life is at hest guessed. but by early introduction. the company eliminates (reduces) the uncertainty surrounding ohsolescence. A good cxample of successful product cannibalization is the software company Corel which intrnduces a new version of its popular CorelDraw every year. The competition can barely keep 
reasons to invest (e.g., quality, innovation, flexibility). This depends on the nature of the business and its strategies.

Baldwin (1991) proposes several tools to attain these goals. The use of rules of thumb is advocated. i.e., rules which direct resources to key competitive commitments and to the preservation and extension of capabilities. Rules are useful tools because they translate complex competitive commitments into unambiguous goals. However, rules can also be biased towards specific goals and, in the process, neglect other important endeavors. Also, they must always be re-evaluated so that they do not outlive their usefulness. One suggested rule is to divest assets. This rule of divesting strengthens the company's commitment to innovation because when an opportunity arises, the company hears less direct cost of obsclescence. Incentives to innovate increase and competitors' incentives to invest decrease. Changing structures and incentives is another suggested rule that can take the form of a strategic alliance of a large firm with a small one. Small firms are more likely to innovate because their success depends on it. Parallel marketing forces is another benefit of alliances that can help transform innovation into success. Managerial incentives that calculate performance (e.g., profits) in which a certain percentage is derived from new products also promote early introduction.

The problem with the above analysis is that it is very general and in no means a methodology for other firms to emulate. Moreover, care must be taken not to put

IIp Morcover. the success is also due to the fact that the older versions stay on the market and become low-priced entry level software. 
innovation before all other objectives because it can blind managers to other more important aspects of the firm. As seen many times, some companies have suffered from over-investment in technology and innovation. Early introduction is sometimes not desirable. and often competition waits for the first move to learn from the experience and to gain very valuable information (Bowman and Hurry, 1993). The propositions by Baldwin (1991) are interesting, but incomplete, and offer no direct valuation process when managers face investment Jecisions

On the other hand, Azzone and Bertele (1989) claim that the strategic approach is convenient only when dealing with extreme situations. There is still the problem of choosing the appropriate FMS in the case where you opt for the flexible systems. To compute profitability, one has to use cash flows expressed as a function of the firm's strategic position. The proposed method consists of three steps:

1) The firm's strategic position is expressed by a few numerical values, each representing performance requirement of the manufacturing system. All systems fulfilling these requirements are equivalent with respect to the firm's strategic position.

2) The general concept of flexibility is subdivided into a few elementary concepts. Each elementary flexibility can be measured in a deterministic or stochastic way. 
3) Connections between the cost of obtaining strategic performances and the manufacturing system's flexibility are defined. This allows for the consideration of the effect of flexibility on the investment's expected net cash flows.

The demand for a product is affected by response time, service, technological compatibility and introduction of new products; thus they can all be competitive advantages. Azzone and Bertelè's (1989) model determines the expected cash flows as a function of the firm's strategic position. The firm's strategic position is turned into a few performance indicators, expressed numerically, which become constraints in the model. As per the Meredith and Suresh (1986) classification, this model qualifies as an analytic justification approach with a mix of programming. For this reason, it suffers from the same weaknesses as those of simulation methods: complex and some sources of value missing. As well, with a number of definitions of flexibility floating around in the literature, it is doubtful that their quantification of flexibility is complete. However, they have segmented the flexibility aspect of FMS into a qualitatively comprehensive and simple list

Aggarwal. Edward, and Mellon (1991) also lean toward the combination of strategic analysis and capital budgeting. As mentioned by Gerwin (1992), the major difficulty with the capital budgeting of AMT's is the valuation of intangibles. ${ }^{13}$ Aggarwal et al. (1991) propose strategic analysis of the industry (and more) to identify the

\footnotetext{
" Genvin goes a step further by implying that on top of the normal strategic benefits. technologies can
} crente new opportunities not thought of at the time of adoption. 
competitive strengths, weaknesses, opportunities and threats. More importantly, AMT's should be assessed against conditions of declining competitiveness and loss of market and not the usual status quo of no competitive response. This is wise advice for evaluating any investment. The value of flexihility is argued to be dependent on the nature of business. Also. the value of real options for future growth generated by flexible manufacturing svstems increases with uncertainty regarding the future.

To help in the financial valuation of the decision process, Aggarwal et al. suggest an adjusted net present value analysis The adjustments include cash flow for 'soft intangibles ${ }^{-14}$. cash flow that would depend on competitors' reactions, the value of future real options. and the decline in current levels of cash flows in the absence of the new investmer t..

There is no suggested formal way to evaluate intangibles and revenue enhancement. If they are uncertain, they will require a higher discount rate, and thus, Iower value This will produce the same short term bias as in the case of normal NPV. Moreover. there is a question of whether or not the option value in the analysis should be obtained using the traditional option pricing method. If that is the case, the option need not he discounted. since time and risk are included in the calculation of the option value. Finally. options inherent to the project can interact with each other because they are all dependent on the same underlying asset, and as such, can change in value (Trigeorgis,

\footnotetext{
'" 'Sof intangibles' refers to such benefits as the quality and the delivery times.
} 
1991, 1993). This is further discussed in the next section in the context of options theory. This model is very interesting conceptually; however, it fails to satisfy robustness criteria pertaining to subjectivity and practicability as in Table 1.

A look at the R\&D literature provides a possible tool capable of evaluating uncertainty and risk. Options theory from finance has started to appear as a better alternative in R\&D because unlike NPV, it reacts positively to time and volatility, as is the case with R\&D. AMT's could be treated as an extension of R\&D because of the same time. risk and uncertainty characteristics. Meredith and Suresh (1986) suggest that investments in AMT's can be treated as R\&D projects where you adopt a small pilot project (research) and learn more about its uses, costs and future capabilities. Then, you move on to full scale implementation (development) or incremental investment. In such cases, the small investment is the action of buying the option on the whole technology; if it does not succeed, then only the cost of the option or pilot is lost. Also, such option acquisition provides the opportunity to learn about the project or the technology which in return increases the possibility of success. The R\&D view is a good idea, but in cases of adoption for replacement of existing manufacturing systems, it does not provide a precise methodology for considering all cash flows and choosing between alternatives. It cannot value all intangibles related to AMT's due to the limited scale and scope of a pilot project. ${ }^{15}$ The introduction of options theory to evaluate risk and uncertainty, however, must be retained and we will see its uses in the following section.

" Information regarding the adaptability of the project to new products or process introduction will surely be lacking due to the time frame of the pilot experiment. 


\subsection{Options-Based Justification Approaches}

The Meredith and Suresh (1986) classification overlooked the application of options theory to capital justification. The application of options theory in R\&D has been demonstrated by Lounsbury (1992) who developed a practical model for the purpose of justifying R\&D investments, and the use of such a model at Merck \& Co.

Financial options are claims that give the right (not the obligation) to the holder to buy (a call option) or sell (a put option) a certain asset (the underlying asset) for a specified price (exercise price) before or at a specified date (expiration date). Options are particularly interesting when the returns associated with the underlying asset are volatile and uncertain A holder of an option will invest only when the returns become attractive. This way. benefits can be reaped with limited downside risk since the investor has no obligation beyond the purchase of the option itself. NPV analysis is unable to deal with this limited downside risk and thus underestimates the real value of the investment.

The options framework can be extended (called real options framework) to evaluate projects where decisions and choices will be made at a later date. For example, a firm may hold land suitable for urban renewal, but not embark upon the first development project that appears because that would preclude the firm from undertaking other potentially more valuable projects with the same land at a later point in time (Sick, 1989).

This analysis is also very useful in the development of natural resources. Moreover, any 
decision responding to changes in the environment involves real options (price, demand, etc ). The options framework can be used to value firms, patents on products and technology, natural resources, managerial flexibility, convertible debt and preferred stock (Sick. 1989; Damodaran, 1994; Copeland et al., 1994).

Real options arise when a project has uncertain benefits and costs and there is an opportunity to delay, expand the project (or any other modification) contingent on the information to be gathered in the future. If the uncertainty can be easily quantified, such as the price of standard commodities, then the analysis is simpler (Sick, 1989). Sick (1989) argues that industries plagued with many uncertainties (i.e., several stochastic variables) will be the last to adopt real options framework as a capital budgeting tool. The main reason is the difficulty of implementation. This may be legitimate assumption, however, compared to the traditional justification approaches, this framework is perfectly suited to value and study risk and uncertainty. It is natural to thirk that beyond the technical difficulties, these industries would gain the most from its use. Manufacturing firms that are faced with such a competitive market, invest in installations like AMT's. To value AMT's and FMS with the options framework, it is needed to go farther than the traditional real options as stated by Sick (1989) and Trigeorgis $(1993,1991)^{16}$ and study the more strategic variables such as flexibility.

1. These are options to defer. expand or contract. abandon and stan up or shut down. 
There exist, however, some caveats to using financial option pricing models to value real options (Sick, 1989; Damodaran, 1994). Financial options are typically shortlived. Thus, the timing of exercise is of secondary importance. It is not so in the case of Iong term projects with real options. Options are written on underlying assets that are traded and that cannot have a negative price; pricing depends greatly on the tradability and the possibility of arbitrage. Also, option pricing models usually deal with a single option. In the case of real options, they are often compound options that affect the value of the underlying asset. Moreover, with real options, the exercise price can be random and the variance can change over time because of the longer time horizon. Finally, exercise of the financial option is assumed to be instantaneous, which is probably not the case with real options

As stated earlier, real life investments often involve many real options and according to Trigeorgis (1991), it is often impossible to write down the set of partial differential equations describing the underlying asset. Also, adding up option's value may not be appropriate because it is shown that multiple options interact (Trigeorgis, 1991, 1993) Even more interesting is the fact that the omission of one or more options is insignificant as the total number of options grows (Trigeorgis, 1993). While his model does not completely meet the requirement of rule 1 as per the robustness criteria's table, especially for AMT's, it might be a good basis for the development of a model for valuing AMT's. 
The model of Trigeorgis (1993) is a numerical method for valuing complex investments with multiple interacting options. It is a log-transformed variation of the binomial option pricing designed to overcome problems of consistency, stability and efficiency encountered in Cox, Ross, and Rubinstein (1979). The method is designed such that the valuation process is consistent, unconditionally stable, and computationally efficient. These characteristics are defined as follows. Consistency implies that the discrete-time process used has the same mean and variance for every time-step as the underlying continuous process. Numerical stability means that the approximation errors in the computations will be dampened out rather than amplified.

Those models are indeed very useful to value projects faced with uncertainty and risk For example, the model by Trigeorgis (1993) satisfies most of the robustness criteria for capital budgeting. However, the inclusion of pertinent parameters depends on project Iypes In particular, it does not completely satisfy the source of revenue rule for AMT's or FMS It is quite plausible to envision a modified Trigeorgis model to include the specific characteristics in AMT's or R\&D. The modeling of flexibility as a real option should be a major step in valuing AMT's within the options framework.

\subsection{Synthesis}

The tools presently available to practitioners and academics alike seem to be incomplete when subjected to valuation problems of a highly risky and uncertain nature. Traditional financial methods such as the NPV are increasingly criticized and identified as 
the culprit in investment myopia. Other methods, more qualitative in nature, have tried to evaluate the benefits of certain technologies and flexibilities, however, they remain very qualitative and subjective and thus very poor as a justification tool. More complex methods such as AHP, simulation and dynamic programming have made tremendous gains towards solving the problems in valuation with uncertainty and risk. Unfortunately, these methods a:e not only complex to implement, but also difficult to use and understand. To most. they are not very intuitive; this prevents them from getting wide acceptance.

On the other hand, the options framework is gaining wider acceptance into many fields of management outside finance. The main reason is that it is naturally intuitive and tern simple to understand. The concept itself is so simple that most people would have dealt with them without even realizing it. What finance has provided is methods of valuing options This has left the door wide open for any academics or practitioners to model the needs particular to their field using options framework. This is how this study is contributing to research by modeling manufacturing flexibility as options for the purpose of valuation and decision making. 


\section{THE MODEL}

\subsection{Ise Of Options Theory In Capital Budgeting: Merck Example}

Appendix I provides an overview of option pricing terminology and a brief summary of the binomial option pricing model; these are central to this research and its comprehension. Before developing the model per se, an analogy is shown here to explore the possible application of options theory At Merck, such modeling is used to value Research and Development projects (see Table 2). As stated earlier, the argument for the use of options is the fact that the value of R\&D is derived from the uncertainty in the husiness environment For simplicity Merck uses the Black-Scholes Option Pricing model for European options (no exercise before expiration), even though it might not be an accurate analogy for $R \& D$ investments.

Merck is a large pharmaceutical company that often enters into business relationship with small firms to gain access to research. Contracts usually entail an initial financing of the research with the right to make further progress payments. These payments are contingent on the progress of the research and its marketing potential. Merck has the right to continue the financing but not the obligation; this is a classic example of an option contract. On a typical project, the returns are difficult to model both hecause of the high degree of uncertainty regarding the size and the profitability of the future market segments and because sales are not expected to commence until five or more years In this context, the expected costs of development are viewed as the exercise 
price. If the cost is lower than the expected cash inflows, then it is profitable to exercise the option and develop the product. Time to expiration is the time at which the option will become worthless; this may be due to obsolescence or introduction of competing technology or products. If striking the option requires a certain length of time before the acquisition of the asset, such as development of products, then it must be considered when eraluating the time to expiration of the option! ${ }^{17}$ To measure uncertainty regarding the project (in this case the cash inflows). they use the volatility of the stock of a typical hiotechnology firm

Table 2 - Practical Use Of Options Theory At Merck (Nichols, 1994)

I. The eicreise price is the cost of the imestment to be made at a future time (approximation is made)

s The slock price is present salue of cash flows (evcluding the intestment and costs in the years before crercising)

T Time to expiration is varied (sensitu iț analy sis) between expected exercise time and expected time when option will be worthless

r. The carrance is evaluated from a sample of standard dev iation of returns for tspical firm stocks (i.e.. thotechnology in therr casc)

r. The risk free rate is the US Treasurn rate

Standard Blach \& Scholes Formula for Europcan option pricing

$\rightarrow \quad(1,1)-1, \cdots(1,1,-\sigma \sqrt{7})$

l $\frac{\operatorname{lnc} \cdot 11+\left[r 1+\left(\sigma^{2} 2\right)\right] /}{\pi \sqrt{t}}$

$\mathrm{N}\left({ }^{*}\right)$ - The standard normal cumulatuc probabilı! distribution

(" - Europeall call price. i.c. the value of an option that cannol be exercised before the expiration dille In this case. It is the value of the research.

This is different from financial options where strikıng the option converts it almost instantly to its underly ing asscl. I.c. buy ing stocks. 
It does not matter if the expected cash flows are negative or positive because there is too much uncertainty; a conservative range for volatility of a typical biotechnology project is between $40 \%$ to $60 \%$. However, if the value of research, (value of the option) calculated using the Black-Scholes option pricing formula, is greater than or equal to the known real cost of research today, then it is in the firm's interest to invest in such research. In time, information will reduce the uncertainty surrounding a project's expected cash flows and at that point, it will be possible to make a sound decision regarding investment in the development of the product. The same procedure can be used to study manufacturing technology where added value is attributed to options such as flexibility, if the environment is uncertain.

\subsection{Flexibility}

Flexibility is a major characteristic of AMT's. Most of the intangible's benefits and costs stated earlier can usually be classified as emanating from flexibility. The definition and classification of flexibilities are as many as the authors who define them. ${ }^{18}$ The definition of flexibility provided by Azzone and Bertelè (1989) is not the iniversally accepted definition in the literature. However, it is simple and covers a majority of flexibilities seen in the literature. The difference in the interpretation and the value of flexibility is in the way thitt it is modeled quantitatively. This study uses some of the terminology and the qualitative characteristics from Azzone and Bertelè (1989). The flexibility concept as adopted in this study has been divided into five major flexibilities: 
I. Routing flexibility: The ability to operate with one or more machanes out of order

2 Process flexibility. The ability to operate product shanges among a given mix with low set-up times

3 Product flexibility: The ability to introduce new products into the production with low costs. Unlike Azzone \& Bertelè, we have joined production flexibility with product flexibility: this combination is more appropriate in our study since they are so closely related Production flexibility is the probability that the manufacturing system will be able to process a new product.

+ Volume flexibility: The ability to operate with a low reduction of the operating margin during a decrease in market demand.

5 Expansion flexibility: It is measured by the cost difference between acquiring a machine at the starting time and adding it afterwards.

As a preamble to the development of the model, flexibilities can be qualitatively modeled into real options using the parameters needed in the traditional Black-Scholes formulation Table 3 shows a possible way of modeling these flexibilities.

The underlying asset for most real options d. "ined previously in the literature is the valie of the project (NPV) without the initial investment outlay. Expansion is such a real option and thus, the project NPV is the underlying asset. The exercise price of an expansion option is naturally the extra investment outlay; this is a simple extension of the

Sce Malialanabis ( ( 9993) for a review of the concepts and measures of nevibility. 
project Volume flexibility resembles expansion, however, it is composed of a put and a call This is due to the ability of gaining added revenue when demand increases and saving when demand lags. In our study the main source of uncertainty for our production system is demand To keep the model manageable it is better to only have one stochastic variable. For our study we assume the demand as being the principle stochastic variable affecting revenues and value of the project. For this reason, we will use the variance of demand as a proxy to the variance of the returns associated with the project (the underlying asset). 
Table 3 - Modeling Of Flexibility Into Parameters Or Options Valuation

\begin{tabular}{|c|c|c|c|c|}
\hline Flerihilit! & $\mathrm{X}$ (exercise price) & $\begin{array}{l}\text { S (price of } \\
\text { underlying asset }\end{array}$ & $\begin{array}{l}\text { T (time to } \\
\text { maturity) }\end{array}$ & $\begin{array}{l}\sigma^{2} \text { (variance of } \\
\text { the underlying } \\
\text { asset) }\end{array}$ \\
\hline Volume & $\begin{array}{l}\text { Cost of changing } \\
\text { the volume (up or } \\
\text { down) }\end{array}$ & $\begin{array}{l}\text { NPV of project minus } \\
\text { the initial investment. } \\
\text { The volume option is } \\
\text { a put and a call and } \\
\text { thus it can be } \\
\text { evercised in higher or } \\
\text { lower demand }\end{array}$ & Same & $\begin{array}{l}\text { Variance of the } \\
\text { returns of the } \\
\text { project (S): } \\
\text { (demand) }\end{array}$ \\
\hline $\begin{array}{l}\text { Expansion (\& } \\
\text { ahandon or } \\
\text { sall age) }\end{array}$ & $\begin{array}{l}\text { Investment in } \\
\text { cipansion }\end{array}$ & $\begin{array}{l}\text { NPV of project minus } \\
\text { the inttial investment }\end{array}$ & Same & $\begin{array}{l}\text { Variance of the } \\
\text { returns of the } \\
\text { project (S): } \\
\text { (demand) }\end{array}$ \\
\hline Product & $\begin{array}{l}\text { Cost of change } \\
\text { plus opportunit! } \\
\text { cost of forgone } \\
\text { retur' of previous } \\
\text { utilit! }\end{array}$ & $\begin{array}{l}\text { New NPV (projected } \\
\text { by previous product } \\
\text { introduction and/or } \\
\text { grow1ll due to new } \\
\text { products) munus } \\
\text { initial investment. } \\
\text { minus cost of } \\
\text { allernatuc facilit! }\end{array}$ & Same & $\begin{array}{l}\text { Variance of returns } \\
\text { associated to new } \\
\text { products in the } \\
\text { firm or industry } \\
\text { product: (growith of } \\
\text { returns due to new } \\
\text { products) }\end{array}$ \\
\hline $\begin{array}{l}\text { Production } \\
\text { (to be combined } \\
\text { with Product } \\
\text { nevihility for this } \\
\text { research) }\end{array}$ & $\begin{array}{l}\text { Not an option per } \\
\text { se. but means that } \\
\text { uhile expıration } \\
\text { lime approaches. } \\
\text { Froduct flexibilit! } \\
\text { becomes less } \\
\text { praclicable }\end{array}$ & & & \\
\hline
\end{tabular}

Product flexibility is the most significant and valuable because of its strategic nature It :s : ery hard to estimate the value of new products especially if their nature is unhnown However, past experience can provide some clue to its value, frequency of iccurrence and probability Moreover. present growth due to new products and the ability of production facilities to cope with such growth might indicate future trends 
Production flexibility is not an option per se, but it influences the probability that new products will be compatible with the production facility. With time, the probability of compatibility surely decreases. The asset corresponding to product flexibility is of course the new products NPV. In addition, this value must be compared to the alternative of investing in new facilities. The exercise price is influenced by the investment required for the change but also by the possible forgone revenues from the abandoned product(s). In all cases, the life of other equipment more or less determines the time to expiration of the option.

This study will concentrate on product, volume and expansion flexibilities. The product flexibility (combined with production flexibility) affects product life cycles and product innovation in the firm and as such affect a majority of the firm's cash flows. Volume flexibility is another very important flexibility because its value is directly related to the changes in demand, the main source of uncertainty: this is similar for expansion flevibility

Process and routing flexibility are not formally studied because of their more internal, project specific characteristics; this would limit the inyability of this research to provide a generic model for multiple uses. However, a glance at those flexibilities as renl options provides added insights. The exercise prices of routing and process flexibility are simply the cost of using the flexibility when it is needed. The corresponding asset is the savings related to its use. Routing flexibility depends on the saving from non-stoppage 
versus normal stoppage (this value could change greatly depending on the industry). The variance of stoppage is used in this case. Process flexibility deals more with the function of optimal production Deviation between present production mix and optimal production mix (determined by demand, prices, costs, etc.) represents the asset on which routing flevibility must be compared. It is suspected that this will vary according to returns of ıarious products, however, only relative change is significant (i.e., ratios of returns between products)

\subsection{Model Development: Background}

As a basis for the valuation model, the framework proposed by Trigeorgis (1993) will be used This framework can incorporate the value of real options and intangibles "ithout relying heavily on probability distributions. Moreover, as an option valuation method. it is deemed more efficient, stable, and consistent than previous other methods. It can easily accommodate American as well as European type options As stated earlier, this research will add to the body of knowledge in real options by modeling several Hevibilities into this framework for better estimation of the value of AMT's.

Transformation of the flexibilities into real optio:s requires the identification of several key parameters inherent to option pricing. For each option (i.e., flexibility), the underlying asset on which the option is written must be valued (V). The exercise price or cost of exercising the option is also required $(X)$. In some cases, these parameters change over time either randomly or according to some function. Time to maturity or expiration 
date $(T)$ is another crucial parameter in option pricing. Finally, the variance of the underlying stochastic variable is necessary $\left(\sigma^{2}\right)$. Preferably, only one of the variables is stochastic. If this is not the case, it is still possible to calculate the value of the real option, hut with added complexity to the model.

\subsubsection{Trigeorgis' Model (1991)}

A look at the model proposed by Trigeorgis (1991) will set the stage for the derelopment of a similar model with the added capability of valuing flexibility. The Trigeorgis (1991, 1993) model consists of adding the value of real options to the traditional NPV analysis of investment projects. The options treated in this model are commonly encountered in the real options valuation literature and are referred to as the managerial flexibility (Trigeorgis 1991, 1993; Brennan and Schwartz, 1985: Sick, 1989. Damodaran, 1994; Copeiand et al., 1994). They are expansion, contraction, abandonment (or switch use) and deferral options.

The model developed in this research will build on this concept of real options. The difference hetween this work and previous research is that other options not previously considered are modeled and valued. These options are particular characteristics of flexible manufacturing systems. As mentioned previously, the major characteristic on which this study concentrates is flexibility. To avoid redundancy, expansion flexibility is not re-modeled and is valued the same way as Trigeorgis (1991, 1993) Moreover, product flexibility goes beyond the switch use option because it deals 
specifically with future possibilities, while switch use deals only with the present alternative. Those other uses are usually less valuable today than the project under consideration but might eventually represent a better alternative.

The model proposed by Trigeorgis $(1991,1993)$ is broken down into four steps. The first step is the specification of the parameters. These initial parameters include the Ialue of the project, the variance of future cash flows, investment outlays (representing evercise prices). timing, time to maturity and the riskless discount rate. The value of the project is calculated using the traditional NPV without any adjustments for real options embedded into the investment

The second step consists of transforming the continuous process into its discrete equivalent This is necessary in cases where the valuation of the option is done using a hinomial tree approach. The model developed here uses the binomial dynamic programming method These values include the time increments of the valuation nodes (in the continuous process, this is infinitely small), and the probabilities associated with either a positive or negative change in the asset value, and the magnitude of such changes

Thirdly. the binomial tree is built from time zero to time to maturity. This process determines the terinınal values of the project at different states of the world (ups and downs in value!. The present value of the project and the mid-point values are not yet 
determined. These values depend on the terminal values in ach state and thus the same process must be duplicated again but in a backward fashion; this is the fourth step.

Finally, the fourth step consists of recalculating the value of the project at each time-state node starting with the terminal node. Moreover, each time a cash flow (i.e., dividend) or option is encountered, the value of the project must be adjusted accordingly. The real options of the Trigeorgis $(1991,1993)$ framework are modeled as such. The s.vitch use or abandonment option is defined as the maximum value between the project value and the salvage (or new use) value. When the expansion possibility is encountered, the net present value of the expansion is added to the previous value; contracting is the opposite where the value is due to savings The defer option depends on the maximum value between the value of undertaking the project now or its discounted expected value in the next time step Table 4 shows clearly these adjustments in the context of the Trigeorgis ( 1991 ) example. 
Table 4 - Adjustment For Multiple Real Option (Trigeorgis, 1991)

\begin{tabular}{|c|c|}
\hline Reil option & Tolal opportunity value adjustment \\
\hline 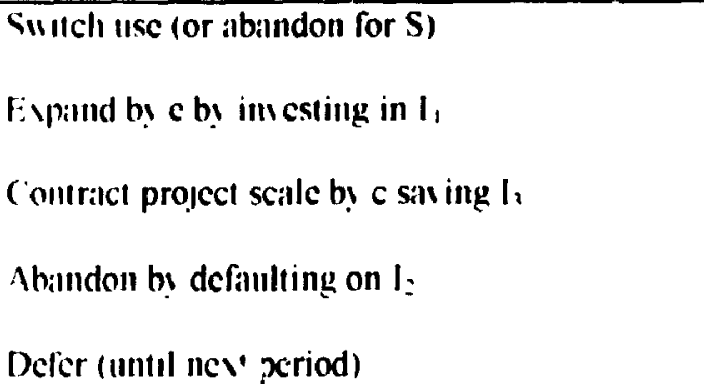 & $\begin{array}{r}R^{\prime}=\max (R . S) \\
R^{\prime}=R+\max \left(c V-I_{1 .}(0)\right. \\
R^{\prime}=R+\max \left(I_{3} \cdot c V .(0)\right. \\
R^{\prime}=\max \left(R-I_{2} \cdot(0)\right. \\
R^{\prime}=\max \left(c^{-n} E\left(R_{1} \cdot 1\right) . R_{1}\right)\end{array}$ \\
\hline 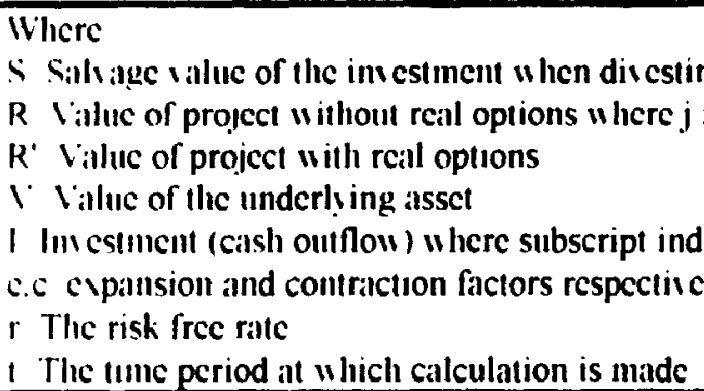 & tate \\
\hline
\end{tabular}

The example consists of evaluating the following multi-option project. Operating the project requires several initial investments at year 0,2 and $3\left(I_{11}, I_{2}, I_{3}\right)$. There is an option to delay this project for the time being by $T_{1}$ yeats. There is also the possibility of abandoning the project in its construction stage by forgoing $I_{2}$ The project can be scaled down by c. thereby saving $I^{\prime}:$, or expand by a fraction e with an extra investment $I_{4}$ at year 1 Finally, at anytime. management can switch the project from the current use to its best alternative use. this may include abandonment for its salvage value (S).

Trigeorgis (1993) shows that the value of multiple options simply cannot be the sum total of the value of individual options as proposed in earlier research. The real 
options embedded in the project are inseparable from each other and the underlying asset itself. and thus. interact with each other. First off, just the presence of an option changes the value of the underlying asset for all earlier options. Moreover, exercising of an option can alter the asset and change the value of subsequent options causing a second-order inturaction. The degree of interaction will depend on: a) whether the options are of the same or opposite type, b) the separation of their exercise times (influenced by whether they are European or American options), c) their relative degree of being 'in or out of the money.' and d) their order or sequence.

If two options are of opposite types (call \& put) so that they can be optimally exercised under opposite circumstances, then the conditional probability of exercising the latter option, given prior exercise of the other, would be smaller than the marginal probability of exercising the latter option alone. The degree of interaction would then be small and their value approximately additive. If they are of the same type then the conditional probability of exercising is higher and so is the interaction; the sign of the interaction depends on the options (put- negative, call- positive). Alsr, in extreme cases, exercising an option can kill all other subsequent options (i.e., abandon).

In the particular example chosen, the value of investment calculated with option interaction is about half of the value of the simply added option values. Moreover, because of this phenomenon of diminishing marginal option value. ${ }^{19}$ omission of a few real

For cxample. in Tri.: orgis (1993) study. three options had a value of 83 or 86 . four had 86 or 87 and all five h.ad a value of only 87: NPV without the options was -14.7. 
options may be negligible. ${ }^{2 n}$ The model will be a $v t y$ close approximation of the real value especially if overlapping options have been eliminated. ${ }^{21}$

\subsection{The Model}

\subsubsection{The Environment:}

The development of the model is based on an investment in a manufacturing sistem This investment will be setup to be as generic as possible and it will resemble the one proposed by Trigeorgis (1991, 1993). For this research, the project is a one time incestment in a new production facility The need for production capacity as well as its amount has already been determined. Fo, a discussion of optimal capacity choice and the use of finan ijal options for such a decision, see Pindyck (1988). The value of the investment is calculated with the traditional present value of cash flows approach. The investment outlays are not included in the initial value of the project at hand The life of the investment, the risk free interest rate as well as the variance of the investment are assumed to be known or well estimated. As mentioned previously, we use the variance of the demand as a proxy for the variance the value. Different ranges of value of theses parameters will be studied in a sensitivity analysis.

The exact size of the error would depend on the type of the neglected options. the extent to which they are in the moncy. and the relative size of their evercise cost. It would alsn depend with the overlap of their exercise regions with the other included options

A simple selection rule proposed is to climınate those (usially put) options that are of similar type and that cin be exercised under similar circumstances as nther included real options. particularly if their evercise costs are such that they are : $\eta$-the-money options. 
The investment is in a flexible manufacturing system and it should be compared to an investment in a traditional system. ${ }^{22}$ The system will have the capability to respond to fluctuations in demand (volume flexibility), to changes in the value of the project (expansion and contraction option/ flexibility) and the possibility of new products replacing the old in the proposed production system (product flexibility) ${ }^{2 i}$. The routing and process flexibiity are not directly incorporated in the model because they tend to be very project specific in nature however. As mentioned previously, the model will be built from the work of Trigeorgis (1991,1993); see Appendix 7 for the full design of the logtransformed bi..smial method

\subsubsection{Expansion Flexibility:}

In our study we will model the flexibility as real options using the terminology of Trigeorgis (1991. 1993) found in Table 4 The option adjustment for expansion flexibility is identical to the expansion option defined by Trigeorgis (1991, 1993). $R^{\prime}: R+\max \left(e l^{\circ}-I_{+}, 0\right)$. Here we include also the contraction option defined as such: $R^{\prime}=R+\max \left(S\right.$ (n)ings $\left.-c^{\prime}, 0\right)$, where savings represent the lower investment to follow compared to the full project's investments This flexibility could be modeled as dynamic or static The Trigeorgis $(1991,1993)$ paper models it in a static fashion. Dynamic

Remember that we are try ing to be as generic as possible: thus. the reader must bear in mind that chamges and additions to the model would have to be made to studi specific systems. companies and industries

We define Product flexibility in our model as being the combination of Product flevibility and Productıon flevbilıty as defined by Az/zone and Bericlè (1989). This means that our definition meludes the probability of a new product introduction as uell as the probability that new product is compattible with the production facilit! in place. 
expansion flexibility would mean either the possibility of expanding anytime and any number of times, or anytime at a set number of times. The first possibility is more complex since restrictions on size, timing, set-up time and cost would have to be incorporated This is beyond the scope of this study In any case, the total value would be the sum of the two options less a margin for interaction because of different timing (See Irigeorgis 1993) The other possibility would imply some unknown timing for the expansion. however, the theory on American call options tells us that exercise is only (ptimal at expiration for a stock with no interim cash flow (in or out). Thus, this option is ecuuivalent to an expansion on or near the end of the lifetime of the project. This research anly uses the static expansion option where the timing is pre-fixed

Figure 2 - Binomial Tree for Expansion flexibility

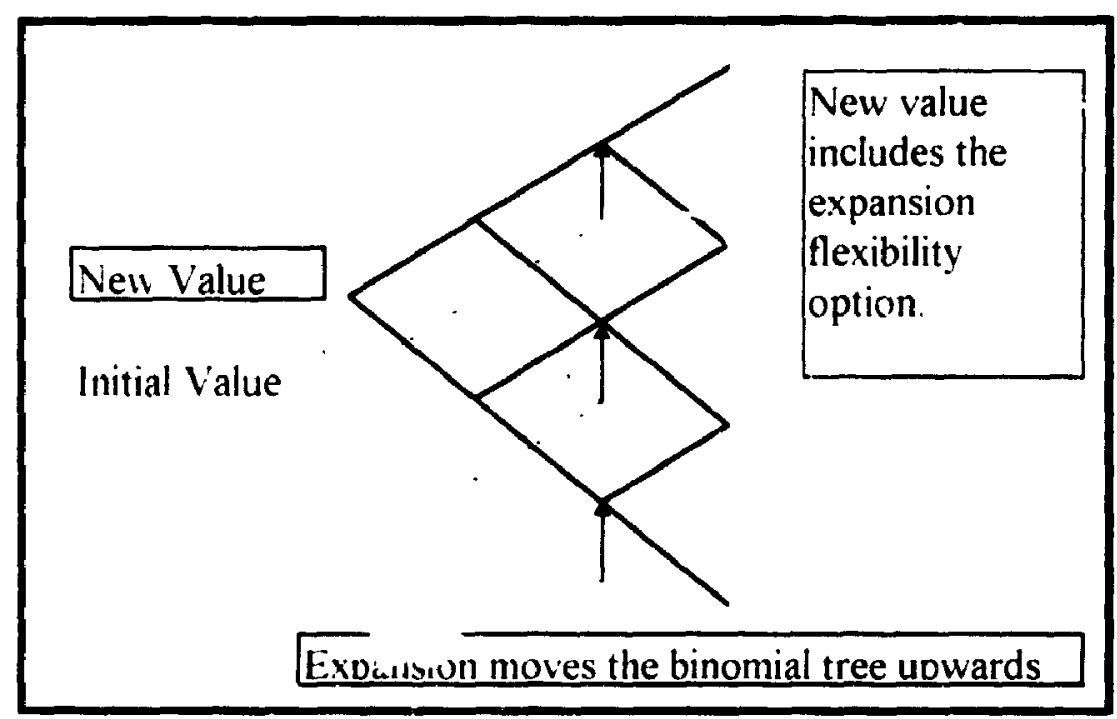




\subsubsection{Volume flexibility:}

Volume flexibility makes response to demand changes possible. Thus, the abseice of such flexibility will decrease the value of the project if demand is stochastic, which is the case in this study. In this study. for simplicity, we have assumed that value of the project as calculated by the initial basic NPV, will not change if the project is flexible to demand changes. Thus, the initial NPV value must be adjusted downward for the absence of volume flexibility. To do this, we have to recreate the binomial tree model as suggested where the higher demand values are equal to the initial value (higher demand but no response; thus same production as initial condition) and the lower portion of the tree, where demand is lower than in the initial scenario, and where the revenues are not only lower, but the costs are higher either because of over production, or because of lower operating margin for lower production levels. This downward adjustment can be viewed as the opportunity cost of choosing or fixing the production to the level of expected demand, this means that you cannot profit from changes in the demand level.

In the model, we have omitted the cost for changing production as well as lower and upper bounds of the production system as it is presently. The correction for lower production is added in the model tree as a percentage of the expected change. Fror our purposes. we used a value of ten percent Thus, instead of $V(i)=\exp \left(X_{1}+i H\right)$ we have $V(i)=\exp \left(X_{0}+1.1 * i H\right)$, where $i$ is negative. 
Figure 3 - Binomial Tree for Volume Flexibility

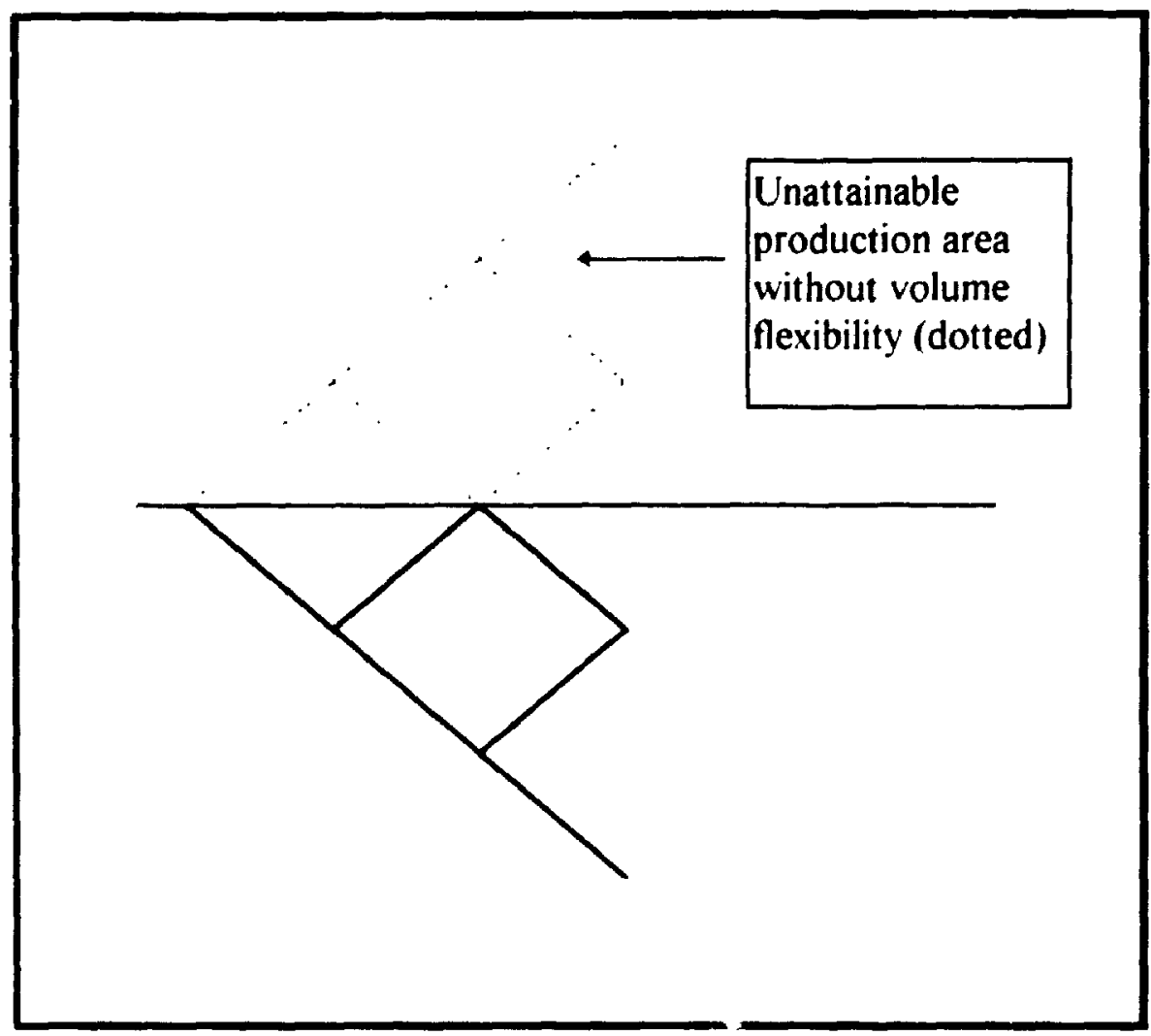

\subsubsection{Product Flexibility:}

In order to value R\&D investments, Lounsbury (1992) proposes the following: We have a current outlook for the new technology or product as well as a pessimistic (L) and optimistic $(\mathrm{H})$ outlook and an implementation cost. Using a Beta distribution for allowing for skewness, the probability of the value (V) being greater than the cost $(C)$ is multiplied by the conditional value of $V_{c}-C$, where $V_{s}$ is the average value of $V$ in the area I ( $\operatorname{lor}(\mathrm{C}$ to $\mathrm{H})$. This same procedure, assuming a normal distribution, could be obtained 
those obtained by Trigeorgis (1991). Moreover, it is compared to a series of American call option values that are calculared using the Black and Scholes formula.

We also proceeded to test the model by generating European call option values for different stock prices and times to maturity. Graphs of those are used to show that the model values the options in the same manner as the standard Black Scholes. It will show that our model is thus truly an option pricing model.

\subsection{Sensitivity Analysis}

The main concern when valuing options and investments in general is the accuracy of the input parameters. In particular, variance is used to model stochastic phenomenon, but its measurement and estimation are often problematic; this gives rise to additional uncertainty. For this reason, we study changes in variance and its effect on the value of investment in flexible manufacturing systems. Moreover, the risk free rate is also of interest to this research. This is a major component of the cost of funds and uncertainty surrounding its value could possibly affect greatly the value of the investment.

The sensitivity analysis is more qualitative in nature. This is so because we needed to choose a generic scenario that does not necessarily represent real life data. In particular it focuses on the direction, shape and magnitude of the relationships and not the exact numbers and changes. We defined an up (down) relationship as one where the NPV increases (decreases) when the value of the parameter increases. A $U$ shape relationship is 
costly This is true until the end of the life of the investment where transformation costs "would be greater or equivalent to a new facility. Moreover, by that time, the new product or technology. if valuable, will have probably been adopted by the competition. At any other time. we suppose for now that competition is included in the NPV analysis

To find the value of the option associated with flexibility, our model uses the difference between the value of the project with flexibility and its value without flexibility. Fien though the model is initially based on the NPV analysis, the value of the option(s) cannot be found by simply finding the difference between the NPVs of the two streams of cash flows This study focuses on how flexibility can be valued, knowing that the Iraditional NPV framework does not work First, the NPV analysis fails to adequately asses the discount rate in the presence of real options. Secondly, the difference in NPVs does not take into account the limited downside risk of options, a major source of value in opmons Thirdly, the NPV framework does not consider the basic premise of options, that 15. the choice of not exercising the option if it is not optimal to do so Therefore, the use of option pricing theory is more appropriate in valuing flevibility For a detailed numerical illustration please refer to Copeland et al (1994. pp 448-456) 


\section{METHODOLOGY}

\subsection{The algorithm}

Our model is built from the algorithm proposed by Trigeorgis (1991) and was programmed in Visual Basic for Microsoft Excel ${ }^{\mathrm{TM}}$ for Windows ${ }^{\mathrm{TM}}$. The reason for this choice is that Excel is a standard spreadsheet software that is widely available and easy to use Moreover, it includes a programming language that makes it more powerful and flexible than other spreadsheet software with their macro languages. The algorithm as proposed by Trigeorgis (1991) and the complete Visual Basic program for implementing our model are presented in Appendix 8 and Appendix 9 respectively.

\subsection{Scenario}

To test our model we chose to build on the example used by Tigeorgis (1993). Since we wanted a generic model and we did not have real life data, the choice of scenario " as arbitrary This scenario of Trigeorgis (1993) is a project with a lifetime of 15 years where the present value of the project, net of investments, is 100 . The required investments are 10,90 and 35 occurring at year 0,3 and 5 respectively. In our case, this project is a production system for a product or technology. We have omitted the delay, abandonment, contraction and switch use options We kept the expansion option, where the project can be expanded by $50 \%$ in the year 7 at a cost of 30 . We added the possibility of Volume flexibility and its absence and modeled it as described earlier. The product flevibility included the following parameters: the possible new product is expected to have 
a value of 200. an investment of 250 would be required to produce it and it has life of 15 vears Moreover, variance of return for typical new product(s) is estimated at 0.40 while the probability of introduction of such product today is zero and the probability of compatibility with the system at hand is 100 As mentioned earlier, for simplicity we have assumed that probability of introduction (compatibility) increases (decreases) linearly to (nne (zero) during the life of the investment. The variance of returns for the present project is 024 and the risk free rate is 005 In both new and present product(s) the I ariance of the returns is proxied by the variance of the demand

\subsection{Robustness of the Model:}

Since we are dealing with the development of a model, it is difficult to parallel the work of other authors. However, we build our methodology on some of the tests performed by Trigeorgis (1991, 1993) because of the closeness of the models In particular. Trigeorgis tested his model on the basis of simple option valuation We do not need to replicate this work to compare our model with other option valuation methods but we go through the exercise to compare our results with those of Trigeorgis (1991, 1993).

In mentioned earlier, this is simply to verify that our results matched those by Trigeorgis (1001. 1993). since our model is an extension of Trigeorgis (1991, 1993).

A series of simple tests were performed to see if the main engine of our program "as problem free One test included value generation of options to be compared with 
those obtained by Trigeorgis (1991). Moreover, it is compared to a series of American call option values that are calculated using the Black and Scholes formula.

We also proceeded to test the model by generating European call option values for different stock prices and times to maturity. Graphs of those are used to show that the model values the options in the same manner as the standard Black Scholes. It will show that our model is thus truly an option pricing model.

\subsection{Sensitivity Analysis}

The main concern when valuing options and investments in general is the accuracy of the input parameters. In particular, variance is used to model stochastic phenomenon, but its measurement and estimation are often problematic; this gives rise to additional uncertainty. For this reason, we study changes in variance and its effect on the value of investment in flexible manufacturing systems. Moreover, the risk free rate is also of interest to this research This is a major component of the cost of funds and uncertainty surrounding its value could possibly affect greatly the value of the investment.

The sensitivity analysis is more qualitative in nature. This is so because we needed to choose a generic scenario that does not necessarily represent real life data. In particular it focuses on the direction, shape and magnitude of the relationships and not the exact numbers and changes. We defined an up (down) relationship as one where the NPV increases (decreases) when the value of the parameter increases. A U shape relationship is 
when the NPV initially increases and then decreases. In traditional option valuation, we would only expect up and down relationships. Care must be taken when interpreting these results because this is not a test of the behavior of options but a test of the behavior of our ststem which includes real option. We studied all the combinations of flexibilities where the villie of the risk free rate changed from $1 \%$ to $3 \%, 5 \%, 7 \%$ and $9 \%$ and the variance changed from $3 \%$ to $10 \%, 17 \%, 24 \%$ and $31 \%$. The range chosen is similar to the one used by the Trigeorgis (1991), and the number $(5 \%)$ and the size $(7 \%)$ of the intervals were chosen arbitrarily for convenience (more than five values was very computationally time consumıng; In the base case scenario, the present value of the project was $\$ 100$; in the censitivity analysis, we did not use that figure since we wanted the present value of the cash inflows (value of project) and cash outflows to be influenced by the movements in the risk free rate We assumed cash inflows of $\$ 10$ at the end of each year for the lifetime of the project. 15 years All others variables are identical to the base case scenario (see section +21 


\section{RESULTS AND DISCUSSION}

\subsection{Result of the Robustness Test}

The first robustness test was performed on our model to confirm its behavior as an option pricing model for a range of different asset values and times to maturity. These results are analyzed qualitatively only. Appendix 3 shows the graphs of call option values. Our model clearly behaves as it should even at the extremities of parameter values.

We also compared the valuation of an American call option performed by our model in comparison with the standard Black Scholes option pricing model. This test was not performed by Trigeorgis $(1991,1993)$. The value of an American call should be the same as the European with no interim cash flows. Hence, the Black Scholes formula provides an accurate benchmark. We found some differences between our model and the Black Scnoles. But again, they are very small, under $0.4 \%$ (See Appendix 2). This was expccted since the Black Scholes option pricing model is a continuous model, while ours is based on a discrete time binomial model. There are some exceptions especially for calls that are deep out of money where we have a difference as large as $7 \%$. Research has shown that the Black Scholes formula underprices in the money calls and overprices out of the money calls (Tucker 1990, p.307) ${ }^{24}$. The study of such mispricing, however, is beyond the scope of this study.

:I In particular. our deep out of the money calls values are lower in value than Black Scholes and thus consistent will empirical observations. 
A third robustness test consisted of reproducing part of Table 1 of Trigeorgis (1991) for values of American put options. As mentioned earlier, this was done to verify whether or not our model can replicate the one proposed by Trigeorgis (1991). We observed four minor differences all of which were under $\pm 0.6 \%$. We attributed these differences to the choice of software used and its precision and treatment of decimals (See Appendix 2). All the above robustness tests show that we can be confident that our model IIIl value options correctly for a given set of input data.

\subsection{Base Case Scenario}

Table 5 shows the results of the base case scenario describe earlier in section 4.2 . V'flex. Xflex, Pflex and No flex indicate the presence of flexibility (volume. expansion, and product respectively) or its absence. in the test of our model. As expected, each flexibility adds value to the project. This is due to the fact that uncertainty and risk exist (variance) and that flevibility offers a better response to such changes. Moreover, we notice that the sum of the value of the flexibilities does not equal their combined value including interactions

Volume and expansion have a positive interaction and thus provide more value than the sum of their individual effect on the project. Thus, each flexibility will not only increase the value of the project, but the value of the other flexibility as well. This interaction exists only because the two options are not mutually exclusive and the striking of one does not kill the other option and itself as well 
On the other hand all other combinations of flexibilities show negative interaction.

One of the reasons is that product flexibility is a one time event and striking this option kills all other options such as volume and expansion flexibility. This is partly due to our assumption that switching to the other product eliminates all th. flexibility properties of the system. The reason for this assumption is two-folds: i) simplicity, and ii) to accommodate unknown new products in the future, it is reasonable to expect major changer, would be required to the system. Thus, there is no guarantee that the new setup will be as flexible as it was before; in a sense, we are being conservative.

Table 5 - Option Interaction

\begin{tabular}{|c|c|c|c|c|}
\hline $\begin{array}{c}\text { NPV } \\
\text { Option Valuc }\end{array}$ & $\begin{array}{l}\text { No flex } \\
-.37 .72\end{array}$ & $\begin{array}{r}\text { Vflex } \\
-1+.23 \\
23.485 \\
\end{array}$ & $\begin{array}{c}\text { Xflex } \\
-13.67 \\
24.0+7 \\
\end{array}$ & $\begin{array}{c}\text { Plex } \\
25.51 \\
63.225 \\
\end{array}$ \\
\hline & Vflex \& Xflex & Pflex \& Vflex & Pflex \& Xflex & $\begin{array}{l}\text { Pfiex. Xnex \& } \\
\text { Vflex }\end{array}$ \\
\hline NPI & 20.395 & 38.5 & +2.467 & 63.727 \\
\hline Combined Option Valuc & 58.11 & 76.215 & 80.182 & 101.44 \\
\hline Added Only & +7.5 .32 & 86.711 & 87.272 & 110.76 \\
\hline $\begin{array}{l}\text { Difference between Added Only } \\
\text { and Combined Option Value }\end{array}$ & 10.578 & -10.5 & -7.09 & -9.315 \\
\hline
\end{tabular}

Even though the input data is artificially constructed, the results show how a project that seems to be value eroding under the traditional capital budgeting framework, is indeed value enhancing when the value(s) of various flexibilities is (are) incorporated. More valuable is the way that such value behaves in relation to changes in the initial environment. This is analyzed next using sensitivity analysis. 


\section{S.3 Results of the Sensitivity Analysis}

Sensitivity tests on the variance and the risk free rate were executed in order to study the behavior of the model and the flexibilities. These results provide relationships between these parameters and the value of project embedded with real options. Tables 6 to 13 describe these relationships as up, down or $U$ shape for both the value of the project (NPV) and the value of the options (Value) (For a complete listing, see Appendix 4 and 5) From options theory, we expect all the relationships to be upward trends, i.e., the increase in variance or the risk free rate or both. should make the option more valuable. As variarice increases, the probability of an option being in the money is greater while the downside risk never changes and is always limited to the investment. As for the risk free Iate of interest. options are leveraged instruments and as such, when the cost of funds incr:ases (rate of interest), they become more valuable. Figure 4 and Figure 5 summarize these relationships 
Figure 4 - Graph of NPV

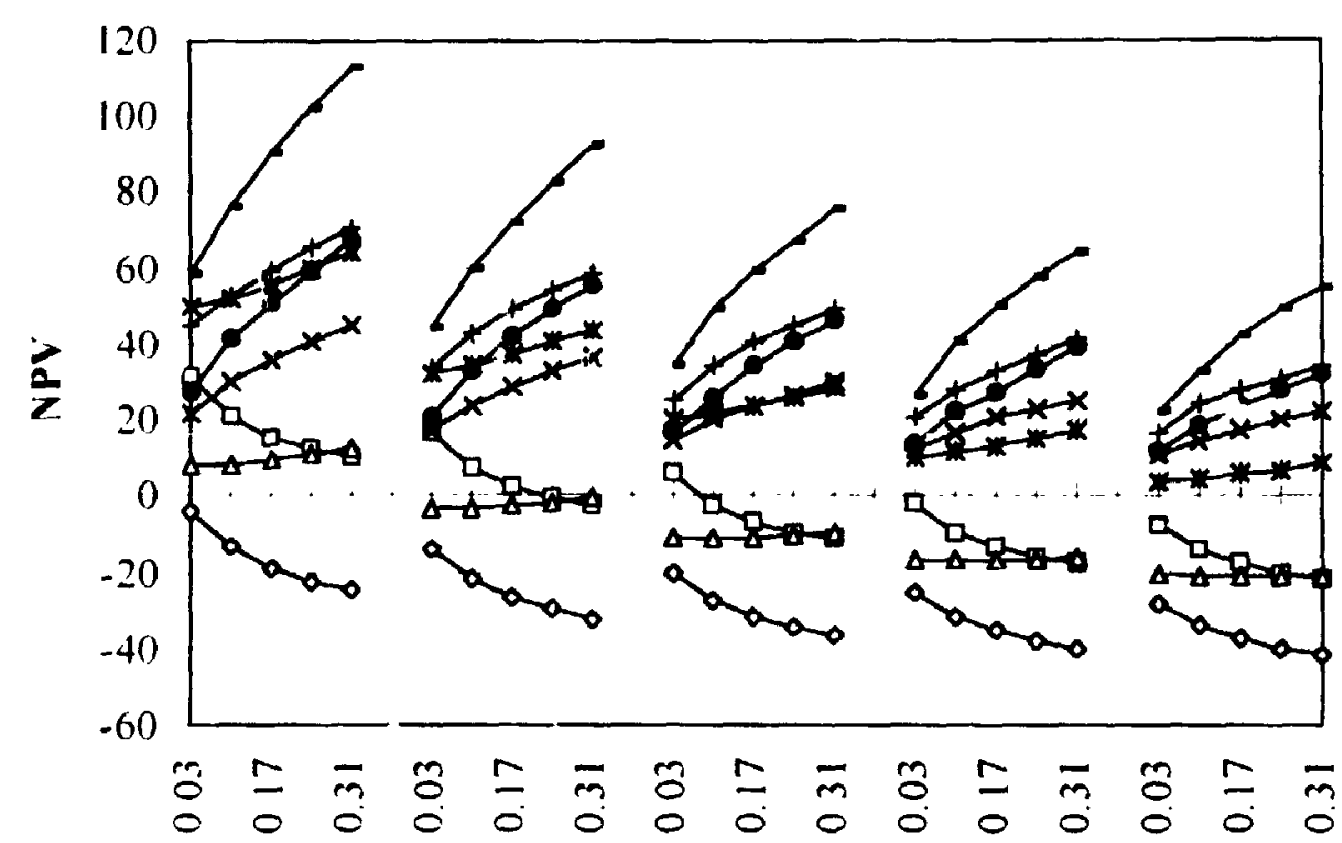

Variance for $r=0.01,0.03,0.05,0.07 \& 0.09$

$\begin{array}{llll}\rightarrow-\text { Noflex } & \rightarrow-\text { Xflex } & \rightarrow-\text { Vflex } & * \text { Pflex } \\ *-\text { Vflex \& Xflex } & \rightarrow-\text { Vflex \& Pflex } & \rightarrow \text { Pflex \& Xflex } & - \text { All flex }\end{array}$

These figures and their corresponding tables (Appendix $4 \&$ 5) show that on some occasions our findings for the value of the NPV and the flexibility are counter-intuitive. In particular, we observe up and U relationships in both the value of the NPV and the value of the option These differences are attributable to other, more subtle, relationships between outflows. inflows, option, and the cost of funds (time value of money) These seemingly irregularities stem from our construct of volume flexibility or its absence. 
Figure 5 - Graph of Options Values

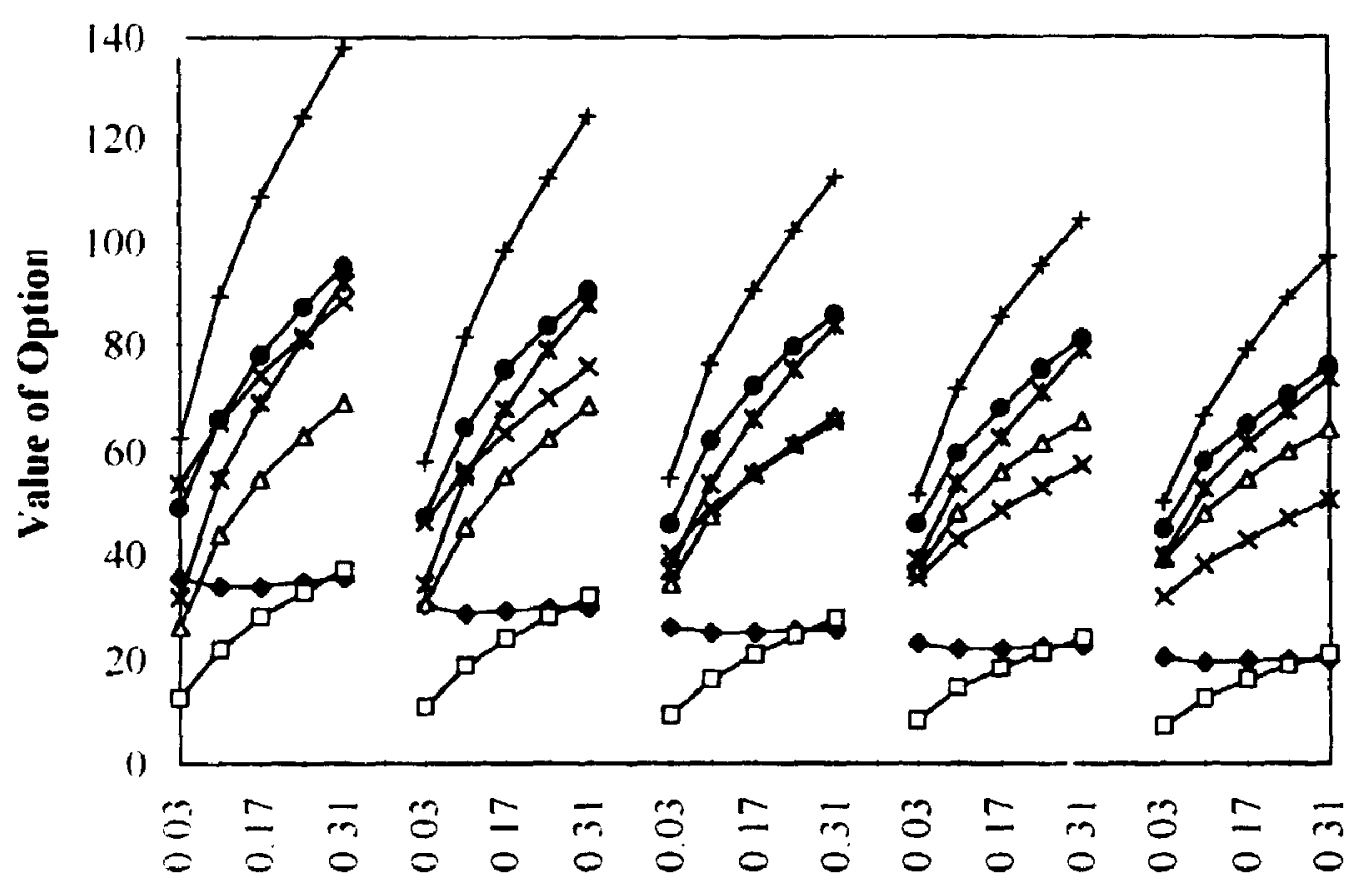

Variance for $r=0.01,0.03,0.05,0.07 \& 0.09$

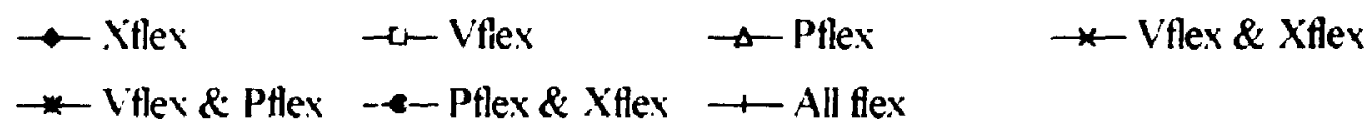

The NPV of the project with no flexibility (Table 6) has a downward relation with the risk free rate This is expected since in a risk neutral world the cash flows are discounted with the risk free rate. Note that risk free world means that the NPV itself is not affected by changes in variance; this can be observed in the table for the value of NPV "ith wolume flevibility ${ }^{25}$

\footnotetext{
" IIc have to use this table since we value volume flevibility from its ausence. thus the table of volume nevibilı!y represemt a simple NPV analy sis wthout an! consideration for real options.
} 
Table 6 - NPV without Flexibility

\begin{tabular}{|cccccccc|}
\hline No flex & $r$ & 0.01 & 0.03 & 0.05 & 0.07 & 0.09 & shape \\
Variance & NPV $(\$)$ & & & & & & \\
003 & & -4.27 & -1372 & -20.38 & -24.95 & -27.98 & down \\
01 & & -13.38 & -21.75 & -27.51 & -31.33 & -33.72 & down \\
017 & & -18.68 & -2650 & -31.79 & -35.22 & -37.27 & down \\
024 & & -22.27 & -29.78 & -3480 & -37.98 & -39.83 & down \\
0.31 & & -24.75 & -32.10 & -36.96 & -40.01 & -41.73 & down \\
shape & & down & down & down & down & down & \\
\hline
\end{tabular}

Because of the way we have modeled volume flexibility, it is normal to find different relationships for the value of the other options when volume flexibility is nonexistent The is because we chose to keep the binomial tree intact when volume flexibility " as present and adjusted it downward when it was non-existent. The observation of a $U$ relations.ip for the value of expansion flexibility option (Table 7) means that the value of the project without flexibility decreases more rapidly for changes in variance, than the value of the project with option increases. Remember, that the value of the option is the difference between the value of the project with and without flexibility. To eliminate the effect of the construct of the absence of volume flexibility, we must study the flexibilities with the presence of volume flexibility This is confirmed by the observation of an upward relationship when we add the vclume flexibility 
Table 7 - Value of Expansion Flexibility

\begin{tabular}{|ccrrrrrr|}
\hline $\begin{array}{c}\text { Xflex } \\
\text { Variance }\end{array}$ & $\begin{array}{c}r \\
\text { Value } \\
\text { (\$) }\end{array}$ & 0.01 & 0.03 & 0.05 & 007 & 0.09 & shape \\
003 & & 35.45 & 30.19 & 2614 & 2300 & 20.55 & down \\
01 & & 3390 & 28.74 & 25.00 & 21.90 & 1948 & down \\
017 & & 3404 & 2911 & 2509 & 21.91 & 1953 & down \\
024 & & 3469 & 2949 & 2529 & 22.23 & 19.71 & down \\
0.31 & & 35.23 & 2984 & 2571 & 2255 & 1993 & down \\
shape & & U shape & U shape & U shape & U shape & U shape & \\
\hline
\end{tabular}

Table 8 - Value of Volume \& Expansion Flexibility Combined

\begin{tabular}{|ccllllll|}
\hline Xflex \& Vflex & $r$ & 001 & 003 & 005 & 007 & 009 & shape \\
Variance & $\begin{array}{c}\text { Value } \\
\text { (\$) }\end{array}$ & & & & & & \\
003 & & 5378 & 4611 & 4014 & $\mathbf{3 5 4 4}$ & 3168 & down \\
01 & & 65.52 & 5624 & 4874 & 4290 & 3813 & down \\
017 & & 7449 & 6361 & 5527 & 4846 & 4285 & down \\
024 & & 81.80 & 7012 & 60.73 & 5306 & 4677 & down \\
031 & & 8868 & 7590 & 6556 & 5713 & 5025 & down \\
shape & & up & up & up & up & up & \\
\hline
\end{tabular}

An interesting relationship is the one between the value of flexibilities to changes in the risk free rate This relationship is caused by the fact that real options and their underlying asset are intertwined and inseparable When the risk free rate increases the Ialue of the underlying asset (project) decreases and decrease in the value of the asset causes a decrease in call options Volume, expansion and product flexibility are all call options Thus, even if the call option should be positively influenced by the rise in rates, it seems the negative effect on the value of the project and consequently. on the option(s), is greater Again, care must be taken in interpreting these results since they only reflect a 
particular set of parameters for the whole system and do not represent generalized observations on option behavior.

Table 9 - Value of Product Flexibility

\begin{tabular}{|cclllllc|}
\hline Pflex & $\mathrm{r}$ & 0.01 & 0.03 & 0.05 & 0.07 & 0.09 & shape \\
Variance & $\begin{array}{c}\text { Value } \\
(\$)\end{array}$ & & & & & & \\
& & & & & & & \\
0.03 & & 25.81 & 30.92 & 34.60 & 37.08 & 38.96 & up \\
0.1 & & 43.50 & 45.27 & 47.61 & 47.99 & 48.07 & up \\
017 & & 54.54 & 54.97 & 55.59 & 55.71 & 54.58 & त shape \\
0.24 & & 62.85 & 62.60 & 61.36 & 61.17 & 59.84 & sown \\
0.31 & & 69.48 & 68.69 & 66.67 & 65.38 & 63.86 & down \\
shape & & up & up & up & up & up & \\
\hline
\end{tabular}

Table 10 - Value of Product and Volume Flexibility Combined

\begin{tabular}{|cclllllc|}
\hline Pflex \& Vflex & $\mathbf{r}$ & 0.01 & 0.03 & 0.05 & 007 & 0.09 & shape \\
Variance & $\begin{array}{c}\text { Value } \\
\text { (\$) }\end{array}$ & & & & & & \\
003 & & 3168 & 34.25 & 36.98 & 38.94 & 39.68 & up \\
01 & & 54.50 & 54.92 & 53.42 & 53.53 & 52.56 & ก shape \\
017 & & 69.35 & 68.38 & 65.98 & 62.66 & 61.22 & down \\
0.24 & & 81.41 & 78.90 & 7561 & 71.55 & 67.63 & down \\
0.31 & & 92.24 & 87.71 & 8361 & 78.94 & 74.09 & down \\
shape & & up & up & up & up & up & \\
\hline
\end{tabular}


Table 11 - Value of Product and Expansion Flexibility

\begin{tabular}{|cccccccc|}
\hline Pflex \& Xflex & $\mathrm{r}$ & 001 & 0.03 & 0.05 & 0.07 & 0.09 & shape \\
Variance & $\begin{array}{c}\text { Value } \\
\text { (\$) }\end{array}$ & & & & & & \\
0103 & & 49.11 & 4741 & 45.69 & 4579 & 4471 & down \\
01 & & 6607 & 6440 & 6198 & 59.10 & 5771 & down \\
017 & & 778.5 & 7550 & 7220 & 68.11 & 65.15 & down \\
024 & & 87.47 & 8389 & 7988 & 75.43 & 70.72 & down \\
031 & & 95.39 & 9067 & 8611 & 8124 & 76.21 & down \\
shape & & up & up & up & up & up & \\
\hline
\end{tabular}

Table 12 - Value of Product, Expansion and Volume Flexibility

\begin{tabular}{|cccccccc|}
\hline $\begin{array}{c}\text { Pfler \& Xflex } \\
\text { \& Vflex }\end{array}$ & r & 001 & 003 & 005 & 007 & 009 & shape \\
Variance & $\begin{array}{c}\text { Value } \\
\text { (\$) }\end{array}$ & & & & & & \\
0103 & & 6231 & 5755 & 5465 & 5160 & 49.93 & down \\
111 & & 8967 & 8179 & 76.35 & 71.91 & 66.83 & down \\
017 & & 10884 & 9860 & 9067 & 8513 & 7927 & down \\
024 & & 12432 & 11238 & 10199 & 95.43 & 88.81 & down \\
113 & & 13782 & 12438 & 11251 & 10408 & 9675 & down \\
shape & & up & up & up & up & up & \\
\hline
\end{tabular}

Table 13 - Value of Volume Flexibility

\begin{tabular}{|ccrrrrrr|}
\hline Viflex & $r$ & 001 & 003 & 005 & 007 & 009 & shape \\
Variance & $\begin{array}{c}\text { Value } \\
\text { (\$) }\end{array}$ & & & & & & \\
013 & & 1230 & 1069 & 939 & 833 & 747 & down \\
01 & & 21.74 & 18.75 & 1634 & 1436 & 1273 & down \\
017 & & 2788 & 23.97 & 2081 & 18.23 & 16.10 & down \\
024 & & 3283 & 2816 & 2438 & 21.29 & 18.76 & down \\
031 & & 3720 & 31.83 & 27.49 & 2396 & 21.05 & down \\
shape & & up & up & up & up & up & \\
\hline
\end{tabular}




\section{CONCLUSION}

We have developed a model to value flexibility in advanced manufacturing technologies. Even though our study focused on the generic aspects of such an investment, it does provide some very interesting and useful insights in the study of flevibility and its value. As expected. flexibility can add tremendous value to a production facility especially when uncertainty and risk are the prevailing characteristics of the business environment.

This goes against the traditional financial analysis where risk undermines the value of investments. This thinking is a direct consequence of the net present value method of aluation Although not theoretically unsound, this method does not take into account the ability of the manager to respond to changes in the environment, which is in itself uncertain In this study, we have shown that the options framework is extendible to the valuation of advanced manufacturing technologies, investment that thrive under uncertainty Additionally, we have also found the use of option valuation very useful in determining the relationships between the timing of revenues and investments, the cost of funds and the overall value of investment projects.

The principal contribution of this research is the model itself. We have modeled volume. expansion and product (including production) flexibilities using real options and lave valued them 


\section{I Implications of this Research}

This research provides a robust tool for financial and production managers alike, for the evaluation of AMT's. Using the approach set out here and modifying it to particular scenarios, managers can value new technologies more appropriately than in the past In addition. this model helps in understanding the benefits and limitations of such

- technologies in their ever changing environment.

This research it also beneficial to professionals in finance and production. By bridging the gap between these two fields, this study opens up new possibilities of cooperation and discovery in both the fields In particular, production professionals will now be more aware of new developments in finance that are more geared towards the kind of problems encountered today in a technology-dominated world. Finance research can use real life production problems as basis for studying and testing new techniques of capital budgeting: options theory is a small part of this growing field.

A major benefit of this study is that it adds to the body of knowledge in the field of real options In particular, several new real options have been defined and modeled for ıaluation purposes, they are the expansion flexibility, volume flexibility and product (production) flexibility. As a capital budgeting tool, this model will complement present tools especially in the valuation of advanced manufacturing technologies. 
As mentioned earlier, the use of options theory in capital budgeting overcomes a major deficiency in traditional discounted cash flow methods. It deals with the stochastic nature of output prices and the rate and the possibility of managerial response to those 、ariations. Moreover, variation in risk and discount rate is also taken into account in the options framework. Real options are important not only because they affect the value of firms and projects, but also because they provide explicit criteria for deciding when operation should be started, closed, abandoned, etc. This is a useful decision tool for managemert of investment projects (Copeland et al., 1994; Brennan and Schwartz, 1985)

The modeling presented here helps to better understand the source of value for projects such as AMT's, characterized by numerous intangibles. When projects contain real options, there exist interactions between the options and the project. The proposed model will help identify the nature of these interactions as well as their magnitude.

\subsection{Limitations of this Research}

This study focused on the valuation of flexibilities in AMT's. The scope of this research was kept narrow to keep it manageable while still providing very useful insights Only three flexibilities were extensively analyzed. However, the present framework can be easily extended to other characteristics of AMT's. 
The generic aspect of our study helps in building a generally useable tool. Unfortunately, in the process, other influential variables specific to industries, companies and geographic areas to name a few, have been omitted from the study. Again, encompassing all possible contingencies becomes an impossible and futile exercise.

Because of time and data constraints, no empirical testing of the model was performed. We test the validity of the model through simulated data. Thus, our model's validity hinges on the appropriateness of the data chosen.

\subsection{Future Research}

A priority in future research on this model for valuing advanced manufacturing technologies is to provide it empirical content. Data will have to be sough in a form that is useable in the model A longitudinal study would greatly help in testing the validity of the model as a valuation and decision tool The use of empirical data would show the predictive ability and the validity of the model in different environments and industries.

In conclusion, the merit of this study lies in its developmental nature. We have filled the gap in the valuation process in production technology theory by applying new developments in corporate finance to production management. This research has not only increased our understanding and knowledge of both the fields, but has also opened multiple avenues of future research 


\section{Appendix 1 - Review of Option Pricing}

Commonly Used Terminology:

$\begin{array}{ll}\text { Asset price (value): } & \mathrm{S}, \mathrm{V} \\ \text { Exercise price: } & \mathrm{X}, \text { ex, I } \\ \text { Risk free rate: } & \mathrm{r} \\ \text { Variance: } & \mathrm{\sigma}^{2}, \mathrm{var} \\ \text { Call price: } & \mathrm{C} \\ \text { Put Price: } & \mathrm{P} \\ \text { Hedge ratio } & \mathrm{h} \\ \text { Upward movement: } & \mathrm{u} \\ \text { Downward movement: } & \mathrm{d} \\ \text { Time to expiration: } & \mathrm{T}\end{array}$

\section{Real option framework}

Asset price (value), real option: $\quad \mathbf{R}, \mathbf{R}^{\prime}$ includes value of real options

Contract or expand ratio: $C$ and e respectively

Salvage value: $\mathbf{S}$ (when using $\mathbf{S}$ for salvage value in real option, it is better to use $V$ or $R$ for asset

States or nodes in binomial process: value to avoid confusion)

Time period in binomial process: subscript $j$

Volume flexibility: subscript $i$

Expansion flexibility:

Vflex

Product flexibility. Xflex Pflex

\section{The Binomial Option Pricing Model}

The binomial option pricing model (BOPM) assumes that the underlying asset price obeys a binomial generating process, i.e., the asset price can either go up or down in a single period. It can be shown that in a multi-period application, the BOPM will converge to the Black Scholes option pricing model.

Example of a one period BOPM: the asset is worth $\$ 10$ and the value can increase by $20 \%$ or decrease by $15 \%$ with $50 \%$ probability. The risk free rate is $10 \%$ and the exercise price is $\$ 10.50$. Where,

$$
\begin{aligned}
& S=\$ 10 \text { (asset price) } \\
& p=0.5 \text { (probability of price increase) } \\
& r=01 \text { (risk free rate) } \\
& u=12 \text { (multiplicative upward movement) } \\
& d=085 \text { (multiplicative downward movement) } \\
& X=\$ 10.50 \text { (exercise price) } \\
& C=\text { Call price }
\end{aligned}
$$


The following figure shows the binomial generating process (spot price):

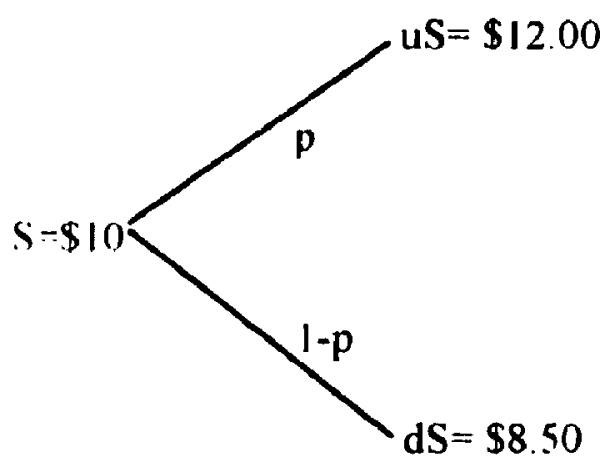

The payoff for the call option is as follows (call price):

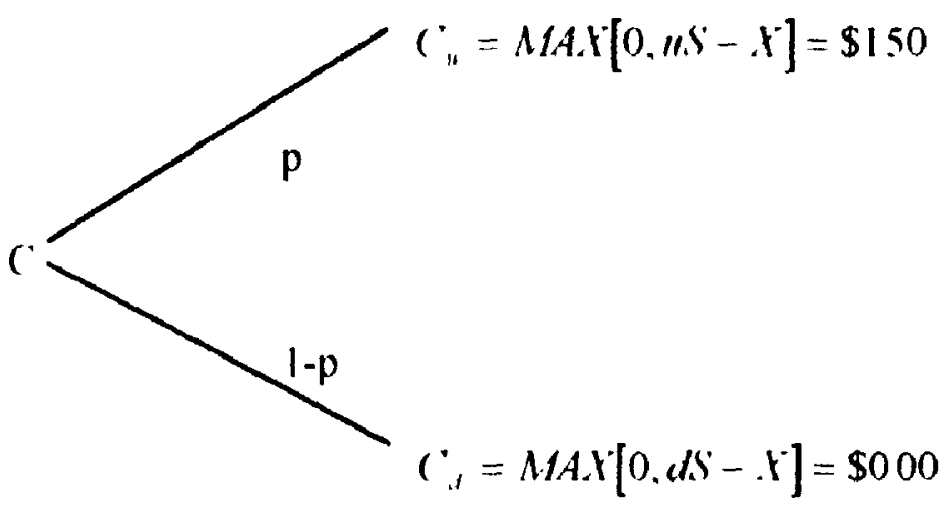

To determine the call value we construct a risk free portfolio where the return at the end of the period is certain and thus must be the risk free rate. The riskless portfolio consists of one unit of the asset and $h$ units of the call option written against the asset (i.e., short position). To be risk free, we equate the two payofts:

$$
\begin{gathered}
u S-h C_{n}=d S-h C_{d} \\
h=S(u-t) /\left(C{ }^{\prime}-C_{d}\right) \\
h=10(120-0.85) /(1.50-0) \\
h=2.33
\end{gathered}
$$

The following figure shows the two possible payoffs: 


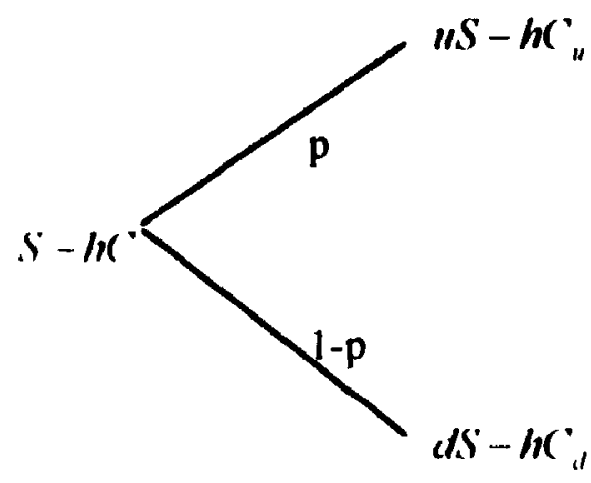

Equating th. two possible payoffs:

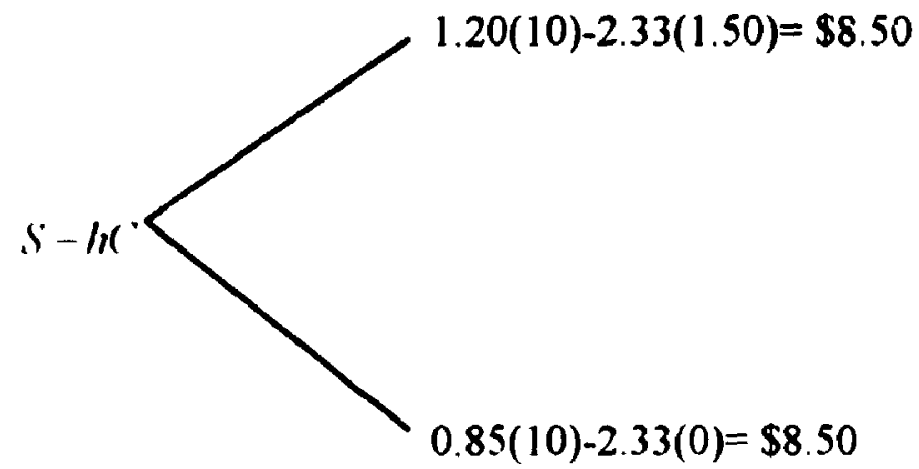

With the hedge portfolio, our payoff is guaranteed to $\$ 8.50$ thus our investment today for such a payoff in one period must earn the risk free rate. Thus we have

$$
(1+r)\left(S-h C^{\prime}\right)=u S-h C_{H}^{\prime}
$$

(1)

$$
C^{\prime}=S[(1+r)-u]+h C_{n} / h(1+r)
$$

substitute h,

$$
C^{\prime}=\left[q C^{\prime}+(1-q) c_{d}\right] /(1+r)
$$

where

$$
q=[(1+r)-d] /(u-d)
$$

in our example 


$$
\begin{gathered}
c=\left[\left(\frac{1.10-0.85}{1.20-0.85}\right) 1.50+\left(\frac{1.20-1.10}{1.20-0.85}\right) 0\right] /(1.10) \\
c=\$ 0.774
\end{gathered}
$$

A multi-period BOPM is just an extension of the above where for example at the end of the second period the possible payoffs are $u^{2} S, d^{2} S$ and udS. The equations become i,ore complex for mulii-period, however, is general n-period set of formula exist. Note that to get the value of the call we must first calculate the end period payoffs and work in a backward fashion to calculate the previous period values until the initial value at time 0 is found 


\section{Appendix 2 - Robustness Tests}

For all Tables in this appendiv.

$\mathrm{X}$. Exercise price

$S$ Stock price or present value of project

$T$ lime to expiration

$r$ Risk free rate of interest

$\sigma^{2}$ Variance of returns associated with the underlying asset

$\mathrm{n}$. Number of iterations in the binomial option pricing methodology

\section{Comparison with Trigeorgis (1991) ${ }^{26}$}

\begin{tabular}{|c|c|c|c|c|c|c|}
\hline \multirow{2}{*}{$\frac{X=\$ 100}{r}$} & \multirow{2}{*}{$\begin{array}{c}n=50 \\
\sigma^{2}\end{array}$} & \multicolumn{5}{|c|}{ Value of American put } \\
\hline & & $\mathrm{T}$ (years) & $S(\$)$ & $\begin{array}{c}\text { Trigeorgis } \\
1991(\$) \\
\end{array}$ & $\begin{array}{l}\text { This model } \\
(\$)\end{array}$ & difference \\
\hline 008 & 004 & 025 & 80 & 20.0000 & 200000 & 0.0000 \\
\hline 008 & 0.04 & 0.25 & 90 & 10.0400 & 10.0376 & 0.0024 \\
\hline 008 & 0.04 & 0.25 & 100 & 32200 & 3.2168 & 0.0032 \\
\hline 008 & 0.04 & 0.25 & 110 & 0.6700 & 0.6714 & -0.0014 \\
\hline 008 & 0.04 & 0.25 & 120 & 0.0900 & 0.0888 & 0.0012 \\
\hline 012 & 0.04 & 0.25 & 80 & 20.0000 & 20.0000 & 0.0000 \\
\hline 012 & 0.04 & 0.25 & 90 & 10.0000 & 100000 & 0.0000 \\
\hline 012 & 004 & 0.25 & 100 & 2.9200 & 2.9201 & -0.0001 \\
\hline 0) 12 & 0.04 & 0.25 & 110 & 0.5600 & 05606 & -0.0006 \\
\hline 012 & 0.04 & 0.25 & 120 & 0.0700 & 0.0687 & 0.0013 \\
\hline 008 & 0.16 & 025 & 80 & 20.3200 & 20.3138 & 0.0062 \\
\hline 008 & 016 & 0.25 & 90 & 12.5700 & 12.5681 & 0.0019 \\
\hline 008 & 016 & 0.25 & 100 & 7.1200 & 7.0878 & 0.0322 \\
\hline 008 & 016 & 025 & 110 & 3.7100 & 3.7302 & -0.0202 \\
\hline \multirow[t]{4}{*}{008} & 016 & 0.25 & 120 & 1.8000 & 1.7928 & 0.0072 \\
\hline & & & & & & \\
\hline & & & & & average & 00022 \\
\hline & & & & & & \\
\hline
\end{tabular}

Note that cash outflow adjustments are not performed preciscly whet they should. This is caused by the fict that dividing the number of years by a number of tteration in the binomial process will not necessarily provide an iteration at the beginning or end of a year. That is $\mathrm{T}=15 . \mathrm{N}=50$. investment III y car 5 wuld happen in year 5.1 because $\mathrm{T} / \mathrm{N} * 16=4.8$ years and $\mathrm{T} / \mathrm{N} * 17=5.1$ ycars In this clidy. we have chosen to use the closest time period to 1 . : one desired. i.c. 5.1 in the example above. This will intariably give rise to minute errors and dil:arences. 


\section{Comparison with Black Scholes Option Pricing Model}

\begin{tabular}{|c|c|c|c|c|c|c|}
\hline$X=\$ 100$ & $n=50$ & & & Value of $\mathrm{Am}$ & erican cal & \\
\hline$r$ & $\overline{\sigma^{2}}$ & $\mathrm{~T}$ (years) & $S(\$)$ & $\begin{array}{c}\text { Black Scholes } \\
\text { (\$) }\end{array}$ & \begin{tabular}{c|} 
This \\
model \\
(\$)
\end{tabular} & difference \\
\hline 1108 & 004 & 025 & 80 & 00690 & 00644 & 0.0046 \\
\hline 008 & 004 & 0.25 & 90 & 1.0255 & \begin{tabular}{|l|}
1.0274 \\
\end{tabular} & -0.0019 \\
\hline 0108 & 0.04 & 0.25 & 100 & 5.0170 & 4.9977 & 0.0193 \\
\hline 008 & 0.04 & 0.25 & 110 & 12.6204 & 12.6272 & -0.0067 \\
\hline 008 & 0.04 & 0.25 & 120 & 22.0666 & 22.0666 & 0.0000 \\
\hline 012 & 0.04 & 0.25 & 80 & 0.0896 & 0.0838 & 0.0058 \\
\hline 1) 12 & 004 & 0.25 & 90 & 1.2173 & \begin{tabular}{|l|}
1.2188 \\
\end{tabular} & -0.0015 \\
\hline (1) 12 & 0.04 & 0.25 & 100 & 5.5819 & 5.5637 & 0.0182 \\
\hline 012 & 004 & 025 & 110 & 13.4743 & 13.4809 & -0.0066 \\
\hline (1) 12 & 004 & 025 & 120 & 23.0208 & 23.0211 & -0.0002 \\
\hline () 08 & 016 & 0.25 & 80 & 1.4274 & 1.4052 & 0.0221 \\
\hline 008 & 016 & 025 & 90 & 4.1476 & 4.1419 & 0.0057 \\
\hline 608 & 016 & 025 & 100 & 8.9160 & 88764 & 0.0397 \\
\hline 1108 & 016 & 025 & 110 & 15.6088 & 15.6333 & -0.0244 \\
\hline 108 & (0) 16 & 0.25 & 120 & 237421 & 23.7440 & -00019 \\
\hline$0 \longdiv { 1 2 }$ & 016 & 025 & 80 & 1.5617 & 15375 & 0.0242 \\
\hline 1112 & 016 & 025 & 90 & 4.4479 & 44411 & 0.0069 \\
\hline 1112 & (0) 16 & 025 & 100 & 9.4134 & 93737 & 0.0397 \\
\hline 012 & $\begin{array}{lll}0 & 16\end{array}$ & 025 & 110 & 16.2837 & 16.3075 & -00237 \\
\hline 1112 & 016 & 025 & 120 & 245472 & 24.5492 & -0.0020 \\
\hline & & & & & & \\
\hline & & & & & average & $0.005 \%$ \\
\hline
\end{tabular}


Comparison with Black Scholes Option Pricing Model (continued)

\begin{tabular}{|c|c|c|c|c|c|c|}
\hline$X=\$ 100$ & $n=50$ & & & Value of Americ & in call & \\
\hline$r$ & $\sigma^{2}$ & $\mathrm{~T}$ (years) & $S(\$)$ & Black Scholes (\$) & $\begin{array}{c}\text { This } \\
\text { model } \\
(\$)\end{array}$ & difference (\$) \\
\hline 0) 08 & 0.04 & 5 & 80 & 20.4759 & 20.4575 & 0.0184 \\
\hline 008 & 0.04 & 5 & 90 & 28.2132 & 28.1798 & 0.0334 \\
\hline 008 & 0.04 & 5 & 100 & 36.0266 & 36.5425 & 0.0842 \\
\hline 008 & 0.04 & 5 & 110 & 45.5218 & 45.5067 & 0.0151 \\
\hline 008 & 0.04 & 5 & 120 & 54.7548 & 54.7429 & 0.0119 \\
\hline 0.12 & 004 & 5 & 80 & 28.3716 & 28.3468 & 0.0248 \\
\hline 012 & 0.04 & 5 & 90 & 37.2153 & 37.1735 & 0.0418 \\
\hline 012 & 0.04 & 5 & 100 & 46.4746 & 46.3973 & 0.0773 \\
\hline 012 & 0.04 & 5 & 110 & 56.0004 & 55.9535 & 0.0469 \\
\hline 0.12 & 0.04 & 5 & 120 & 65.6958 & 65.6397 & 0.0561 \\
\hline 008 & 016 & 5 & 80 & 323285 & 32.2029 & 0.1256 \\
\hline 008 & 0.16 & 5 & 90 & 39.9449 & 39.9474 & -0.0025 \\
\hline 008 & 016 & 5 & 100 & 47.9293 & 47.6919 & 0.2374 \\
\hline 008 & 0.16 & 5 & 110 & 56.2139 & 56.1890 & 0.0249 \\
\hline 008 & 016 & 5 & 120 & 64.7452 & 64.6861 & 0.0591 \\
\hline 012 & 016 & 5 & 80 & 37.7222 & 37.5132 & 0.2090 \\
\hline 012 & 016 & 5 & 90 & 45.9733 & 45.8606 & 0.1127 \\
\hline (1) 12 & 0.16 & 5 & 100 & 545265 & 542080 & 03186 \\
\hline (1) 12 & 016 & 5 & 110 & 633198 & 63.1564 & 0.1634 \\
\hline 012 & 016 & 5 & 120 & 723055 & 721047 & 0.2007 \\
\hline & & & & & average & 0.0929 \\
\hline
\end{tabular}


Appendix 3 - Robustness Test

Call option at $T=1$ year

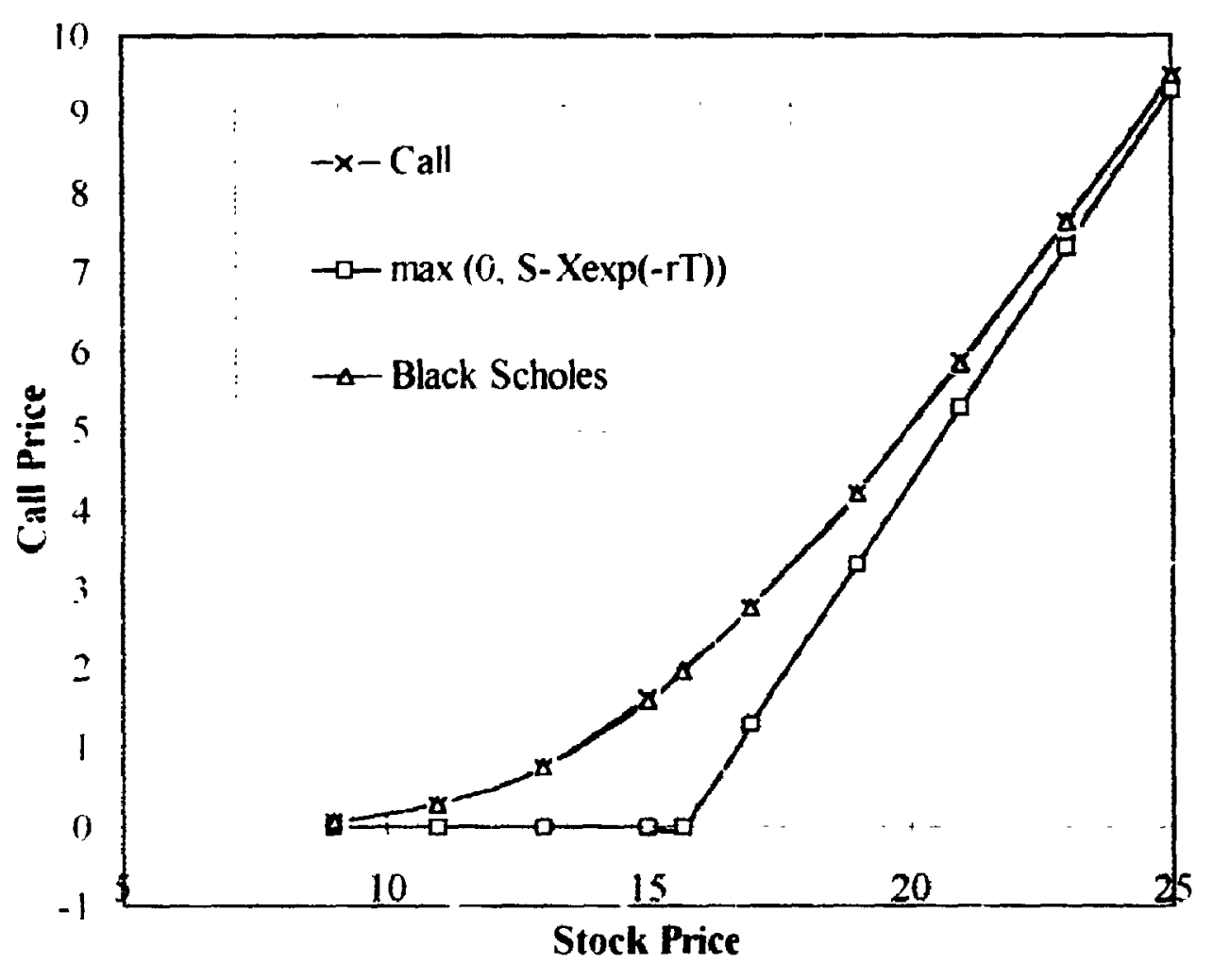

X Exercise price

$S$ Stock price or present value of project

$T$ Time to expiration

$r$ Risk free rate of interest 


\section{Call Option at $\mathbf{T}=9$ months}

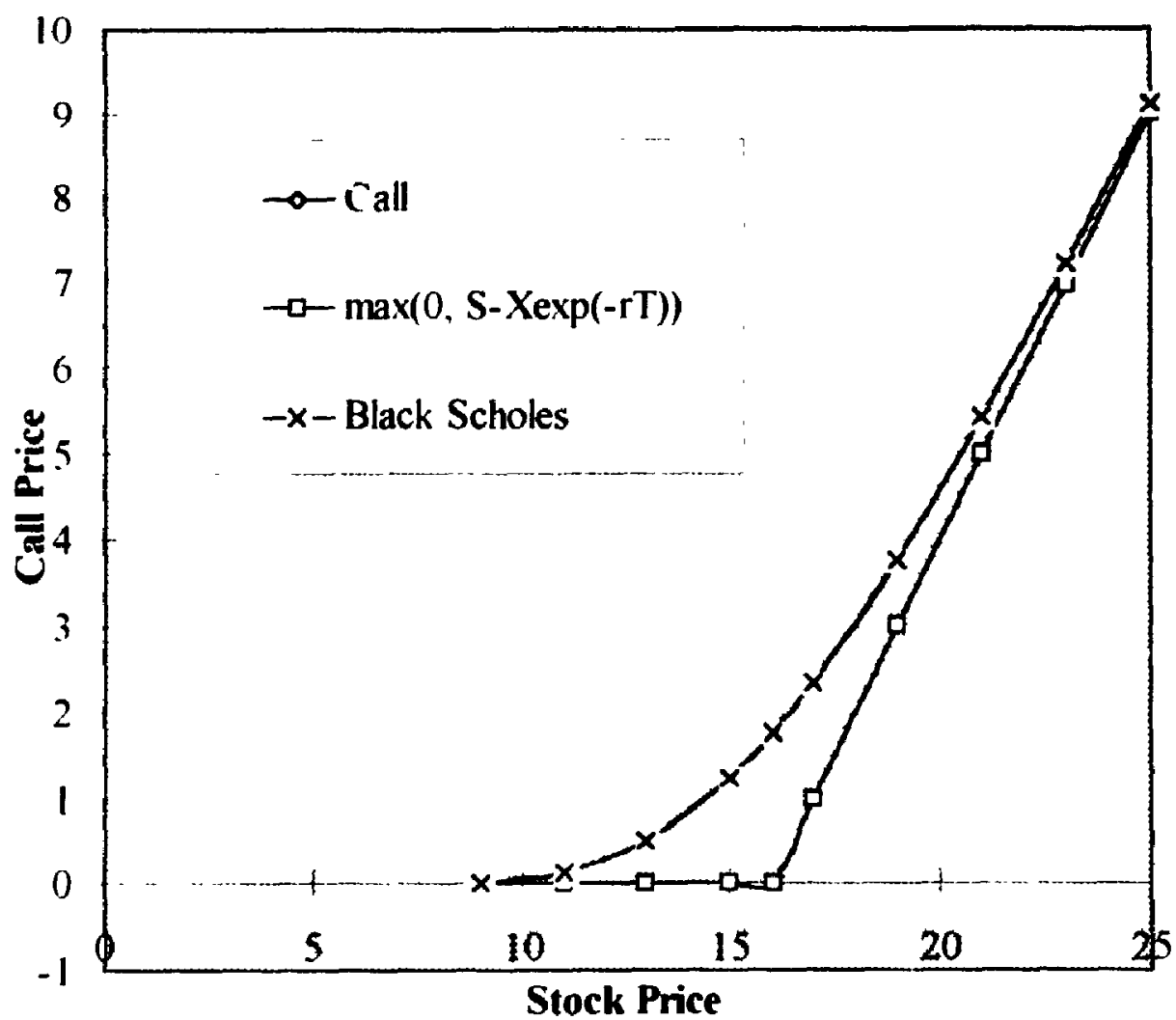

$\mathrm{X}$. Exercise price

$S$ Stock price or present value of project

$T$ Time to expiration

$r$ Risk free rate of interest 


\section{Call Option at $\mathrm{T}=6$ months}

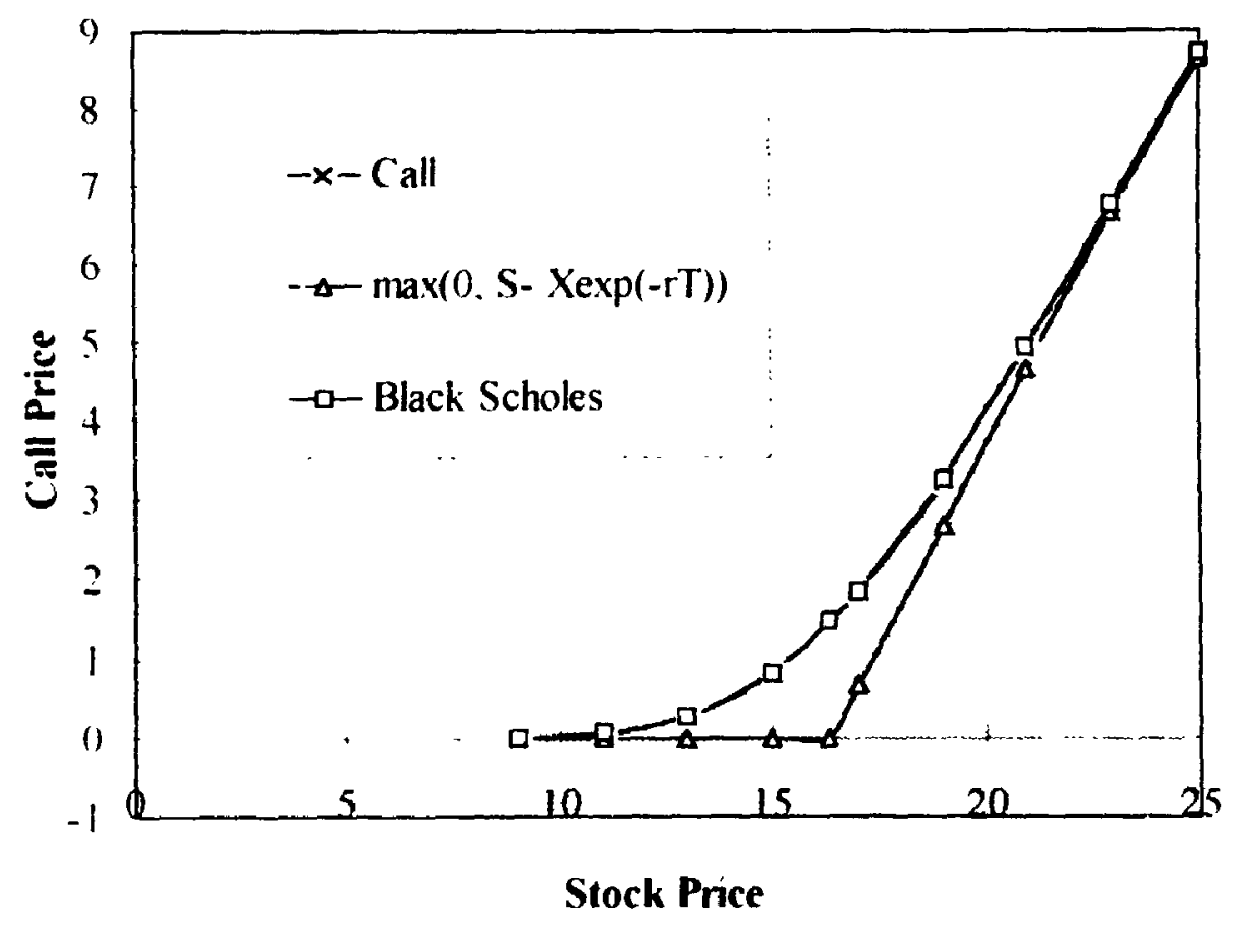

\footnotetext{
$X$ Fxercise price

$S$ Stock price or present value of project

$T$ Time to expiration

$r$ Risk free rate of interest
} 


\section{Call Option at $\mathrm{T}=\mathbf{3}$ months}

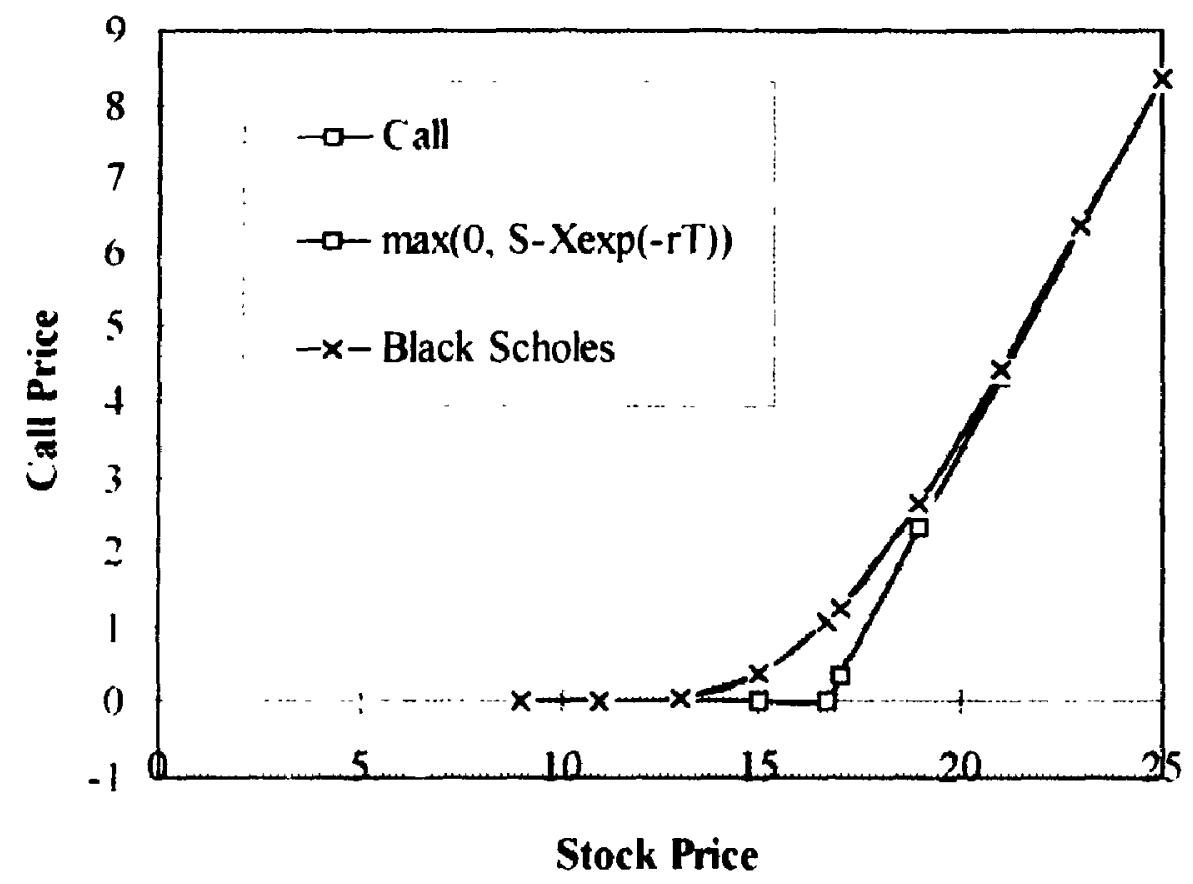

$\mathrm{X}$ Exercise price

S Stock price or present value of project

$T$ Time to expiration

$r$ Risk free rate of interest 
Call Option at $\mathrm{T}=1$ month

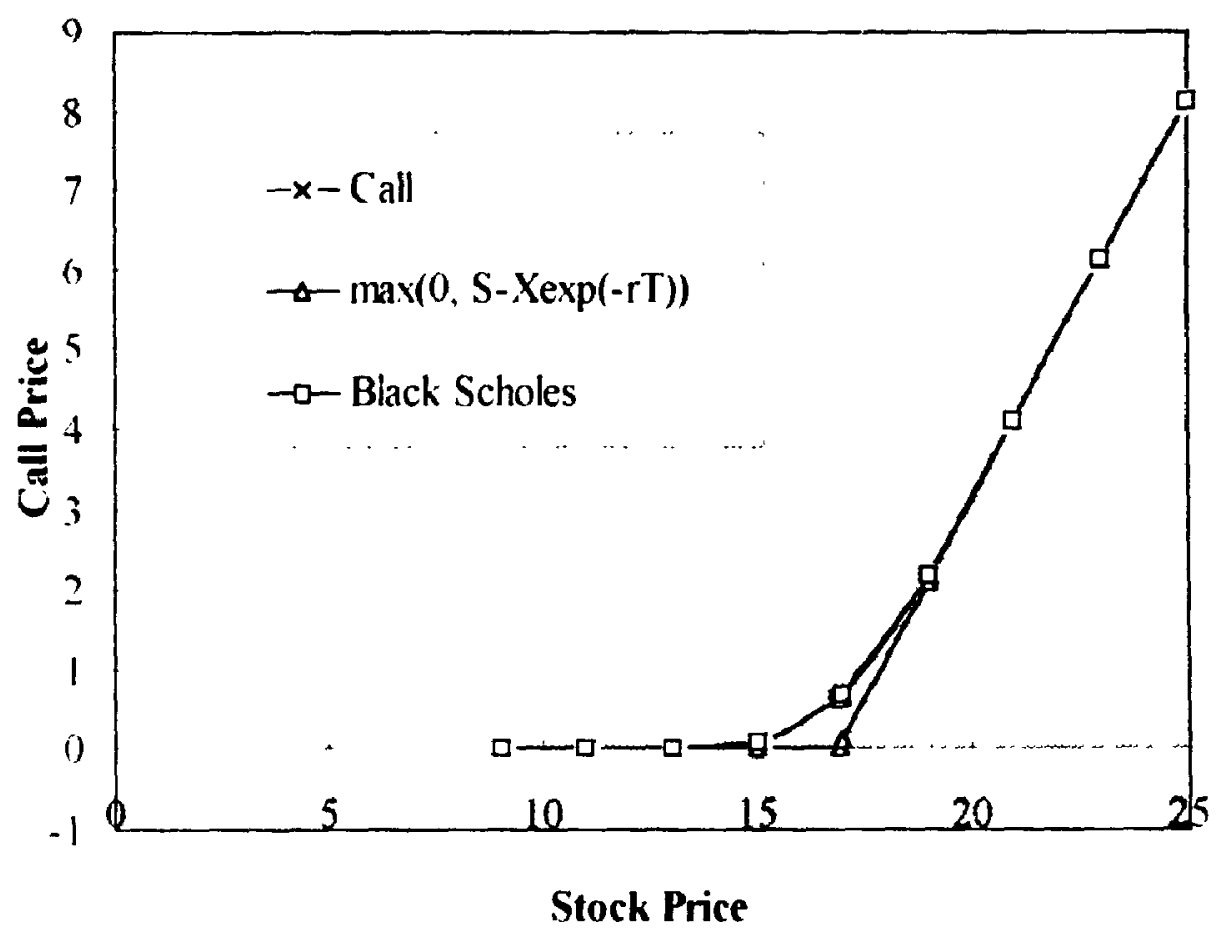

I Fivercise price

$S$ Stock price or present value of project

I Time to expiration

$r$ Risk free rate of interest 


\section{Appendix 4 - Value of the NPV with and without Flexibility}

\begin{tabular}{|c|c|c|c|c|c|c|c|}
\hline Vflex & $\bar{r}$ & 0.01 & 0.03 & 0.05 & 0.07 & 0.09 & shape \\
\hline V'ariance & $\begin{array}{c}\text { NPV } \\
\text { (\$) }\end{array}$ & & & & & & \\
\hline 003 & & 804 & -3.03 & -10.99 & -16.62 & -20.51 & down \\
\hline 01 & & 8.36 & -300 & -11.17 & -1697 & -20.99 & down \\
\hline 017 & & 9.20 & -2.53 & -10.99 & -16.99 & -21.17 & down \\
\hline 024 & & 10.56 & -162 & -10.42 & -16.69 & -21.07 & down \\
\hline 0.31 & & 12.45 & -0.26 & -9.47 & -16.05 & .20 .68 & down \\
\hline shape & & up & up & U shape & U shape & U shape & \\
\hline
\end{tabular}

\begin{tabular}{|ccrrrrrr|}
\hline $\begin{array}{c}\text { Xflex } \\
\text { Variance }\end{array}$ & $\begin{array}{c}\text { N } \\
\text { NPV }\end{array}$ & 0.01 & 003 & 0.05 & 0.07 & 0.09 & shape \\
003 & $(\$)$ & & & & & & \\
01 & & 3118 & 1648 & 5.76 & -1.95 & -7.43 & down \\
017 & & 2052 & 6.99 & -2.51 & -9.43 & -1424 & down \\
024 & & 1537 & 2.61 & -6.71 & -13.31 & -17.74 & down \\
031 & & 1242 & -0.29 & -9.51 & -15.75 & -20.11 & down \\
shape & & 10.48 & -2.26 & -11.25 & -17.46 & -21.80 & down \\
& & down & down & down & down & down & \\
\hline
\end{tabular}

\begin{tabular}{|cccccccc|}
\hline $\begin{array}{c}\text { Pflex } \\
\text { Variance }\end{array}$ & $\begin{array}{c}\mathrm{r} \\
\text { NPV } \\
\text { (\$) }\end{array}$ & 001 & 003 & 0.05 & 007 & 009 & shape \\
003 & & 2155 & 1720 & 14.22 & 12.12 & 1098 & down \\
01 & & 30.11 & 2352 & 2010 & 16.66 & 14.35 & down \\
017 & & 35.87 & 28.46 & 23.79 & 20.49 & 17.31 & down \\
024 & & 40.58 & 3283 & 26.56 & 2319 & 20.02 & down \\
031 & & 44.73 & 3660 & 29.70 & 25.37 & 22.13 & down \\
shape & & up & up & up & up & up & \\
\hline
\end{tabular}




\begin{tabular}{|c|c|c|c|c|c|c|c|}
\hline $\begin{array}{c}\text { No flex } \\
\text { Variance }\end{array}$ & $\begin{array}{c}r \\
\text { NPV } \\
(\$)\end{array}$ & 001 & 003 & 005 & 0.07 & 0.09 & shape \\
\hline 003 & & -427 & -1372 & -20.38 & -24.95 & -27.98 & down \\
\hline 01 & & -1338 & -2175 & -2751 & -31.33 & -33.72 & down \\
\hline 017 & & -1868 & -26.50 & -31.79 & -35.22 & -37.27 & down \\
\hline 024 & & -2227 & -29.78 & -.3480 & -37.98 & -39.83 & down \\
\hline $\begin{array}{c}031 \\
\text { shape }\end{array}$ & & $\begin{array}{l}-2475 \\
\text { down }\end{array}$ & $\begin{array}{l}-3210 \\
\text { down }\end{array}$ & $\begin{array}{c}-36.96 \\
\text { down }\end{array}$ & $\begin{array}{l}-4001 \\
\text { down }\end{array}$ & $\begin{array}{l}-41.73 \\
\text { down }\end{array}$ & down \\
\hline
\end{tabular}

\begin{tabular}{|cccccccc|}
\hline Pflex \& Vflex & $\mathrm{r}$ & 001 & 003 & 005 & 007 & 009 & shape \\
Variance & NPV & & & & & & \\
& (\$) & & & & & & \\
003 & & 2741 & 2053 & 16.60 & 1399 & 11.70 & down \\
01 & & 4112 & 3317 & 2591 & 2219 & 1865 & down \\
017 & & 50.67 & 4188 & 3418 & 27.44 & 23.95 & down \\
024 & & 5914 & 4912 & 40.81 & 33.57 & 27.80 & down \\
031 & & 6749 & 55.61 & 4664 & 38.93 & 32.36 & down \\
shape & & up & up & up & up & up & \\
\hline
\end{tabular}

\begin{tabular}{|cccccccc|}
\hline Xflex \& Vflex & r & 0.01 & 0.03 & 0.05 & 007 & 009 & shape \\
Variance & NPV & & & & & & \\
& (\$) & & & & & & \\
003 & & 4951 & 32.39 & 1977 & 10.48 & 3.70 & down \\
01 & & 52.14 & 3449 & 2123 & 11.57 & 4.42 & down \\
017 & & 5581 & 3711 & 2348 & 1324 & 5.58 & down \\
02.4 & & 5953 & 40.34 & 25.93 & 1508 & 6.94 & down \\
0.31 & & 63.93 & 4380 & 28.59 & 17.12 & 8.53 & down \\
shape & & up & up & up & up & up & \\
\hline
\end{tabular}




\begin{tabular}{|cccccccc|}
\hline Ptlex \& Xflex & $\mathrm{r}$ & 0.01 & 0.03 & 0.05 & 0.07 & 0.09 & shape \\
Variance & NPV & & & & & & \\
& (\$) & & & & & & \\
0.03 & & 44.84 & 33.69 & 25.31 & 20.84 & 16.73 & down \\
01 & & 52.69 & 42.65 & 34.47 & 27.77 & 23.99 & down \\
017 & & 59.17 & 49.00 & 40.40 & 32.89 & 27.88 & down \\
0.24 & & 65.20 & 54.12 & 45.09 & 37.44 & 30.89 & down \\
031 & & 70.64 & 58.57 & 49.14 & 41.23 & 34.48 & down \\
shape & & up & up & up & up & up & \\
\hline
\end{tabular}

\begin{tabular}{|cccccccc|}
\hline $\begin{array}{c}\text { Pflex \& Xflex } \\
\text { \& Vflex }\end{array}$ & $\mathbf{r}$ & 0.01 & 0.03 & 0.05 & 0.07 & 0.09 & shape \\
Variance & $\begin{array}{c}\text { NPV } \\
\text { (\$) }\end{array}$ & & & & & & \\
003 & & 58.04 & 43.84 & 34.28 & 26.64 & 21.95 & down \\
01 & & 76.29 & 60.04 & 48.84 & 4058 & 33.11 & down \\
017 & & 90.16 & 72.10 & 58.87 & 49.91 & 42.01 & down \\
024 & & 102.04 & 82.60 & 6719 & 5745 & 48.99 & down \\
0.31 & & 11306 & 92.29 & 75.54 & 64.07 & 55.02 & down \\
shape & & up & up & up & up & up & \\
\hline
\end{tabular}




\section{Appendix 5 - Value of Flexibility}

\begin{tabular}{|c|c|c|c|c|c|c|c|}
\hline Pflex & $r$ & 0.01 & 0.03 & 0.05 & 0.07 & 0.09 & shape \\
\hline lariance & $\begin{array}{c}\text { Value } \\
\text { (\$) }\end{array}$ & & & & & & \\
\hline 003 & & 0.81 & 30.92 & 34.60 & 37.08 & 38.96 & up \\
\hline 01 & & 43.50 & 45.27 & 47.61 & 47.99 & .48 .07 & up \\
\hline 017 & & 54.54 & 5497 & 5559 & 5571 & 5458 & ก shape \\
\hline 024 & & 62.85 & 6260 & 6136 & 6117 & 5984 & down \\
\hline 0.31 & & 69.48 & 68.69 & 60.67 & 65.38 & 6386 & down \\
\hline shape & & up & up & up & & up & \\
\hline
\end{tabular}

\begin{tabular}{|c|c|c|c|c|c|c|c|}
\hline Pflex \& Vflex & $r$ & 001 & 003 & U05 & 007 & 009 & shape \\
\hline Variance & $\begin{array}{c}\text { Value } \\
(\$)\end{array}$ & & & & & & \\
\hline 003 & & 3168 & 3425 & 3698 & 3894 & 3968 & up \\
\hline 01 & & 5450 & 5492 & 5342 & 53.53 & 5236 & rhape \\
\hline 017 & & 6935 & 68.38 & 6.598 & 62.60 & 6122 & down \\
\hline 1124 & & 81.41 & 7890 & 7561 & 7155 & 6763 & down \\
\hline 011 & & 9224 & 87.71 & 8361 & 78.94 & 74.39 & down \\
\hline shape & & up & up & up & up & up & \\
\hline
\end{tabular}

\begin{tabular}{|c|c|c|c|c|c|c|c|}
\hline Pflex \& Xflex & $r$ & 001 & 0.03 & 005 & 007 & 0.09 & shape \\
\hline lariance & $\begin{array}{c}\text { Value } \\
(\$)\end{array}$ & & & & & & \\
\hline 003 & & 4911 & 4741 & 45.69 & 45.79 & 44.71 & down \\
\hline 111 & & 6607 & 6440 & 6198 & 5910 & 57.71 & down \\
\hline (1) 17 & & 7785 & 7550 & 72.20 & 6811 & 65.15 & down \\
\hline $112 i$ & & 8747 & 8389 & 7988 & 7543 & 7072 & down \\
\hline 0,1 & & 9539 & 90.67 & 8611 & 81.24 & 7621 & down \\
\hline shape & & up & up & up & up & up & \\
\hline
\end{tabular}




\begin{tabular}{|cccccccc|}
\hline Pflex \& Xflex & $\mathrm{r}$ & 0.01 & 0.03 & 0.05 & 0.07 & 0.09 & shape \\
\& Vflex & & & & & & & \\
Variance & $\begin{array}{c}\text { Value } \\
\text { (\$) }\end{array}$ & & & & & & \\
0.03 & & 62.31 & 57.55 & 54.65 & 51.60 & 49.93 & down \\
01 & & 89.67 & 81.79 & 76.35 & 71.91 & 66.83 & down \\
0.17 & & 108.84 & 98.60 & 90.67 & 85.13 & 79.27 & down \\
0.24 & & 124.32 & 112.38 & 101.99 & 95.43 & $88.9 \mathrm{i}$ & down \\
031 & & 137.82 & 124.38 & 112.51 & 104.08 & 96.75 & down \\
shape & & up & up & up & up & up & \\
\hline
\end{tabular}

\begin{tabular}{|c|c|c|c|c|c|c|c|}
\hline Vflex & $\bar{r}$ & 0.01 & 0.03 & 0.05 & 0.07 & 0.09 & shape \\
\hline Variance & $\begin{array}{c}\text { Value } \\
\text { (\$) }\end{array}$ & & & & & & \\
\hline 003 & & 12.30 & 10.69 & 9.39 & 8.33 & 7.47 & down \\
\hline 0.1 & & 21.74 & 18.75 & 16.34 & 14.36 & 12.73 & dcinn \\
\hline 0.17 & & 27.88 & 23.97 & 20.81 & 18.23 & 1610 & down \\
\hline 024 & & 32.83 & 28.16 & 24.38 & 21.29 & 18.76 & down \\
\hline 031 & & 37.20 & 31.83 & 27.49 & 23.96 & 21.05 & down \\
\hline shape & & up & up & up & up & up & \\
\hline
\end{tabular}

\begin{tabular}{|ccrrrrrr|}
\hline $\begin{array}{c}\text { Xflex } \\
\text { Variance }\end{array}$ & $\begin{array}{c}\mathbf{r} \\
\text { Value } \\
(\$)\end{array}$ & 0.01 & 0.03 & 0.05 & 0.07 & 0.09 & shape \\
003 & & 35.45 & 30.19 & 26.14 & 23.00 & 20.55 & down \\
0.1 & & 33.90 & 28.74 & 25.00 & 21.90 & 19.48 & down \\
017 & & 34.04 & 29.11 & 25.09 & 21.41 & 19.53 & down \\
024 & & 34.69 & 2949 & 25.29 & 22.23 & 19.71 & down \\
0.31 & & 35.23 & 29.84 & 25.71 & 22.55 & 19.93 & down \\
shape & & U shape & U shape & U shape & U shape & U shape & \\
\hline
\end{tabular}




\begin{tabular}{|ccllllll|}
\hline Xflex \& Vflex & $\mathrm{r}$ & 0.01 & 003 & 0.05 & 0.07 & 0.09 & shape \\
Variance & $\begin{array}{c}\text { Value } \\
\text { (\$) }\end{array}$ & & & & & & \\
003 & & $\mathbf{5 3 . 7 8}$ & 4611 & 40.14 & 35.44 & 31.68 & down \\
01 & & 65.52 & 56.24 & 48.74 & 42.90 & 38.13 & down \\
017 & & 74.99 & 63.61 & 55.27 & 48.46 & 42.85 & down \\
024 & & 81.80 & 70.12 & 60.73 & 53.06 & 46.77 & down \\
031 & & 8868 & 75.90 & 65.56 & 57.13 & 50.25 & down \\
shape & & up & up & up & up & up & \\
\hline
\end{tabular}



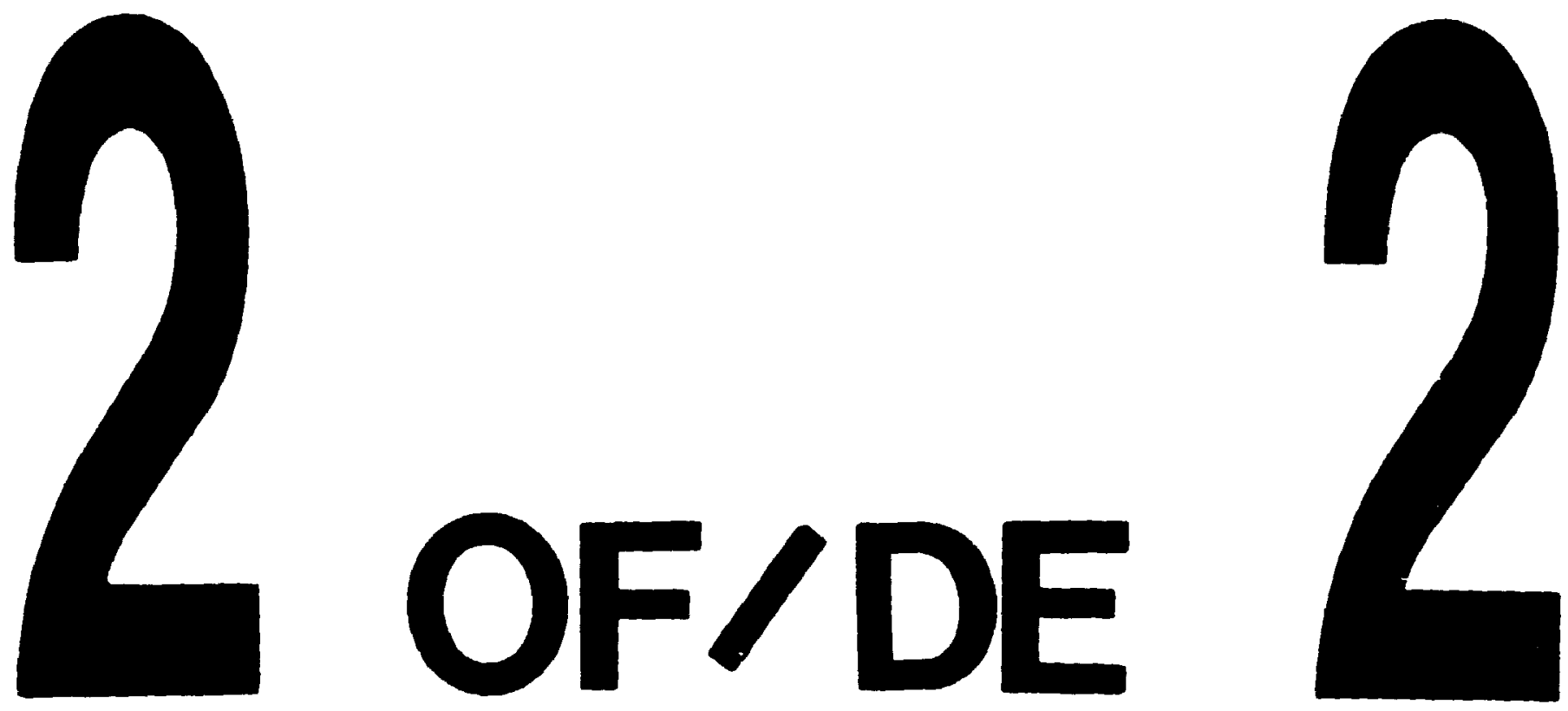

PM-1 31/2"x4" PHOTOGRAPHIC MICAOCOPY TARGET NBS 1010 ANSI/ISO "2 EQUIVALENT

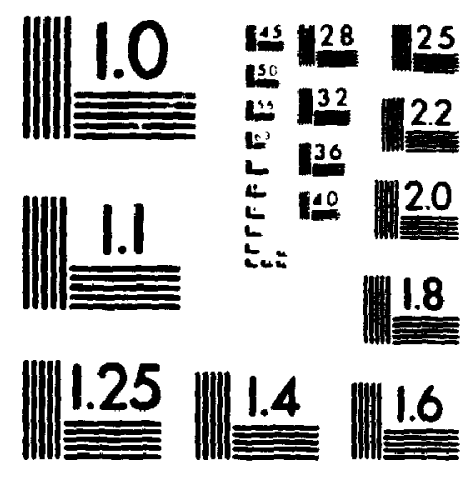




\section{Appendix 6 - Additional Results}

These are the result of a sensitivity analysis where the present value of the project was held constant at $\$ 100$ while the present value of the investments (cash outflows) was influenced by changes in the risk free rate. The results are similar in the sense that rariance influences option value as expected This analysis cantot be performed with both the present value of the project and the investments held constant (i.e. NPV) since our model is a Log transformed algorithm and as stich cannot handle negative values

\section{Value of the NPV with and without Flexibility}

\begin{tabular}{|c|c|c|c|c|c|c|c|}
\hline Vflex & $r$ & 001 & 003 & 005 & 0.07 & 009 & shape \\
\hline lariance & NPV & & & & & & \\
\hline 003 & & -3061 & -2239 & -14.78 & -7.722 & -1187 & up \\
\hline 01 & & -30.38 & -22.36 & -14.96 & -8.i l & -1.778 & up \\
\hline 017 & & -2977 & -2197 & -1478 & -8.136 & -2008 & up \\
\hline 024 & & -28.79 & -2121 & -14.23 & -7801 & -1.881 & up \\
\hline 031 & & -2743 & -2007 & -1331 & -7.102 & -1394 & up \\
\hline shape & & up & up & U shape & U shape & U shape & \\
\hline Xflex & $r$ & 0.01 & 003 & 0.05 & 007 & 009 & shape \\
\hline Variance & NPV & & & & & & \\
\hline (1) 113 & & -2074 & -9033 & 06472 & 10104 & 18753 & up \\
\hline 111 & & -2627 & -1636 & -7.124 & 14742 & 9.4501 & up \\
\hline 017 & & -2902 & -1974 & -111 & -3.065 & 4.3921 & up \\
\hline 024 & & -307 & -21.87 & -1367 & -6.058 & 0.996 & up \\
\hline 031 & & -3153 & -2309 & -15.27 & -8024 & -1.323 & up \\
\hline shape & & down & down & down & down & down & \\
\hline
\end{tabular}




\begin{tabular}{|cccccccc|}
\hline $\begin{array}{c}\text { Pflex } \\
\text { Variance }\end{array}$ & r & 0.01 & 0.03 & 005 & 0.07 & 0.09 & shape \\
0.03 & & 13.434 & 13.491 & 13.634 & 13.931 & 14.445 & up \\
01 & & 18.065 & 18.528 & 19.005 & 19.522 & 20.106 & up \\
017 & & 21.81 & 22.286 & 22.741 & 23.177 & 23.613 & up \\
024 & & 24.739 & 25.155 & 25.51 & 25.822 & 26.105 & up \\
031 & & 27.896 & 27.984 & 28.01 & 28.007 & 28.144 & up \\
shape & & up & up & up & up & up & \\
\hline
\end{tabular}

\begin{tabular}{|cccccccc|}
\hline no flex & $r$ & 0.01 & 0.03 & 0.05 & 0.67 & 0.09 & shape \\
Variance & NPV & & & & & & \\
003 & & -39.49 & -31.34 & -23.82 & -16.87 & -10.46 & up \\
01 & & -46.06 & -38.07 & -30.69 & -23.88 & -17.57 & up \\
017 & & -49.88 & -4205 & -34.82 & -28.15 & -21.98 & up \\
024 & & $-52.4 ;$ & -44.8 & -37.72 & -31.18 & -25.15 & up \\
031 & & -54.26 & -46.74 & -39.8 & -32.41 & -27.51 & up \\
shape & & down & down & down & down & down & \\
\hline
\end{tabular}

\begin{tabular}{|cccccccc|}
\hline Pflex $\&$ Vflex & $\mathbf{r}$ & 0.01 & $0 \mathrm{Ci}$ & 005 & 0.07 & 0.09 & shape \\
& & & & & & & \\
Variance & NPV & & & & & & \\
003 & & 14.218 & 14.606 & 15.169 & 16.089 & 17.404 & up \\
01 & & 22.271 & 23.333 & 24.446 & 25.628 & 26.895 & up \\
017 & 30.045 & 30.992 & 31.934 & 32.885 & 33.86 & up \\
024 & 36.999 & 37.776 & 38.5 & 39.199 & 39.884 & up \\
0.11 & 43.193 & 43.758 & 44.256 & 44.7 & 45.103 & up \\
shape & up & up & up & up & up & \\
\hline
\end{tabular}

\begin{tabular}{|cccccccc|}
\hline X'flex \& Vflex & $\mathbf{r}$ & 0.01 & 003 & 0.05 & 007 & 0.09 & shape \\
& & & & & & & \\
Variance & NPV & & & & & & \\
003 & & -7.817 & 3.5772 & 14.105 & 23.778 & 32.636 & up \\
01 & & -4.152 & 6.1151 & 15.671 & 24.537 & 32.736 & up \\
017 & & -0.416 & 9.1244 & 17.983 & 26.194 & 33.791 & up \\
024 & 3.0866 & 12.074 & 20.395 & 28.089 & 35.193 & up \\
031 & & 6.6342 & 15141 & 22.993 & 30.234 & 36.902 & up \\
shape & up & up & up & up & up & \\
\hline
\end{tabular}




\begin{tabular}{|cccccccc|}
\hline Pflex \& Xflex & $\mathbf{r}$ & 0.01 & 0.03 & 0.05 & 0.07 & 0.09 & shape \\
& & & & & & & \\
Variance & NPV & & & & & & \\
0113 & & 18.59 & 20687 & 23.306 & 26.466 & 30.126 & up \\
01 & & 27.371 & 29.454 & 31.682 & 34.052 & 36.558 & up \\
017 & & 34.384 & 36.038 & 37.724 & 39.445 & 41.206 & up \\
024 & & 39928 & 41.213 & 42467 & 43.714 & 44.961 & up \\
0.31 & & 44702 & 45.649 & 46.548 & 47.406 & 48.249 & up \\
shape & & up & up & up & up & up & \\
\hline
\end{tabular}

\begin{tabular}{|cccccccc|}
\hline $\begin{array}{c}\text { Pflex \& Xflex } \\
\text { \& Vflex }\end{array}$ & $\mathbf{r}$ & 001 & 003 & 005 & 0.07 & 0.09 & shape \\
& & & & & & & \\
$\begin{array}{c}\text { Variance } \\
003\end{array}$ & NPV & & & & & & \\
01 & & 22836 & 26437 & 30.66 & 35421 & 40.593 & up \\
017 & & 38938 & 42154 & 45.503 & 48968 & 52.528 & up \\
024 & & 50.063 & 52778 & 55.505 & 58238 & 60.976 & up \\
0.31 & 59257 & 6152 & 63727 & 65.899 & 68.036 & up \\
shape & 67636 & 69332 & 71042 & 72731 & 74358 & up \\
\hline
\end{tabular}




\section{Value of Flexibility}

\begin{tabular}{|c|c|c|c|c|c|c|c|}
\hline Pflex & r & 0.01 & 0.03 & 0.05 & 0.07 & 0.09 & shape \\
\hline Variance & Value & & & & & & \\
\hline 003 & & 52.919 & 44.832 & 37.456 & 30.804 & 24.9 & down \\
\hline 01 & & 64.123 & 56.6 & 49.7 & 43.398 & 37.678 & down \\
\hline 017 & & 71.687 & 64.337 & 57.563 & 51.323 & 45.592 & down \\
\hline 024 & & 77.208 & 69.95 & 63.225 & 57.002 & 51.256 & down \\
\hline 0.31 & & 82.156 & 74.721 & 67.812 & 61.414 & 55.657 & down \\
\hline shape & & up & up & up & up & up & \\
\hline
\end{tabular}

\begin{tabular}{|cccccccc|}
\hline Pflev \& Vflex & $\mathbf{r}$ & 0.01 & 0.03 & 0.05 & 0.07 & 0.09 & shape \\
& & & & & & & \\
Variance & Value & & & & & & \\
003 & & 53.703 & 45.947 & 38.992 & 32.962 & 27.859 & down \\
01 & & 68.329 & 61.405 & 55.141 & 49.504 & 44.467 & down \\
017 & & 79.922 & 73.042 & 66.757 & 61.032 & 55.84 & down \\
024 & & 89.468 & 82.572 & 76.215 & 70.38 & 65.035 & down \\
0.1 & & 97.453 & 90.495 & 84.058 & 78.107 & 72.616 & down \\
shape & up & up & up & up & up & \\
\hline
\end{tabular}

\begin{tabular}{|cccccccc|}
\hline Pllex \& Xflex & $r$ & 0.01 & 0.03 & 0.05 & 0.07 & 009 & shape \\
& & & & & & & \\
Variance & Value & & & & & & \\
003 & & 58.075 & 52.028 & 47.128 & 43.339 & 40.581 & down \\
01 & 73.429 & 67.526 & 62.377 & 57.927 & 54.13 & down \\
017 & 84.261 & 78.088 & 72.547 & 67.591 & 63.185 & down \\
024 & 92.397 & 86.009 & 80.182 & 74.895 & 70.112 & down \\
031 & 98.962 & 92.386 & 86.35 & 80.813 & 75.762 & down \\
shape & up & up & up & up & up & \\
\hline
\end{tabular}




\begin{tabular}{|cccccccc|}
\hline Pflex \& Xflex & $\mathbf{r}$ & 0.01 & 003 & 0.05 & 0.07 & 0.09 & shape \\
\& Vflex & & & & & & & \\
& & & & & & & \\
Variance & Value & & & & & & \\
093 & & 62.321 & 57.778 & 54.482 & 52294 & 51.048 & down \\
01 & 84.996 & 80.227 & 76.198 & 72.843 & 70099 & down \\
117 & 99.94 & 94.828 & 90.327 & 85.384 & 82.956 & down \\
124 & 111.73 & 106.32 & 101.44 & 97.08 & 93.187 & down \\
0.11 & 121.9 & 11607 & 110.84 & 106.14 & 10187 & down \\
shape & & up & up & up & up & un & \\
\hline
\end{tabular}

\begin{tabular}{|cccccccc|}
\hline I'flex & $\mathrm{r}$ & 0.01 & 0.03 & 0.05 & 0.07 & 0.09 & shape \\
Variance & Value & & & & & & \\
003 & & 8874 & $\mathbf{8} 9519$ & 9.0471 & 91507 & 9.2684 & up \\
01 & & 15.683 & 15.709 & 15.738 & 15.766 & 15.794 & up \\
017 & 20106 & 20.079 & 20047 & 2001 & 19971 & down \\
024 & & 23.678 & 23.585 & 23.485 & 2338 & 23.27 & down \\
031 & 26833 & 26664 & 26487 & 26.305 & 26119 & down \\
shape & & up & up & up & up & up & \\
\hline
\end{tabular}

\begin{tabular}{|cccccccc|}
\hline $\begin{array}{c}\text { Xflex } \\
\text { Variance }\end{array}$ & $\begin{array}{c}r \\
\text { Value }\end{array}$ & 0.01 & 0.03 & 0.05 & 0.07 & 0.09 & shape \\
010 & & 18745 & 21708 & 2447 & 26.978 & 29208 & up \\
01 & & 19.788 & 21708 & 23.571 & 25.35 & 27.022 & up \\
017 & & 20855 & 2231 & 23723 & 25.081 & 26.372 & up \\
024 & & 21.769 & 22926 & 24.047 & 25123 & 26.147 & up \\
031 & & 22.727 & 23647 & 24.534 & 25383 & 26.19 & up \\
shape & & down & down & U shape & U shape & U shape & \\
\hline
\end{tabular}




\begin{tabular}{|cccccccc|}
\hline Xflex \& Vflex & $r$ & 0.01 & 0.03 & 0.05 & 0.07 & 0.09 & shape \\
& & & & & & & \\
Variance & Value & & & & & & \\
0.03 & & 31.668 & 34.918 & 37.927 & 40.651 & 43.091 & up \\
0.1 & & 41.906 & 44.187 & 46.366 & 48.412 & 50.308 & up \\
0.17 & & 49.461 & 51.175 & 52.806 & 54.341 & 55.771 & up \\
0.24 & 55.556 & 56.87 & 58.11 & 59.269 & 60.344 & up \\
031 & & 60.894 & 61.878 & 62.795 & 63.641 & 64.415 & up \\
shape & up & up & up & up & up & \\
\hline
\end{tabular}




\section{Appendix 7 - The Theoretical Design of the Log-Transformed Binomial \\ Method Trigeorgis(1991).}

I is the value of the underlying asset calculated from the present value of the expected cash flows from tmmediatel! underaking a real project without including the cost outlays or imbedded real options. V Inllows a diffusion process of the form.

(1)

$$
\frac{d l^{\circ}}{r^{\circ}}=\alpha u l t+\alpha d
$$

where w. is the instantaneous evpected return on the project. $\sigma$ the instantaneous standard deviation of the prọect valuc and d/ al standard Wiencr process

III ill! dt. $\|^{\prime} \equiv \log l^{\circ}$ follows an arithmetic Brow nian motion.

linder risk neutralıty. $\alpha=r$. where $r$ risk free rate and

$$
d I t=\log \left(I_{i+d i}, I_{i}\right)=\left(r-1 / 2 \sigma^{2}\right) d t+\sigma d z
$$

Fie merements dW are independent. identical and normalls distributed with mean cqual to $\left(r-1 / 2 r^{2}\right)$ dt and virlance cqual to $r^{-2} d t$

Sit that $K^{*} \equiv \sigma^{2}$ ell then dW becomes normally distributed whth mean and variance

$$
E(d W)=\mu k . \quad \operatorname{Var}(d W)=K \text { where } \mu \equiv \mu / \sigma^{2}-1 / 2
$$

Approvimation of the contunuous process is peri.,rmed by subdividing the total period $T$. into $N$ cqual discrete inter als $\tau$ so that $T=N \tau$. Thus. $k$ can be approvimated from $\sigma=T / N$. Within $\tau$. W followis a Varkor random walk moving up by an amount of

$$
\Delta W=H \text { with probability } p
$$


or dow n. $\quad \Delta W=-H$ with probability $1-p$

Mcall and $v$ ariance of this discrete-time Markor process are

$$
\left.E(\Delta W)=2 p H-H: \quad \operatorname{Var}(\Delta W)=H^{2}-\mid E(\Delta W)\right\}
$$

For the discrete-time process to be consistent with the continuous diffusion process in (1). their corresponding means and variances should be equal.

21 zpH $-H=\mu k$. so $p=1 / 2(1+\mu K / H)$ :

$$
\mathrm{H}^{2}-(\mu \mathrm{K})=\mathrm{K} \text {. so } H=\sqrt{K+(\mu K)^{2}} \quad(\geq \mu \mathrm{K})
$$

This guarantecs statility and consistency.

Bi defintion

$\operatorname{Var}(\Delta W) \geq 0)$ and hence. $-1 \leq \mu K / H \leq 1$

Which implies $0 \leq p \leq \mathrm{I}$ (no external constraints on $\mathrm{K} \& \mathrm{H})$

The value of the underlying asset is defined by using naively the NPV on the project. The discount rate Ired should be one that reflects only the cost of the funds for the firm. Other influential parameters that are more related 'o the project itscif are taken into account in the option framework analysis.

The use of the bınomial option pricing model requires the usc of up and down steps (state-step) of the ialue fiunction for cach time step. This step is a function of the risk free rate and the standard deviation of he project valuc. 


\section{Appendix 8 - The Algorithm}

Algorithm Proposed By Trigeorgis (1991, 1993)

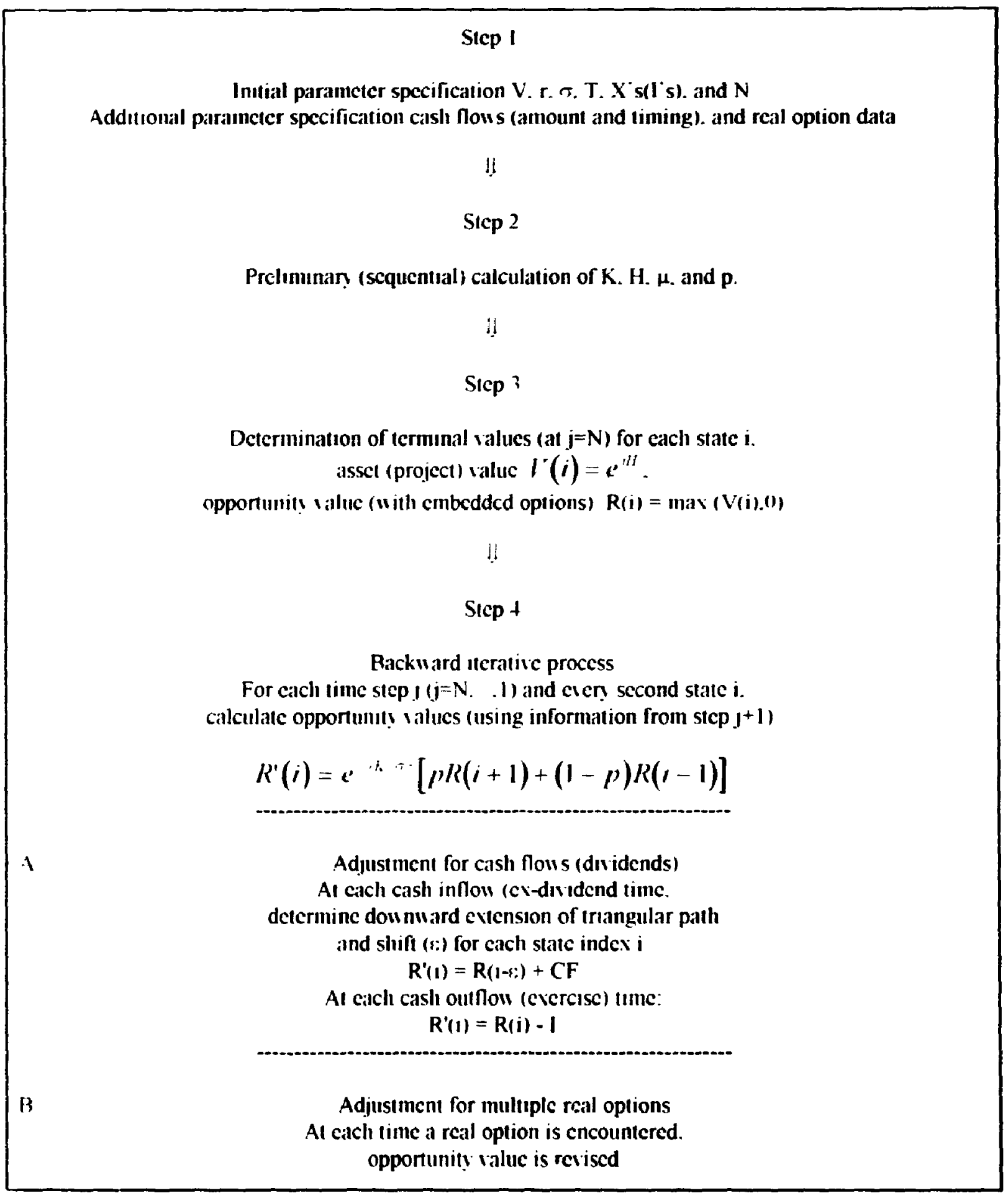




\section{Appendix 9 - The program}

This is the modified version used for sensitivity analysis. For the static version. remove liries marked $w$ ith a star $(*)$ : do not include the star when programming it.

Optıon Esplicit

paramcters

Dim RiskFrceRate As Double

Dim Instant Variance As Double

Dim NetValue As Double

Dim Lifetime As Double

Dim Intervals As Double

prolıminary

Dim $k$ As Double

Dim Mu As Double

Dım H As Double

Dım P As Double

inv cestment

Dim NumberOfInvestment As Integer

Dim Investment() As Double

¿xpansıon vars

Dim ExpansionFlex As Double

Dim vI As Double

Dim xFactor As Doublc

Dim xTime As Double

Dim DinamicX

product iars

Dim ProductFlex As Doublc

Dim PI As Double

Dim P2 As Double

Dim Pcomp As Double 
96

Dim Pintro As Double

Dim NPVnew As Double

Dim Vauiancenew As Double

Dim Renew As Double

Dim View As Double

Dim Inc As Double

illume sars

Dim VolumeFlex As Double

counters

Dim counter As Double

Dim i As Double

Dim I As Double

Dim State As Double

Dim in As Double

Dim , As Double

imam vars

Dim V() As Double

Dim R() As Double

Dim X() As Double

character strumas

Dim Mam Title As String

Dim Message As String

Dim Response

'simulation variables

Dim q As Double

Dim “ As Double

Dim c As Double

Dim t As Double

Dim ! As Double

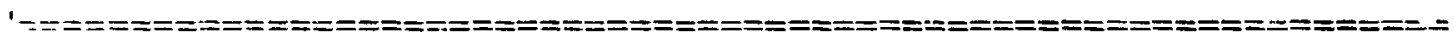

Sub test() 
This is a module for the calculation of project value using a binomial option pricing approach Call InitialParameters 'step 1

Call RealOptionData

* $t=1$

* For $q=0.01$ To 0.10 Step 0.02

* For $1=0.03$ To 0.36 Step 0.07

$* \quad t=t+1$

RiskFrecPate $=\mathbf{q}$ Instant Variance $=\mathrm{w}$

* NetValue $=$ Application. Npv (q. 10. 10. 10. 10. 10. 10. 10. 10. 10. 10. 10. 10. 10. (1). 10)

Call PreliminañCalculation 'step 2

'adjustment for volume flexibility (with and without)

If VolumeFlex $<6$ Then

TerminalValuesV 'step 3

BackwardProcessV 'step 4

End If

normal procedure

Call TcrminalValues 'step 3

Call BackwardProcess 'step 4

'output

Shects ( 7 ). Cells(t. 4). Value $=$ Lifetime

Sheets(17). Cells(t. 5) $\cdot$ Value $=q$

Sheets ( 17).Cells(t. 6). Value $=w$

Sheets( 17).Cells(t. 7) Value $=\mathbf{R}(0.0)$

* Nert "

* Next q

End Sub

Sub InitialParameters(; 'This will input the primary parameters needed MainTitle = "OPTIONS \& PRODUCTION" 
'The estımated value of the project. net of investment outlays

Message = "What is the present value of the project?"

NetValuc $=$ Application. InputBox $($ prompt $:=$ Message. Type $:=1$. Title $:=$ Main Title $)$

If NetValue $=$ False Then NetValue $=$ Sheets (1).Range("d7")

Shects(1). Range("d7"). Value = NetValue

'The as crage expected risk free rate during the life of the project

Message $=$ "What is the average expected risk-free rate of interest during the life of the project?"”

RiskFreeRate $=$ Application.InputBox(prompt $=$ Message. Type: $=1$. Title $:=$ ainTitle)

If RiskFreeRate $=$ False Then RiskFreeRate $=$ Shects ( I) Range("d8")

Shects( 1) Range("d8") Value = RiskFreeRate

The instantenous variance of returns associated with the project

Messagc $=$ "What is the instantaneous variance of returns of the project"? (Variance of

Demand ।"

InstantVariance $=$ Application InputBox(prompt $=$ Message. Type $=I$. Title $:=$ MainTitle $)$

If Instant Variance = False Then InstantVariance = Shcets( I). Range("d9")

Sheets( I) Kange("du"). Value = Instant Variance

"The life of the project

Message = "What is the lifetimc of the investment project?"

Lifetime $=$ Application.InputBox $($ prompt $:=$ Message. Type: $=1$. Title: $=$ MainTitle $)$

If Lifetıme = False Then Lifetıme = Sheets(1).Range("d10")

Sheets( I) Range("dI0") Valuc = Lifetime

'The number of interials

Messirge = "what is the number of time intervals that you would like to use?"

Intervals $=$ Application. InputBox $($ prompt $:=$ Message. Type $:=1$. Title $:=$ MainTitle $)$

If Intervals = False Then Intervals = Sheets ( I) Range("d I I")

Shects( I) Range("d I "). Valuc = Inter als

A message for promptıng the user of questions to come

Mcssage $=$ "The following questions will ask you the number of investment outlays. their amount and their timing!!"

Responsc = MsgBox(prompt $:=$ Message. Title:="Read This!!") 
'The number of investment outlays

Message - "How many investment outlays are there?"

NumberOflnvestment $\quad=\quad$ Application.InputRox(prompt:=Messagc. $\quad$ Type:=1.

Title: = Main Title)

If NumberOfInvestment $=$ False Or NumberOfInvestment $=0$ Then

NumberOflnvestment $=0$

Else Call InvestmentInput

End If

Fnd Sub

Sub RcalOptionData()

'This is the Volume flexibility Section

Message $=$ "Does your production ș̣stem have volume flexibiliț"

VolumcFlcx $=$ MsgBox(prompt:=Message. Buttons:=4. Title:="Volume Flexibility")

If VolumcFlex $=6$ Then

Shects( 1) Range("i3") Valuc = "Yes"

Elsc Shects( I) Rangc("i8"). Valuc = "No"

'This is the Product Flcxibility furestion

Messagc = "Docs your production ș̣stem have product flexibiliț."

ProductFlex $=$ MsgBox(prompt:=Message. Buttons:=4. Title:="Product Flexibility")

If ProductFlex $=6$ Then

Shects (1).Range("i9").Valuc = "Ycs"

Elsc Shects( (1) Range("i甲"). Value = "No"

If ProductFlex $=6$ Then ProductInputFlex

'Thıs is the Expansion Flexibility function

Message = "Does your production ș̣stem have expansion flexibility"

ExpansionFlex $=$ MsgBox $($ prompt $:=$ Message. Buttons:=4. Title: $=$ "Expansion Flcxibility")

If ExpansionFlex $=6$ Then

Sheets( I).Range("il0").Value = "Yes"

Else Shects( (1) Range("110") Value = "No"

If Expansionflex $=6$ Then ExpansioninputFlex 
Find Sub

Sub Preliminary (alculation()

$$
\begin{aligned}
& \mathbf{K}=\text { (Instant Variance * (Lifetime / Intervals)) 'tume-step } \\
& \text { Mu = ((RiskFrceRate / InstantVariance })-0.5) \text { 'drift } \\
& H=\operatorname{Sqr}\left(K+\left(\left(M u^{*} K\right)^{\wedge} 2\right)\right) \quad \text { 'state-step } \\
& P=05^{*}\left(1+\left(\left(M u^{*} K\right) / H\right)\right) \quad \text { probability }
\end{aligned}
$$

Shects (2).Cells $(8,2)$ Value $=K$

Shects(2).Cells(9.2) Vaiue $=\mathbf{M u}$

Shects(2) Cells(8. 4). Value $=H$

Shects (2). Cells(9.4). Value $=P$

Let $\mathrm{X} 0=$ Application.Ln(Net Valuc)

Find Sub

Sub TerminalValucs()

ReDim V(-Interials To Intervals. Interials)

ReDm R(-Interials To Intervals. Interials)

For $1=$ Intern als To -Interials Step -1

Let V(i. Intervals $)=\operatorname{Exp}(X()+(1 * H))$

Let R(i. Intervals) = Application Mar((V(i. Intervals)). ())

Shects(t) Cells( I + Interials - 1. I) Valuc $=R(i$. Intervals $)$

Nest I

Find Sub

Sub BackllardProcess()

Let Statc $=$ Intervals

For $y=($ Internals -1$)$ To () Step - I

Lut Statc $=$ State -1

For $\mathbf{i}=$ State To - State Step -2

'tlic normal backward process

$$
\begin{aligned}
& R(i . j)=\left(\text { Exp }\left(-R i s k F r c \cdot \text { 'rate * }\left(K^{\prime} \text { InstantVariancc }\right)\right)\right) *((P * R(i+1 . j+1))+((1- \\
& P) * R(i-1 . j+(I)))
\end{aligned}
$$


'adjustment for cash flows

If NumberOflnvestment $<>0$ Then

For counter $=1$ To NumberOfinvestment

If (Application.Round(Investment(counter. 2) * (Intervals / Lifetime). 0)) $=\mathrm{j}$ Then $\mathbf{R}($ i. j) $=\mathbf{R}($ i. j) - Investment (counter. 1)

End If

Next counter

End If

adjustment for expansion flexibility

'If ExpansionFlex $=6$ Then

- If DynamicX $=6$ Then Call ExpansionFlexibility

'Else

If (Application.Round(xTime * (Intervals $/$ Lifetime). 0)) $=\mathrm{j}$ Then Call ExpansionFlexibility

'adjustment for product flexibility.

If ProductFlex $=6$ Then Call ProductFlexibility

Sheets(4).Cells( I + Intervals - i. $1+$ Intervals - j). Value = R(i. j)

Nevt $i$

Nert $j$

Sheets(2). Cells(2. 2). Value $=\mathbf{R}(0,0)$

Shects(2). Cells(3. 2). Value $=-14.12$

End Sub

Sub ProductFlcxibility()

Let Pintro $=((1-P I) /($ Intervals -1$)) *(j-1)+P I$

Let Pcomp $=P 2-(P 2 /(\text { Intervals }-1))^{*}(j-1)$

Vnew = BlackScholes(NPVnew. Incw. RiskFrceRate. Lifetime. Variancenew)

Rnew $=$ Vnew * Pintro* Pcomp

$R(i, j)=$ Application $\operatorname{Max}(R(i . j)$. Rncw)

End Sub 
Sub ExpansionFlexitility()

$$
\mathbf{R}(\mathrm{i} . \mathrm{j})=\mathbf{R}(\mathrm{i} . \mathrm{j})+\text { Application. Max(xFactor * V(i. Intervals })-\mathbf{x l} .0)
$$

Fnd Sub

Sub ProductInputFlex()

MainTitle = "PRODUCT FLEXIBILITY"

Messagc $=$ "What is the estimated present value of new product(s)?"

NPVnew $=$ Application.InputBox(prompt:=Message. Type:=1. Title:=MainTitie)

Message = "What is a good estimation of the variance of returns for such new products?"

Variancenew $=$ Application. InputBox(prompt $:=$ Message. Type $=1$. Title $=$ MainTitle)

Message = "What is the probability of a successful new product introduction presently?"

$\mathbf{P I}=$ Application. InputBox(prompt:=Message. Tỵpe: $=1$. Title $:=$ MainTitle)

Message = "What is the probability that a new product now introduced would be compatıble for production on this system?"

P2 = Application InputBox $($ prompt $=$ Message. Type $:=1$. Title $:=$ MainTitle $)$

Message $=$ "What is the estimated investment for a new production system for a new product?"

IncI $=$ Application. InputBox(prompt:=Message. Type: $=1$. Title $=$ MainTitle)

End Sub

Sub ExpansionInputFlex()

MainTitle = "EXPANSION FLEXIBILITY"

Message = "V'hat is the factor of expansion possible for this project?"

$\checkmark$ Factor $=$ Application InputBox $($ prompt $:=$ Messagc. Type $:=1$. Title $:=$ MainTitle $)$

Message = "What is the amount of the investment required for the proposed expansion?"

$\mathbf{I}=$ Application InputBox $($ prompt $=$ Message. T $:$ pe $:=1$. Tit $!:=$ MainTitle $)$

Message = "Is the expansion dịnamic (Yes) or static (No)"?"

DịnamicX $=$ MsgBox(prompt $:=$ Message. Buttons $:=v b$ YesNo. Title $:=$ MainTitle $)$

If Dy namicX $=$ vbNo Then

Message = "When will it be possible to undergo an expansion?"

$\mathrm{v}$ Timc $=$ Application. InputBox(prompt:=Message. Type $=1$. Title: $=$ MainTitle) 
End If

End Sub

Sub InvestmentInput()

'Resetting of Investment data

For counter $=1$ To 4

Shects( 1$)$ Cells $(7+$ counter. 6). Value $=$ Empty

Sheets $(1) \cdot$ Cells $(7+$ counter. 7$) \cdot$ Value $=$ Empty

Nevt counter

The loop for entering all the investment outlays

ReDim Investment(NumberOfInvestment. 2)

For counter $=1$ To NumberOflnvestment

Investment(counter. 1) = Application. InputBox(prompt:=

"What is the value of the investment " \& counter \& "?".

Type: $=1$. Title: $=$ MainTitle)

Investment(counter. 2) = Application.InputBox(prompt:=

"What is the timing of the investment " \& counter $\&$ "?".

Type:=1. Title:=MainTitlc)

Shects (1).Cells $(7+$ counter. 6). Value $=$ Investment $($ counter. 1$)$

Shects ( 1$) \cdot$ Cells $(7+$ counter. 7$) \cdot$ Valuc $=$ Investment $($ counter. 2$)$

Nevt counter

End Sub

Sub TerminalValuesV()

ReDim V(-Intervals To Intervals. Intervals)

ReDim R(-Intervals To Intervals. Intervals)

Let $V(0.0)=$ NetValue

Let $\mathbf{X} 0=$ Application.Ln(NetValuc)

For $\mathrm{i}=$ Intervals To -Intervals Step -1

Let $V(i$. Intervals $)=\operatorname{Exp}(X 0+1.1 *(i * H))$

If $V(i$. Intervals $)>=V(0,0)$ Then 
Let $R(i$. Intervals $)=V(0.0)$

Else

Let $\mathbf{R}($ i. Intervals $)=$ Application.Max((V(i. Intervals $))$. 0)

End If

Sheets(5). Cells ( I + Intervals - i. 1).Value $=\mathbf{R}(\mathrm{i}$. Intervals $)$

Next i

End Sub

Sub BackwardProccssV()

Let State $=$ Intervals

For $\mathrm{j}=$ (Inteivals - 1) To 0 Step -1

Let State $=$ State -1

For $1=$ Statc To - Statc Step -2

'the normal backnard process

If $1>0$ Then

$$
R(i .1)=V(0.0)
$$

Elsc

$R(1 .)=,(\operatorname{Exp}(-\operatorname{RiskFrceRate} *(K /$ Instant Vartance $))) *((P * R(i+1 . j+1))+((1$

$-P) * R(i-1 . j+1)))$

End If

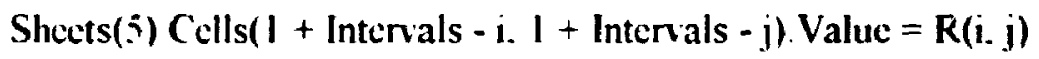

Next !

Nait j

Let $\mathbf{X}()=$ Application $\operatorname{Ln}(\mathbf{R}(0.0))$

Fnd Sub 


\section{Appendix 10 - Justification Approaches (Suresh \& Meredith, 1986)}

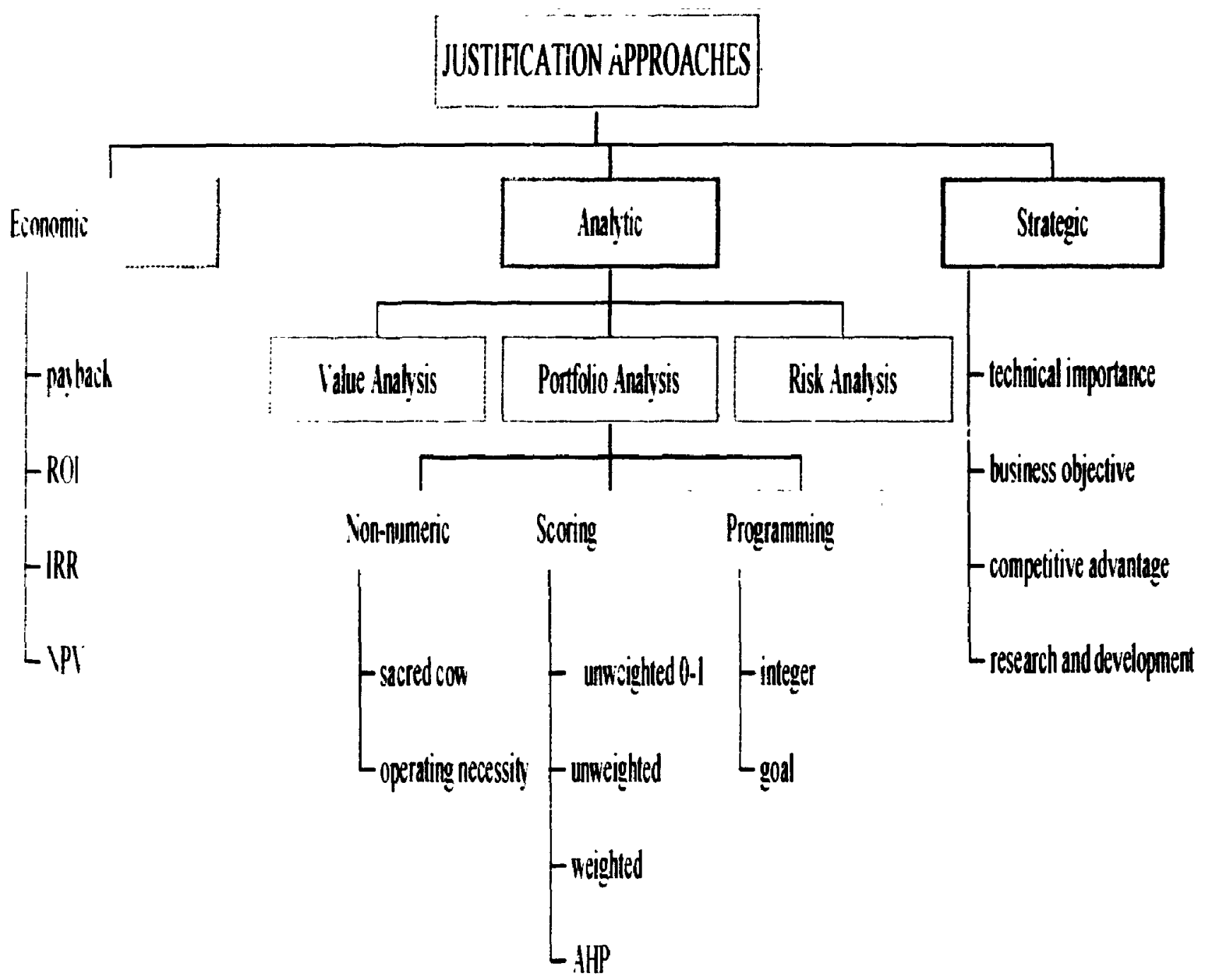




\section{Appendix 11 - How To Use The Model}

The first step in using the model is to program it for use with a computer. The version of the computer program in Appendix 9 can be used in Excel, version 5.0 or higher, as a Visual Basic Module. To start the application of the model, you just have to start the module (in Appendix 9. the module is called "test").

The second step is to find the values of input parameters. Some estimations will be required Items in square brackets as in the computer progran in Appendix 9 are requested from the user by the program. These are:

I Risk free rate ( $r$ : Make an estimation of the rate of interest on any asset deemed to be risk free (or close to) such as Treasury Bills, for the whole lifetime of the project. Historical data may be useful in forecasting this rate if you expect the rates to be similar to what they were in the past [Risk free rate]

2 Value of the project (PV or V): Calculate this amount using the cash inflow estimates that would normally be used in your traditional NPV analysis but remember to use the risk free rate of interest as the discount rate [Present value of the project]

i Investments (1). Use investments that would normally be used in the NPV analysis, but use them as input in the model at their expected time of occurrence. There is no need to discount them since the model does it automatically. [number of investments, amount and timing]

+ Intervals (N). 50 is deemed sufficient. However, for better accuracy, you can increase that number, especially for projects with long lifetimes. Keep in mind that it will require greater computing power and more time. [number of intervals]

: Lifetime (T): The expected life of the production system may be obtained from manufacturers of the parts, machinery and computers that make-up the production 
system In-house engineering might also be able to provide such information. Another consideration may be the possibility that this technology will become obsolete before the physical system itself breaks down completely. [lifetime]

6 Variance of returns of the underlying asset $\left(\sigma^{2}\right)$ : In our model, we use the variance of the demand as a proxy for the variance in returns on the project. Note that this is an extreme case where any changes in value of the investment project are due to changes in demand. Analysis of historical data for this product (or similar, or family of products) can provide good estimates of what might be expected in the future. [Variance]

7 Volume Flexibility: This model assumed an additional cost of $10 \%$ when producing at a level lower than initially expected (optimal production level). This should be modified according to the system under study. In the template (Appendix 9), this adjustment is programmed internally and does not form part of the initial inputs. [presence of Volume flexibility]

8 Product flexibility: Values for this option as well as the probabilities of introduction and compatibility could be estimated using past experience with new products. The relationship between the probabilities are programmed and must be modified before hand as with volume flexibility. [New PV, new I, new $\sigma^{2}$, probabilities at time zero]

9. Expansion flexibility: This option is easily characterized by production system where capacity is easily increased by adding a module to the production system. The expansion level should be relatively easy to determine. [Expansion factor, timing of expansion] 


\section{REFERENCES}

Adams, Richard A., and Clark Hawkins, 1974, A Goal Programming Model for Capital Budgeting, Financial Management, Spring 1974, 52-57.

tggarwal, R.. Edward, J., \& Louise E. Mellon, 1991, Justifying Investments in Flexible Manufacturing Technology: Adding Strategic Analysis to Capital Budgeting under Incertainty. Managerial Finance, Volume 17, Number 2/3, 77-88.

Azzone, $G$ and $U$. Bertelè, Measuring the Economic Effectiveness of Flexible Automation A New Approach. International Journal of Production Research, Vol.27, no. ร. 1989

Baldwin. C Y.. 1991. How Capital Budgeting Deters Innovation- and What to do About it. Research/Technology Management. Nov.-Dec., 39-45

Baldwin. C Y.. Richard S. Ruback, Inflation, Uncertainty, and Investment, The Journal of Finance. Volume XLI, Number 3. 657-669.

Ball. Clifford A.. A Review of Stochastic Volatility Models with Application to Uption Pricing. Financial Markets, Institutions \& Instruments, Volume 2, Number 5, 55-71.

Bhaskar, K, 1978, Linear Programming and Capital Budgeting: The Financing Problem, Journal of Business Finance \& Accounting 5(2), 159-194.

Bierksund. P. and S. Ekern, 1990, Managing Investment Opportunities Under Price I 'ncertainty From 'Last Chance' to 'Wait and See' Strategies, Financial Management, Altumn 1990.65-83

Bowman. E H. and D. Hurry, 1993, Strategy Through the Option Lens: An Integrated View Of Resource Investments and Incremental-Choice Process, Academy of Management Review 18(4), 760-782. 
Brennan. M.J., and E.S. Schwartz, 1985, Evaluating Natural Resource Investments, Journal of Business, 1985, Vol. 58, no. 2, 135-157.

Brick. Ivan E., and Daniel G. Weaver, 1984, A Comparison of Capital Budgeting Techniques in Identifying Profitable Investments, Financial Management. Winter 1984, 2939

Caplin. D., and J. Kornbluth, 1975, Multiobjective Investment Planning Under Uncertainty, OMEGA. The International Journal of Management Science, 1975, Vol. 3, No 4. 423-441.

Cox, J., S. Ross, and M. Rubinstein, 1979, Option Pricing. A Simplified Approach, Journal of Financial Economics, 7, September 1979, 229-263.

Canada, J.R., and W.G. Sullivan, Economic and Multiattribute Evaluation of Advanced Manufacturing Systems, Prentice Hall, 1989.

Copeland. T.E. Koller, T., and J. Murrin, Valuation Measuring and Managing the Value of Companies. McKinsey \& Company, Inc. Chapter 15, 1994.

Copeland, T.E., and J.F. Weston, Financial Theory and Corporate Policy, third edition, Addison-Wesley, 1988

Damodaran. A. Damodaran on Valuation: Security Analysis for Investment and Corporate Finance, John Wiley \& Sons, Inc., Chapter 16, 1994.

Gerwin. D. and H. Kolodny, Management of Advanced Manufacturing Technology, Strategy, Organization \& Innovation, John Wiley \& Sons, Inc., 1992.

Jog. V., Michalowski, W., and T. Trzaskalik, 1994, Solving the Capital Expenditure Planning Problem by an Interactive Dynamic Programming Procedure, Working Paper, Carleton University.

Lee, C Jevons, 1988, Capital Budgeting under Uncertainty: The Issue of Optimal Timing, Journal of Business Finance \& Accounting, 15(2), Summer 1988, 155-168. 
Lounsbury. H. B. Options theory as a framework for decision-making in R\&D investments, Master of Management Studies Thesis, Carleton University, 1992.

Luehrman, T.A., 1994, Suientific Management at Merck: An Interview with CFO Judy Lement. Harvard Business Review, Jan -Feb., 88-99.

Mahalanabis. S. A Comparative Study on Concepts and Measures of Flexibility, Master of Management Studies Thesis, Carleton University. 1993.

Meredith, JR, and N.C. Suresh, 1986, Justification techniques for Advanced Manufacturing Technologies, International Journal of Production Research 24(5), 10431057

Miller. Edward. 1978. Uncertainty Induced Bias in Capital Budgeting. Financial Management. Autumn 1978, 12-18

Vitchell. GR, and W.F Hamilton, 1988, Managing R\&D as a Strategic Option, Research/Technology Management, May-June, 15-22.

Vichols. N A, 1994, Scientific Management at Merck An Interview with CFO Judy I.ement. Harvard Business Review, Jan.-Feb., 88-99

Pike. R . 1989, Do Sophisticated Capital Budgeting Approaches Improve Investment Decision-Making Effectiveness?, Engineering Economist 34(2), Winter, 149-161.

Pindyck. Robert S., 1988, Irreversible Investment, Capacity Choice, and the Value of the Firm. American Economic Review, Vol. 78, December 1988, 969-985.

Pindyck, Robert S., 1991, Irreversibility, Uncertainty, and Investment, Journal of Economic Literature, Vol. XXIX, September 1991, $1110-1148$. 
Rychel, Dwight F., 1977, Capital Budgeting with Mixed Integer Linear Programming: An Application, Financial Management, Winter 1977, 11-19.

Sealey Jr., C.W., 1978, Utility Maximization and Programming Models for Capital Budgeting, Journal of Business Finance \& Accounting, 5(3). Spring 1978, 355-365.

Sick. G.A., 1986, A Certainty-Equivalent Approach to Capital Budgeting, Financial Management, Winter, 23-32.

Sick, G A., 1989, Capital Budgeting with Real Options, Monograph Series in finance and Economics, Monograph 1989-3, 1989.

Teisberg. Elizabeth Olmsted, 1994, An Option Valuation Analysis of Investment Choices, Management Science, Vol. 40, No. 4, April, 535-548.

Thanassoulis, E., 1985, Selecting a Suitable Solution Method for a Multi Objective Programming Capital Budgeting Problem, Journal of Business Finance \& Accounting 12(3). Autumn, 453-471.

Trigeorgis, Lenos. The Nature of Option Interactions and the Valuation of Investments with Multiple Real Options, Journal of Financial and Quantitative Analysis, Vol. 28, No. I. March 1993, 1-20

Trigeorgis, Lenos, A Log-Transformed Binomial Numerical Analysis for Valuing Complex Multi-Options Investments, The Journal of Financial and Quantitative Analysis, Vol. 26, No 3. September 1991, 309-326.

Tucker. Alan. Financial Futures, Options \& Swaps, West Publishing Company, 1991. 

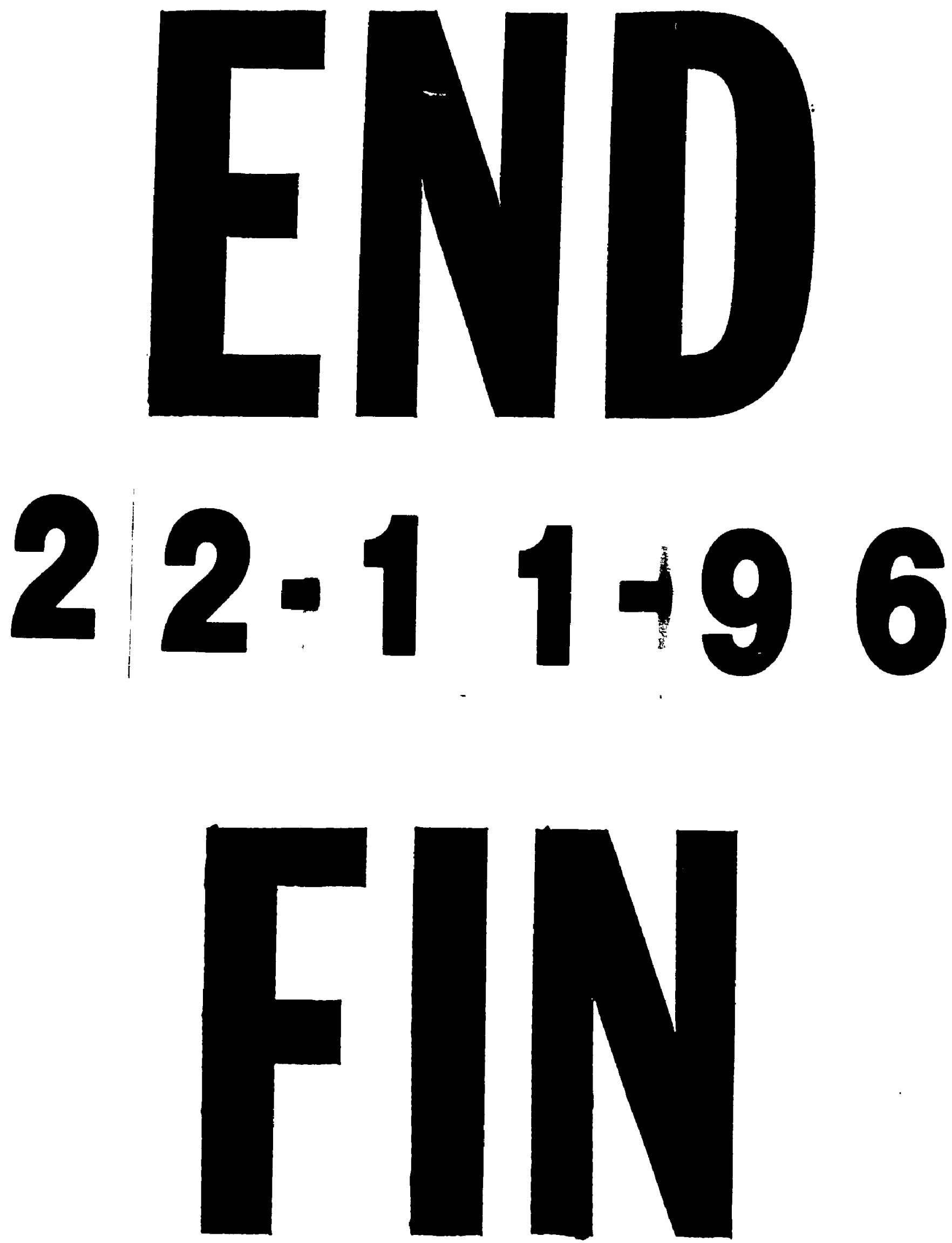